SCREEN STARS AS STYLE ICONS:

AN EXAMINATION OF AUDREY HEPBURN AND SARAH JESSICA PARKER

by

Daryna Granik

Bachelor of Cultural Studies, Odessa National Polytechnic University, Ukraine (2010)

Masters of Cultural Studies, Odessa National Polytechnic University, Ukraine (2012)

A Major Research Paper presented to Ryerson University

in partial fulfillment of the

requirements for the degree of

Master of Arts

in the Program of

Fashion

Toronto, Ontario, Canada, 2015

(C) Daryna Granik, 2015 


\section{Author's Declaration}

I hereby declare that I am the sole author of this major research paper. This is a true copy of the major research paper, including any required final revisions, as accepted by my examiners.

I authorize Ryerson University to lend this major research paper to other institutions or individuals for the purpose of scholarly research.

I further authorize Ryerson University to reproduce this research paper by photocopying or by other means, in total or in part, at the request of other institutions or individuals for the purpose of scholarly research.

I understand that my major research paper may be made electronically available to the public. 


\title{
Screen Stars as Style Icons: An Examination of Audrey Hepburn and Sarah Jessica Parker
}

Daryna Granik, 2015

Master of Arts, School of Fashion, Ryerson University

\begin{abstract}
Through the examination of two film stars from different eras, Audrey Hepburn and Sarah Jessica Parker, this major research project (MRP) will examine how style icons are created. In order to achieve iconic style status, one must have a distinct and instantly recognizable look that represents new cultural ideals and appeals to a wide group of people. Style icons must actively participate in the fashion industry, taking a place on a creative side of the process by collaborating with designers, advertising fashion brands, and advocating and promoting fashion trends; this helps to establish their authority. Consumers of fashion also play an important role in the process. Screen narratives help actresses to embody the myths that are as repetitive and consistent as their looks circulating in the media. Through fashion, style icons represent these myths and embed them in culture. In return, they are regarded as cultural heroes and style icons.
\end{abstract}




\section{Acknowledgements}

I would like to thank my wonderful supervisor Joseph Medaglia for his support, patience, encouragements and inspiration along the way. And thanks to Dr. Alison Matthews David, who made us work as hard as possible. 


\section{Dedication}

To my loving and supportive parents, Yuliana and Konstantin Granik, and my beloved Granny Roza. 


\section{Table of Contents}

Page

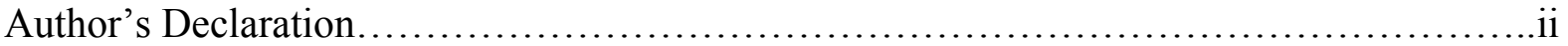

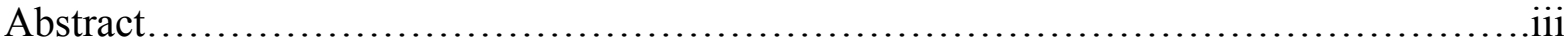

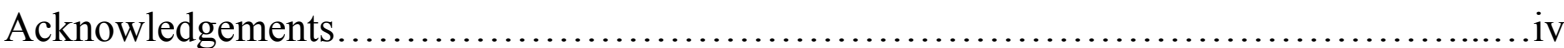

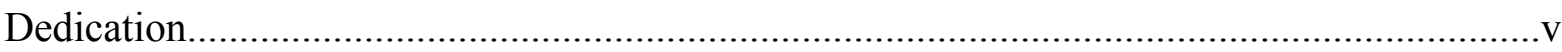

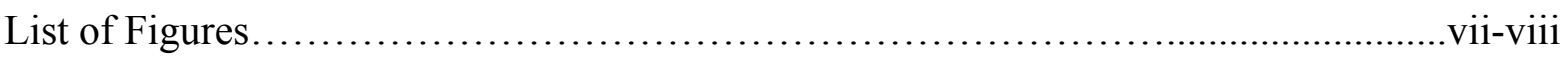

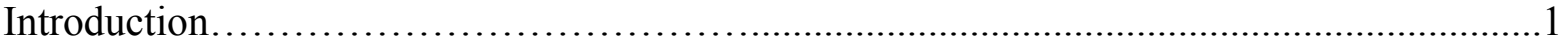

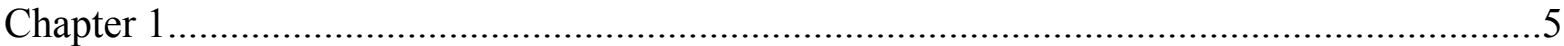

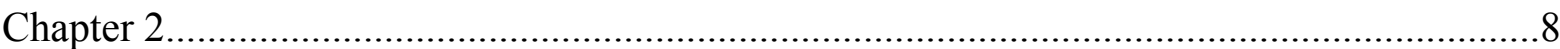

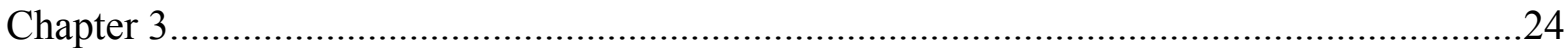

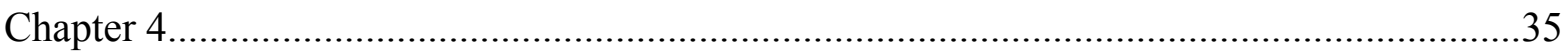

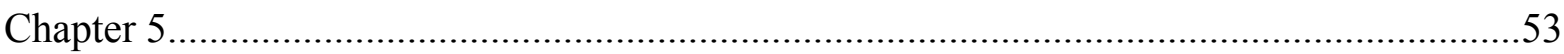

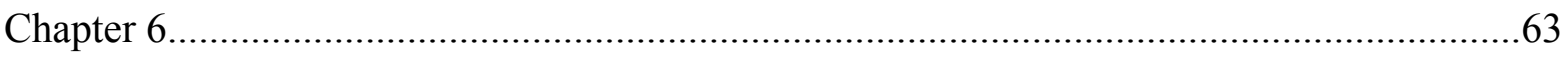

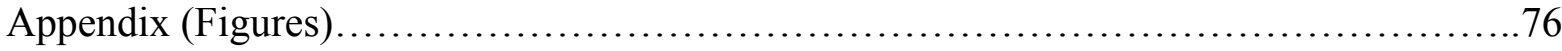

Works Cited................................................................ 109 
Figure 1: Audrey Hepburn advertising Longines (2001) .............................76

Figure 2: International covers of Harper's Bazaar magazines, September 2014.............76

Figure 3: Anita Ekberg in Federico Fellini's "La Dolce Vita" (1960)........................77

Figure 4: Madonna's bustier by Jean Paul Gaultier for "Blonde Ambition Tour" (1990)......77

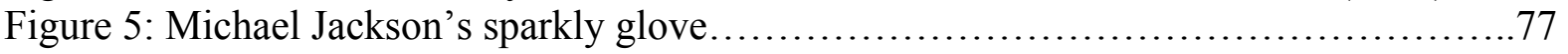

Figure 6: A doll of Britney Spears in a costume from "Oops!..I did it again" music video ...78

Figure 7: Frida Kahlo on the cover of Vogue Paris, 1939................................ 78

Figure 8: T-shirt by Anna K from her line "Fashion Dictionaries", 2014...................79

Figure 9 : Audrey Hepburn as Princess Ann, a ball scene, Roman Holiday (1953)...........79

Figure 10: Audrey Hepburn as Princess Ann, in her bedroom before going to sleep, Roman

Holiday (1953) ........................................................... 80

Figure 11: Audrey Hepburn in Roman Holiday (1953), before and after a hair-cut...........80

Figure 12: Audrey Hepburn in Funny Face (1957), singing "Bonjour Paris" ...............80

Figure 13: Audrey Hepburn in Funny Face (1957), dancing scene.......................81

Figure 14: Beyonce from her music video "Countdown" (2011) is compared to Audrey

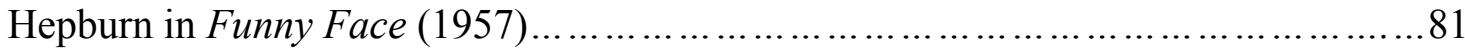

Figure 15: Givenchy costumes for Audrey Hepburn in Funny Face (1957).................81

Figure 16: Audrey Hepburn in Funny Face (1957), dressed similarly as editor-in-chief of the

fashion magazine Quality.................................................... 82

Figure 17: Audrey Hepburn in Funny Face (1957) with Fred Astaire......................82

Figure 18: Image from the opening scene of Breakfast at Tiffany's (1961).................82

Figure 19: Audrey Hepburn in Breakfast at Tiffany's (1961).................................83

Figure 20: Audrey Hepburn in Breakfast at Tiffany's (1961), party scene...................83

Figure 21: Audrey Hepburn and George Peppard in Breakfast at Tiffany's (1961)...........84

Figure 22: Audrey Hepburn and George Peppard in Breakfast at Tiffany's (1961)...........84

Figure 23: Audrey Hepburn in Breakfast at Tiffany's (1961)..............................85

Figure 24: Audrey Hepburn and George Peppard in Breakfast at Tiffany's (1961)..........85

Figure 25: Audrey Hepburn and George Peppard in Breakfast at Tiffany's (1961)..........86

Figure 26: Blaire Waldorf (by Leighton Meester) channeling Audrey Hepburn in Breakfast at

Tiffany's (1961) in a dream scene of TV-show Gossip Girl (2007-2012).............86

Figure 27: Sarah Jessica Parker as Carrie Bradshaw in the pilot episode of Sex and the City

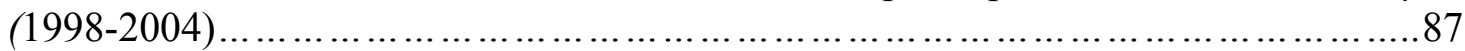

Figure 28: Sarah Jessica Parker as Carrie Bradshaw in the pilot episode of Sex and the City

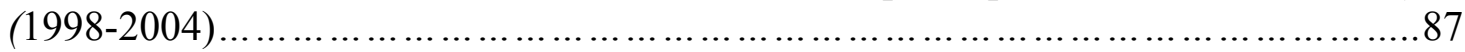

Figure 29: Sarah Jessica Parker as Carrie Bradshaw gets engaged to Mr. Big in film Sex and

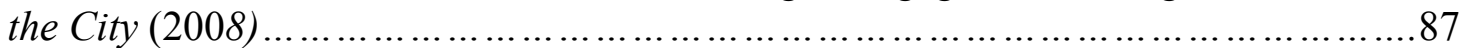

Figure 30: Sarah Jessica Parker as Carrie Bradshaw in Sex and the City (1998-2004).........88

Figure 31: Sarah Jessica Parker as Carrie Bradshaw in Sex and the City ...................88

Figure 32: Sarah Jessica Parker as Carrie Bradshaw in Sex and the City ....................89

Figure 33: Sarah Jessica Parker as Carrie Bradshaw in Sex and the City ....................89

Figure 34: Sarah Jessica Parker as Carrie Bradshaw in Sex and the City ...................90

Figure 35: Sarah Jessica Parker as Carrie Bradshaw in Sex and the City ....................90

Figure 36: Sarah Jessica Parker as Carrie Bradshaw in Sex and the City (1998-2004).......91 
Figure 37: Sarah Jessica Parker as Carrie Bradshaw in Sex and the City (1998-

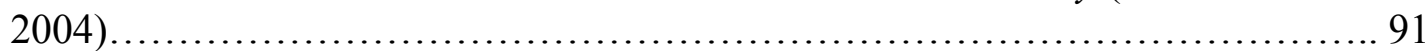

Figure 38: Sarah Jessica Parker as Carrie Bradshaw in Sex and the City ......................92

Figure 39: Sarah Jessica Parker as Carrie Bradshaw in Sex and the City .....................92

Figure 40: Sarah Jessica Parker as Carrie Bradshaw in Sex and the City ..................93

Figure 41: Sarah Jessica Parker as Carrie Bradshaw in Sex and the City ....................93

Figure 42: Sarah Jessica Parker as Carrie Bradshaw in Sex and the City .....................94

Figure 43: Quote by Carrie Bradshaw regarding her investments. Season 6. Episode 1....94

Figure 44: Poster with a quote by Carrie Bradshaw regarding her investments. Season 6.

Episode 1. Labeled authorship of Sarah Jessica Parker.............................94

Figure 45: Quote by Carrie Bradshaw regarding shopping on TV show Sex and the City

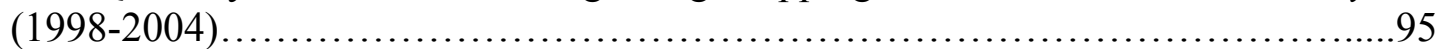

Figure 46: Sarah Jessica Parker as Carrie Bradshaw in Sex and the City (1998-2004), A

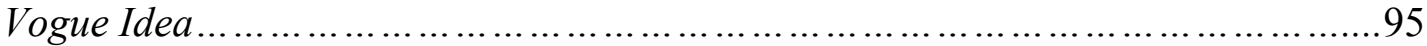

Figure 47: Sarah Jessica Parker on the cover of Vogue (US), February 2002 ............ 96

Figure 48: Sarah Jessica Parker on the cover of Vogue (US), August 2003................96

Figure 49: Sarah Jessica Parker on the cover of Vogue (US), September 2005.............97

Figure 50: Sarah Jessica Parker on the cover of Vogue (US), June 2008................ 97

Figure 51: Sarah Jessica Parker on the cover of Vogue (US), May 2010.................98

Figure 52: Sarah Jessica Parker on the cover of Vogue (US), August 2011 ...............98

Figure 53: Sarah Jessica Parker stars in TV-show Glee (2012-2013) as an editor-in-chief of

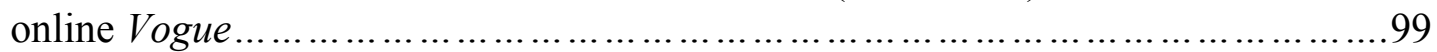

Figure 54: Sarah Jessica Parker with Anna Wintour on "Late Night With Seth Meyers"

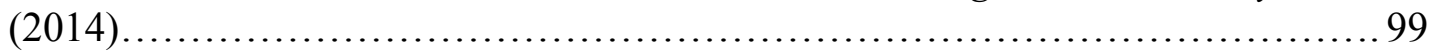

Figure 55: Sarah Jessica Parker pays homage to Diana Vreeland in Harper's Bazaar

(March 2009).......................................................... 100

Figure 56: Sarah Jessica Parker in advertisement for Gap (2004)..................... 100

Figure 57: Image of Audrey Hepburn from Funny Face (1957) used in Gap ad campaign................................................................ 101

Figure 58: Unflattering photo of Sarah Jessica Parker as Carrie Bradshaw in Sex in the City

(1998-2004), They Shoot Single People Don't They?...

Figure 59: Sarah Jessica Parker's collaboration with Hallmark.........................101

Figure 60: Audrey Hepburn in Rome. Image from "Audrey in Rome" (Luca Dotti)......102

Figure 61: Audrey Hepburn in Rome. Image from "Audrey in Rome" (Luca Dotti)......102

Figure 62: Audrey Hepburn in Rome. Image from "Audrey in Rome" (Luca Dotti)......103

Figure 63: Audrey Hepburn in Rome. Image from "Audrey in Rome" (Luca Dotti)......104

Figure 64: Audrey Hepburn in Rome. Image from "Audrey in Rome" (Luca Dotti)......104

Figure 65: Audrey Hepburn in Rome. Image from "Audrey in Rome" (Luca Dotti)...... 105

Figure 66: Audrey Hepburn and her husband, Mel Ferrer, in Rome on Spanish Steps, looking as a scene from a film Roman Holiday (1953). Image from "Audrey in

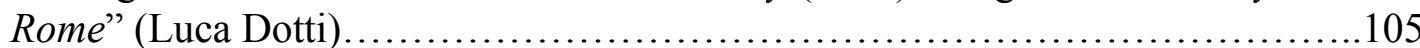

Figure 67: Audrey Hepburn and her husband, Mel Ferrer, in Rome. Image from "Audrey in Rome" (Luca Dotti)....................................................... 106

Figure 68: Audrey Hepburn in Rome. Image from "Audrey in Rome" (Luca Dotti)......107

Figure 69: Audrey Hepburn in Rome. Image from "Audrey in Rome" (Luca Dotti)......107

Figure 70: Sarah Jessica Parker at various event. Her style is very reminiscent of the style of her character Carrie Bradshaw........................................... 108 


\section{Introduction}

Fashion and cinema have always been connected: Film productions have long collaborated with fashion designers and inspired popular fashion collections (e.g. for major department stores). However, one of the most influential products of Hollywood is the creation of celebrity and style icons. These personalities inspire viewers to emulate their appearances, clothes and lifestyles. Today the term "style/fashion icon" is widely used in popular media, literature and fashion publications. My research focuses on female style icons who have been created through the film industry and become cultural phenomenons. This major research project (MPR) focuses on two particular female figures of different time periods, Audrey Hepburn and Sarah Jessica Parker (otherwise identified as SJP). Both actresses have gained status as style icons through their cinematic performances and enduring fashion choices.

In my research, I was guided by four main questions:

1. What is a style icon? Does this concept include dressing the body only, or does it revolve around image, lifestyle, overall cultural authority, and the personification of cultural values?

To begin to address this question, some clarification of terms is needed: The terms "style icon" and "fashion icon" differ as much as the terms fashion and style do. Fashion icons are specific to a time period and can be recognized by their individual style choices. A style icon is timeless - their look has lasted over time and is tied to their personality and uniqueness.

2. How and why do style icons function in culture? What is their purpose? This research considers North American society's need to embody dreams and aspirations in film stars. Does a style icon reflect a particular time period and culture, and therefore create a cultural need to recognize a new style icon for various time periods? Style icons represent new cultural values and norms (e.g. body and beauty ideals, outlooks on sex and women's 
roles in society, fashion trends), which makes them appealing to new generations of women who see them as role models. Style icons can be considered ground-breaking heroes who challenge the norm yet are still accepted in society.

3. How do on-screen and off-screen images of popular actresses merge and is this conflation part of the process of establishing a style icon, whereby the actresses" "off-screen authenticity" becomes part of their aspirational screen image? What are the boundaries between an icon's on-screen and off-screen image?

It might seem for the masses that street and paparazzi photographs, which circulate in celebrity magazines and across the Internet, are spontaneous but they play an important role in the image-making of an icon due to their wide dissemination. These are constructed as carefully as an icon's on-screen images and staged photography. Therefore it is important to examine how off-screen images contribute to the "icon-creation" process.

4. What are the culturally appropriate paradigms, myths and archetypes included in the creation and functioning of a style icon? What symbolic meanings and cultural mechanisms are reflected by style icons?

While still embodying earlier cultural values, Audrey Hepburn exemplified the period of America in the 1950-1960s when youth and celebrity culture were being developed. Alternatively, Sarah Jessica Parker represented the postmodern era of America in the 19902010s, and embodied the cultural values of consumerism, eclecticism and a fixation with sex. Both style icons' images revolved around dominant cultural ideals, but also challenged conventional notions of beauty and femininity in their time. In order to investigate my research questions, I examined the work of Audrey Hepburn and Sarah Jessica Parker that was the most popular and enduring, and which played the greatest role in establishing their iconic status. Through an examination of their seminal cinematic and televised work, this 
MRP explores how the actresses on-screen images impacted their off-screen lives, and considers the role that fashion played in this process.

Twenty years after her death, Audrey Hepburn is still considered to be one of the most iconic fashion personalities. Cultural sociologist Jeffrey Alexander writes, "If fashion has a patron saint, it's Audrey Hepburn" (327). She remains an eternal style icon, inspiring thousands of everyday followers, and new media productions (e.g. Gossip Girl). Her images grace book covers related to fashion and style and are used to endorse fashion brands such as Gap and Longines, whose brand reflects timeless and elegant style (see figure 1). Audrey Hepburn epitomizes "timelessness" and "elegance," and her iconic status was achieved through an individual and classic style that personified youth, beauty and perfection.

Through her on-screen character Carrie Bradshaw, Sarah Jessica Parker (SJP) came to embody the postmodern, sexually-saturated decade of the 2000s. Her persona was so influential, that the actress has not been able to move past her notoriety as Carrie Bradshaw. In the post-Sex and the City movies and in subsequent roles, she has been typecast as fashion editors (Glee) or career women who struggle to balance love and work. Moreover, the fashion of her heroines in her roles after Sex and the City still resemble Carrie, who has become an iconic fashion figure due, in part, to the efforts of the show's stylist, Patricia Field. SJP has remained very involved in the fashion industry, just as her character Carrie may have done in the television narrative. As an example, in 2014 SJP co-chaired the Met Ball Gala alongside Vogue's editor-in-chief Anna Wintour. She also created a line of fashionable stationary and postcards for Hallmark and designed a few shoe lines (Milligan). All of these activities have contributed to her attempt to establish herself as a real world authority in the fashion industry.

For both Hepburn and SJP, their style consolidated culture and helped to create myths around them in real life that reflected the archetypes that they performed in their on-screen lives. Did the actresses exploit these archetypes or did they create new roles outside of the 
box to appeal to mass culture? Fashion can be considered one of the most important tools that helped them to reach iconic status.

In this MRP, the research seeks to reveal connections between fashion, film and popular culture and demonstrate how cultural phenomena like 'style icons' are created. As revealed through this study of Audrey Hepburn and Sarah Jessica Parker, film stars often come to embody qualities of culture, reflecting the dominant social and cultural cues that exist in a given time and place. Through this examination of Audrey Hepburn and SJP, the research illuminates the particular mechanisms at work in the creation of a style icon. The study clarifies how an icon must develop a distinct and instantly recognizable look reflecting cultural ideals that appeal to a wide group of people. They must be aware that their screen personas help to create a repetitive and persistent myth of personality that becomes embedded in culture and is supported by media scrutiny of their real lives. To establish authority as a style icon, they must also actively participate in the fashion industry and take a creative role in the process. Lastly, while a star actively cultivates their status as a style icon, the role of the consumer must not be overlooked, as it is the fashion consumer who determines an icon's true status. 


\section{Chapter 1}

The style icon as a concept has a limited explanation and examination in literature. This chapter begins by examining the Oxford English Dictionary's definition of an icon, and how it relates to the conception of a style icon. In this chapter, I discuss the earliest instances of female style icons, consider how these powerful women of the past have influenced fashion, and discuss how their practices relate to those of screen actresses today, who use similar practices in order to establish iconicity.

According to the Oxford English Dictionary, the etymology of the word "icon" comes

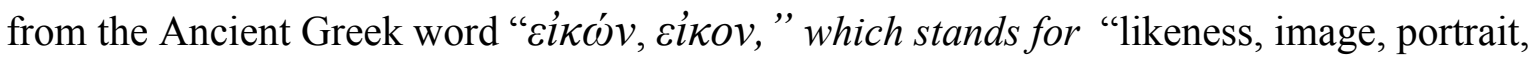
semblance, similitude, simile," and "عik $\kappa \varepsilon v$ — to be like". It was first included in the dictionary in 1572, and had a meaning of "An image, figure, or representation; a portrait; a picture, 'cut', or illustration in a book" (“Icon”). The religious Orthodox interpretation suggests an icon is: "A representation of some sacred personage, in painting, bas-relief, or mosaic, itself regarded as sacred, and honoured with a relative worship or adoration" ("Icon"). Although there is no definition for "style/fashion icon" in these sources, establishing a conception for a'style icon' is important to the study of fashion and culture and relates to the "trickle-down theory of fashion" by Veblen and Simmel.

The theory, proposed in the late nineteenth century, implied that fashion is determined in high classes of society by those who have wealth and power: "The elite initiates a fashion and ... the mass imitates it in an effort to obliterate the external distinction of class" (Simmel 541). However, today screen and television actresses hold this kind of social power and status, inspiring the masses to emulate their looks. Style icons project screen narratives of desirable lives through their fashions, and these trickle down to those film and television viewers who become their followers. 
The concept of a "style icon" is therefore connected to key words in the Oxford English Dictionary description of an "image / likeness/ representation/ adoration" (“Icon”). Film, television or media personalities that we call "icons" tend to personify and represent ideas and values that viewers impose upon them as a result of the narrative, in a reciprocal act with culture. Through their interaction with screen stories, viewers make meaning from more than what is seen on the surface, and impose their needs (e.g. of authority and belonging) and beliefs on these figures.

In November 2014, the digital magazine Swide published an article "5 Italian Fashion Icons before Fashion Icons Existed." The title of this article suggests that "Fashion icon" is a contemporary notion. In this piece, Jonathan Bazzi begins his survey of "Italian Fashion Icons" with Isabella D’Este (1474-1539) and ends with Luisa Casati (1881-1957). What connects the five "iconic" women of the feature is that they served as muses and models for the greatest painters of their times. Bazzi suggests that these 'icons' had social and political power, had influence on intellectual movements, were famous for their fashion choices, and discusses how their images are still circulated today. Similar tendencies were observed in this MRP research: Audrey Hepburn and Sarah Jessica Parker still influence contemporary culture and the fashion industry, and their looks get wide cultural dissemination, overcoming the boundaries of the screen.

Phyllis G. Tortora names Madame de Pompadour, the official chief mistress of King Louis XV of France as "the earliest figure that might be considered a fashion icon". She argues:

Styles of subsequent periods were named after her in recognition of her fashion leadership, such as hairstyle dressed high in the front that became known as the pompadour, as well as a number of nineteenth-century styles bearing some 
resemblance to rococo fashions, including the pompadour bodice of the 1870 s and the pompadour sleeve of the 1830 s and 1940s. (Tortora)

For a person to be considered a style icon there have to have been many visual representations made of them (e.g. paintings in the past; photographs today) in order for them to be recorded and remembered; they must leave a fashion heritage for future followers.

Tortora states that "fashion icons" are usually "individuals who are in the public eye by reason of their position as royalty or high society or their involvement in politics, the entertainment industry, or the fashion industry, or because of some significant accomplishment." The keyword here is "public eye," which denotes a style icon's representation in media today (e.g. in paintings, theatre, photographs, on film and television screens or online). For the screen actresses that are examined in this MRP, the attributes of saturated imagery, cultural influence and fashion impact are supported by their presence in films and promotional images, their friendships with artists and their patronage of designers or artists. 


\section{Chapter 2}

\section{LITERATURE REVIEW}

In this Chapter I present common topics that arose during the literature review regarding various types of icons. I refer to the research of cultural icons and celebrity icons, as this literature provided the most extensive understanding of mechanisms and conditions of iconicity. Since style icons may be seen as cultural icons who are primarily appreciated for their use of fashion to embody the cultural values, theories of cultural and celebrity icons were specifically examined. Ideas of "recognition”, “ambiguity”, “consumption”, "collectivity", and the importance of "mythologies" in constructing a style icon were observed as being significant to the understanding of style icons.

Defining a Style Icon. One of the challenges of defining a style icon is that this term is used throughout popular culture narratives and implies associations with meanings of "famous", “staple”, “inspirer”, “notable”, “outstanding”, “influencer”. In February 2015, Canadian highend retailer Holt Renfrew launched a loyalty program for their customers, called "Holt Icon". They explained that they viewed their "most devoted customers as icons, distinguished personalities that shape the place we call home" (Holtrenfrew.com). Their use of this hyperbolized adjective to identify consumers of luxury goods as icons reflects how the term has gained significance in a contemporary cultural context.

Jonathan Meades suggests that "iconic" should be the adjective of the age, considering its dissemination in media, advertisement and entertainment industry. For example, the Canadian magazine FASHION's May 2015 issue featured an article called "It Girls and Icons", and a September 2014 cover of the American Harper's Bazaar was dedicated to "Icons styled by Carine Rotfield". This story and the accompanying word "Icon" was spread out through worldwide editions of Harper's Bazaar, reaching audiences from Brazil to Poland and from Mexico to Singapore and Australia (see figure 2). The term icon is 
often used in academic publications as well, such as "Reading Women: Literary Figures and Cultural Icons from the Victorian Age to Present" (Badia and Phegley), Ramona Curry's “Too Much of a Good Thing: Mae West as Cultural Icon", and Will Brooker's "Batman Unmasked: Analysing a Cultural Icon”. Authors often do not clarify their use of this term, but their inclusion of it exemplifies how the word "icon" has saturated various realms of publishing.

Researchers, such as Parker, Meades, and Tomaseli and Scott, Hariman and Lucaites, deconstruct the popular usage of "cultural icons" in their publications. Although Hariman and Lucaites' book focuses on iconic photographs their understanding and explanation of the meaning of "an icon" and "iconic" is applicable to the concept of a style icon. Iconic photographs follow the same mechanism as iconic personalities in terms of how they are created and function.

How Cultural Icons Function. Mike Parker's definition of "a cultural icon" is very much related to the concept of a style icon. In discussing cultural icons Parker states that they "are phenomena that we can see (distinct images) that last with us in collective memory (durability and reproducibility) and they have natural meaning reflecting who we are as human beings" (11). Style icons are also distinctly visual. For example, images of Audrey Hepburn and Sarah Jessica Parker have been embedded in popular culture for 60 and 20 years, respectively, which proves their durability and visual appeal. Photographs of both actresses have been widely reproduced and referenced in media, and as the following chapters show, they reflect the values and norms of their specific cultural contexts. Moreover, on-screen, Hepburn and SJP perform narratives of "collective perception", which are a key argument of Parker's research. Other explanations of cultural values are relevant to the concept of style icons and are discussed below. 
Jonathan Meades singles out four conditions of the truly iconic in his article "Iconic: Adjective of the Age", which apply not only to cultural icons, but style icons as well:

1. "Condition A. It affects us whether we like it or not" (Meades). Some personalities are identified as style icons in the media and are promoted as such. They are regularly associated with the word "icon" and their status is perceived as common knowledge.

1. "Condition B is that the image transcends its subject" (Meades). Without knowing the actual story, we might worship or follow styles of certain icons. For example, the image of Anita Ekberg from Federico Fellini's film "Dolce Vita" (see figure 3) where she is swimming in Trevi Fountain, has become iconic and referential not only to the notions of "Rome", "Italy", "Italian cinematography", but to the aspirational concept of "Italian dolce vita" in general. Nevertheless, despite the iconic feature of the image, the name of the actress might not be as familiar to the general public as this visual image.

2. "Condition $\mathrm{C}$ is that the subject should be legible in a sort of visual shorthand" (Meades). In his discussion, Meades provides examples of Napoleon and his pose with a hand tucked in his uniform, Charlie Chaplin and his bowler hat and mustache, Mick Jagger and his lips. With style icons, condition C is very strong as we observe such features to be referenced in fashion photography, advertisement and graphic design. The cone bra, sparkly glove and red leather pantsuit certainly are referential to Madonna, Michael Jackson and Britney Spears' images, as they were circulated in media and have become iconic elements of these star's looks (see figures $4,5,6$ ). Condition $\mathrm{C}$ is also connected to the fourth condition. 
3. Condition D is "immediacy of recognition" (Meades). Style icons are recognizable and their influence on people's behavior is also usually evident through emulation. For example, a pink tweed suit and a pillbox hat is an immediate reference to Jackie Kennedy, while an airy white dress is associated with Marilyn Monroe. "The icon has to be the visual equivalent of an unmistakable catchphrase", says Meades. This could be the reason why iconic costumes can be easily recreated as Halloween costumes and are unmistakably recognizable.

However, Meades claims that "an actor who is a chameleon (Peter Sellers, Alec Guinness, Meryl Streep) is unlikely to become an icon" which is arguable. In his book chapter entitled "Chameleon", (160) Simone Werle disputes this statement. Although it includes only one personality, Madonna, the list of style icons of the twenty-first century can be continued with the example of Rihanna, who (like Madonna) also changes her image with every album. Rihanna is involved in the fashion industry and was awarded with the "Fashion Icon Award" by the Council of Fashion Designers of America (CFDA) Fashion Awards in 2014 ("Introducing the 2014 CFDA Fashion Icon"). This award reflects her status as a style icon in culture, no matter if we agree or not (as per Condition A in Meades' argument).

Even with Madonna's ever-changing images, there is a consistency to her persona, an immediacy of recognition and a visual shorthand in the period of those looks. Whether she is a tomboy, femme fatale or disco diva, all those periods are supported by consistent media coverage (music videos, live performances, commercials and magazine spreads) and are immediately associated with the style of the 1980s, early 1990s or mid-2000s.

The main disadvantage of this article by Meades is that, firstly, it is not an academic publication. Although it is one of a few attempts to break down the functionality of icons in culture, it lacks depth and references to other sources to validate his opinion. Nevertheless, 
his conditions of cultural iconicity can be observed in life and supported by examples from different spheres of activities.

Parker's central argument in his PhD research, "Cultural Icons: A Case Study Analysis of their Formation and Reception" states that "primary cultural icons are distinct, durable, reproducible images that reside in the collective memories of large communities of people" (27). In his study, he also breaks down iconic qualities into four categories:

1. Cultural icons are always "distinct images" (Parker 12). This quality corresponds with Meades' third condition of icons being "legible in a sort of visual shorthand". Hariman and Lucaites call it "aesthetic familiarity" (29). Viewers are familiar with the images of distinct hair-styles, silhouettes and accessories of certain cultural and style icons and can easily refer to them. The reference is understood from the cultural discourse with which people are familiar. This familiarization helps to get across the message of what the outfit represents.

2. "These images are ... durable and reproducible" (Parker 12). In the words of Tomaselli and Scott, this condition of iconicity is observed as "representing continuity" (qtd. in Parker 53). Iconicity is achieved through constant media circulation. Iconicity also requires consumption, through which reproducibility can achieve wider dissemination. Tomaselli and Scott also discuss Madonna, whose iconic status has been achieved over decades in the public eye, whose image matured and gained greater meaning throughout this period of time (Parker 56-59). "Iconic continuity, for Tomaselli and Scott, is thought of as a gradual maturing of an image" (Parker 56). The condition of durability and reproducibility is very much applicable to cultural and style icons who have been in the media for a long time or those who have passed away, such as Audrey Hepburn. 
3. "They reside in the collective memory of people" (Parker 12). Collectivity is a major factor of the mass culture that we live in today. Depending on the sphere of activity (fashion, music, cinema or television) or sub-culture (hip-hop, bohemian artists or party kids), iconicity can be achieved through collective recognition of a large group of people. "Collectivity" as a factor for an icons' existence has been researched by Mary F. Rogers and Irma Dosamantes-Beaudry. It is discussed later in detail in the themes that reoccur in iconic statuses of personalities.

4. Lastly, icons reflect "tragic-dramatic narratives that are formed and received by communities particularly receptive to the development of iconic meaning" (Parker 13). What Parker calls "tragic-dramatic narrative", Hariman and Lucaites' discuss as "emotional scenarios" of iconic photographs, that "provide the viewing public with powerful evocations of emotional experience" (35). In the meantime, Tomaselli and Scotts suggest that essential conditions of iconicity are "accreting layers of meaning or connotation" (qtd. in Parker 53), which, in the structuralist framework of Barthes is understood as "mythology". This factor of iconicity includes narratives, scenarios and layers of meaning necessary for icons to exist in culture. Although this MRP examines the narratives embodied by style icons, such narratives are not necessarily "tragic-dramatic" but aspirational, because they how one can achieve a better life through transformation and self-improvement in fashion (e.g. as in the 'Cinderella' and 'Pygmalion' narratives).

In the conclusion to his research, Parker states, "Cultural icons are used. They not only play an important part in the way modern cultures define their existence, their importance is also reflected by the manner in which distinct iconic forms are utilized in daily life" (229). Cultural icons are not only used, they are consumed. Consumption, as a factor in the way cultural icons function is greatly discussed in the literature about iconography. Fashion 
followers consume style icons through images and goods, and they use consumption as a shopping practice as a way to emulate a favourite star. In Tomaselli and Scott's discussion, another condition of cultural iconicity is "attaining an exemplary status and by exerting a certain seduction" (qtd. in Parker 60), which in the realm of fashion and style icons is the desire to consume, purchase and emulate.

\section{THEMES REOCCURRING IN ICONIC STATUSES OF PERSONALITIES}

Collectivity. Collectivity as one of the themes that appear in the literature concerning cultural and style icons is evident in various frameworks and approaches. I identify collectivity as the inclusion of an icon in the realm of interests and activities of a large group of people that share similar beliefs and values. For an icon to function in culture, they must be appreciated and followed by a large number of people. Collectivity can be understood from various perspectives, and is often discussed in psychoanalytic and marketing theory.

As an example, Irma Dosamantes-Beaudry discusses the formation of the painter Frida Kahlo’s cultural iconicity from a psychoanalytic and psychosocial approach. In her article "Frida Kahlo: the creation of a cultural icon", she states that the development of cultural symbolic figures is connected to psychological processes of "attachment, validation, idealization and identification" (Dosamantes-Beaudry 3). Dosamantes-Beaudry suggests that in the art circles of female painters of Mexican heritage and in Chicana artists groups there was a need for an influential role model. Because Kahlo embodied the values of those groups, she was seen as "a defender of their culture" (12). Kahlo became a cultural icon that acted as "a magnet of meaning by drawing to itself a multiplicity of meanings that are projected to it by its believers of a particular culture during a particular time" (8). Kahlo is also considered a prominent style icon, representing bohemian and folkloristic styles (Brooks; Fydrych; Werle). Her feature on the cover of Vogue Paris in 1939 (see figure 7) demonstrates this status. Although Kahlo dressed in traditional Tihuana attire to emphasize and celebrate 
her heritage, aesthetic values and political views, Dosamantes-Beaudry notes that Kahlo's image was used by other artists to represent their shared aesthetic values and political ideals (8). As a "transitional object", her cultural iconicity had "a capacity to serve as repositories for the admirer's projections while simultaneously retaining their separate and independent identity as objects" (9).

In her book "Barbie Culture", sociologist Mary F. Rogers alternatively used a consumerists' lens to examine the Barbie doll as a cultural icon. She began her discussion by arguing that an icon provides "a point of recognition widely shared by with other members of one's society... They let people experience commonality amidst diversity, shared interests amidst conflicting ones, participation in the same broad culture amidst many subcultures" (2). Rogers suggests that a cultural icon prompts followers to make an "identification of one sort or another as fans, collectors, designers or consumers". She identifies "small social worlds building up around the icon", and discusses how "a cultural object that exemplifies some set of values, beliefs and norms in a society- gets a strong grip on a sizeable part of the population" (6). Because Barbie incarnates different kinds of women (e.g. working girls, girls dressed in national costumes, girls participating in various sports and hobbies) she appeals to different social groups and becomes a visual icon for cultural processes. Rogers states that the "cultural icon gets enmeshed in people's everyday lives and social relations" (6).

Style icons often influence not only the fashion choices of their followers, but also their general life choices. This is reflected in lifestyle books with titles such as "What Would Audrey Do?" by Pamela Keogh, "How To Be Lovely? The Audrey Hepburn's Way of Life" by Melissa Hellsternand, and "So Audrey. 59 Way to Put a Little Hepburn in Your Step", by Cindy De La Hoz. The number of publications available, and their popularity on online 
retailers Amazon or Goodreads.com prove that there are many groups of people who identify with style icons.

Apart from discussing real people as icons, Rogers singles out two types of cultural icons, fictive and fantastic icons, which also serve as a projection of human needs (3). However, both types relate to imaginative characters and not real people. In Roger's words, a fictive icon contributes to a culture by letting members act as if something is real or true even while they "know" it is not. Like Barbie, Aunt Jemima and Scarlett O'Hara are fictive icons that let people imaginatively explore race, sexuality and femininity. (3)

At the same time,

a fantastic icon contributes to a culture by exaggerating what is actual, possible, or conceivable. Such an icon invites fantasy by taking the as-if or the fictive toward its outer limit. Barbie is such an icon, as are Superman and Playboy centerfolds. Fantastic icons are capable of releasing people's imagination from the constraints of their culture's definitions and requirements. (3)

As fictive and fantastic icons we can take into account movie characters, like Carrie Bradshaw from Sex and the City, Holly Golightly from Breakfast at Tiffany's and Sabrina from the movie of the same name starring Audrey Hepburn. In these films, the heroines experience female fantasies connected to fashion and transformation, which help their viewers relate to and explore the themes they were dealing with in their fiction worlds.

Consumption. Consumption is a vital part of a fashion system. Style icons along with cultural icons are heavily involved in the circulation of their consumption by expanding their image in the fashion industry through their collaboration with companies and advertising. In her discussion of Barbie, Rogers writes 
The construction of this cultural icon thus involves a dense web of products identified not only with Barbie and Mattel but also with other corporate sponsors and popular culture. Much of Barbie's iconic status has built up from these countless connections with other commodities characteristic of postindustrial economies. Such commodities speak to desires shaped by mass advertising and fulfilled along the border between fantasy and reality. (95) Sarah Jessica Parker reflects this mechanism through her active involvement with companies: by creating card sets with Hallmark, launching personal shoe lines, developing perfume, or working with advertising companies like Gap (Byers and Krieger; Milligan). By affiliating with Vogue magazine, she establishes her fashion authority by expanding her ties in the fashion industry and encouraging the consumption habits of her fans. In Chapter 6, I further discuss consumption as one of the mechanisms of the functioning of style icons by examining similarities and themes in my analysis of Audrey Hepburn and SJP.

Mythology and Archetypes. Almost all researchers that speak to cultural icons claim that in order to become iconic, one must include and reinforce certain cultural myths (Holt; Rogers; Tomaseli and Scott;). As Parker states, "Mythology and meaning, created with the active participation of receptive communities, are essential characteristics of iconic phenomena" (142). The way myths and archetypes function in creating iconic brands and personalities is discussed in the following passage from different theoretical perspectives.

Douglas B. Holt, who has a marketing approach and writes about brands and branding strategies states that "icons come to represent a particular kind of story - an identity myth that their consumers use to address identity desires and anxieties... Icons perform a particular myth society especially needs at a given historical moment, and they perform it charismatically" (2). As discussed with Frida Kahlo, her iconic status was achieved at the 
point in time when there was a need for that parallel to the social movements in a specific cultural ambiance (Dosamantes-Beaudry). Kahlo was not a cultural icon for French or Chinese females or painters, because a cultural need for that has not been observed. However her style might be followed beyond the borders of her country due to her wide global media exposure, which happened after she gained the status of a cultural icon.

Holt identifies myths as:

simple fictions that address cultural anxieties from afar, from imaginary worlds rather than from the worlds that consumers regularly encounter in their daily lives. The aspirations expressed in these myths are an imaginative, rather than literal, expression of the audience's aspired identity. (8)

He also writes that an icon is a "material embodiment of the myth" (8), which is relevant if we also take into consideration the original religious meaning of an icon and Biblical myths that icons represented in the original meaning of the word "icon" through paintings. Moreover, this argument is also connected to the desacralized feature of contemporary culture, when screen personalities and celebrities are vested with superhuman qualities. The tendency to vest screen personalities with transcendent power was noticed by Jackie Stacey who writes, "the feelings of love and adoration towards stars are often represented through the discourse of religious worship in which stars become goddesses and no longer belong to our world" (142). These practices are discussed regarding female spectatorship practices. Jeffrey C. Alexander, an American cultural sociologist and a researcher of celebrity icons states icons are;

mythical characters in a rather strict sense... Female celebrity icon carries the mythical meaning of its archetypically gendered forms. The female celebrity icon is a princess, a femme fatale, or a heroine, and her stories revolve around the myth of love. (330) 
In “Growing Up with Audrey Hepburn,” Rachel Moseley identifies love narratives as a key staple of feminine culture. Ien Ang sees one's personal life as "the core problematic of narrative" (79) in melodrama on television in her research on television fiction and women's fantasies. They are seen to be so due to the romanticized aspirations of love leading to marriage and acquiring social status as well as fall into normative gender stereotypes. At the same time male celebrity icons fall into categories of "a hero, a villain, he struggles over greatness in his mythical stories" (Alexander 331). These arguments are similar to the typology of stars, provided by the researcher of stars, Richard Dyer, whose book Stars in 1979 has become seminal in the popular cultural studies.

Dyer writes, "What is important about stars ... is their typicality or representativeness. Stars in other words relate to the social types of a society" (53). He explains a social type as "a shared, recognizable, easily-grasped image of how people are in society (with collective approval or disapproval built into it)" (53). Style icons, therefore are stars recognized by large groups of people. Dyer looks at stars as at images, which is relevant to this research, where icons are observed as images. However, stars are more typical and straight-forward, as they follow archetypical roles.

According to film theory, female archetypes represented in cinema usually depict a woman as: 1) the mother 2) the wife 3) the seductress/vamp/femme fatale 4) the virgin (Nichols 399-405). In research on how women engage with television shows, author Ien Ang also comments that "contemporary popular television fiction offers an array of strong and independent female heroines, who seem to defy ... stereotypical definitions of femininity" (75). So there is a tendency of cultural icons to operate within the stereotypical parameters given by the cultural norms. For the creation of style icons, functioning in the discourse of stereotypes is necessary in order to be placed in a box first, in comparison to which they can be then elevated to the iconic status. 
Despite the tragic-dramatic narrative, as discussed by Parker for cultural iconicity, the most popular narrative for female viewers is a princess narrative and a Cinderella story that has been researched by Rachel Moseley. Many researchers, such as Stella Bruzzi, Rachel Moseley, Gabrielle Finnane claim that the Cindrerella myth is tied to the cinematic role of Holly Golightly, which is Audrey Hepburn's iconic character in Breakfast at Tiffany's. The Cinderella story is also associated with her other Hollywood movies: Roman Holiday (1953), Sabrina (1954) and Funny Face (1957); though in Roman Holiday, it is Cinderella in reverse, where a princess aspires to experience the life of a regular girl. Moseley describes the Cinderella myth as "a key trope" and "a staple of feminine culture" that offers "the magical spectacle of transformation and the promise of a better self and a better life" ("Trousers and Tiaras" 39). Helen Warner also mentions the "Cinderella" motif in relation to SJP's persona ,which is cultivated and disseminated through popular magazines ("Fashion on Television" 112). The importance of shoes in building the character of Carrie Bradshaw is obvious and seminal in connection with the fairy-tale personage who got transformed into a princess with a glass slipper. To the same extent, a French couturier, Hubert de Givenchy, played the role of Cinderella's fairy godmother to help Audrey Hepburn achieve visual transformation with his beautiful gowns.

The "princess motif" is another trope used in creating the image of style icons. In their article, "From Ugly Duckling to Cool Fashion Icon: Sarah Jessica Parker's Blonde Ambition" Michele Byers and Rosalin Krieger state that SJP's character Carrie Bradshaw represents the stereotype of a Jewish American princess (JAP) through "phenotype, mannerism, food, language and clothes" (53). Although the stereotype of the JAP is not discussed in this MRP, the "princess" motif is still prevalent in the construction of SJP as a style icon and possesses aspirational value for viewers. Audrey Hepburn, however, plays an actual princess in her seminal movie Roman Holiday, which established her as a new Hollywood princess after she 
won an Oscar for it in 1953 (Wasson 25, 46). Fiona Handyside references Peter Kramer, saying that Roman Holiday worked as a typical example in establishing "Hepburn's identity as a modern princess, i.e. a Hollywood star" (289). Here the Hollywood star as a social type becomes synonymous with the "princess motif" and its importance is validated.

Associative locations. David Holt, in examining the advertisements of iconic brands, stated that "identity myths are usually set in populist worlds", which "create credibility that the myth has authenticity, that it is grounded in the lives of real people whose lives are guided by these beliefs." (9) The same mechanism is performed with the style icons and their associative connections with locales. Handyside explores Hepburn's connection to European cities, emphasizing that the actress was promoted "as different" (288) in comparison with her American contemporaries: She was presented mostly as a "European" and her most significant transformations occurred in Paris and Rome. Meanwhile Sarah Jessica Parker's persona and movie heroines are located in New York. All of her experiences with the city become interwoven with her iconic status.

Ambiguity. Some cultural icons are relatively straightforward and cause solid associations such as James Dean and the figure of the social rebel (Parker 120), or Rita Hayworth and the femme fatale (Staiger 292), but many of them contain ambiguities. Although Marilyn Monroe is an icon of sex appeal, she is not viewed only as a bombshell, but also "a victim", who was “innocent" or "manipulative" (Dyer 178). She definitely falls into an archetype of "sex kitten" (to a common knowledge which corresponds to "Condition B" of Meades' understanding of an icon), but still there are double meanings that she plays with within her image. It might also be connected with the "dramatic appeal" (40) of Parker's discussion, when the story in collective memory of communities is still unclear and causes discussions.

Researchers suggest that what makes cultural icons so powerful, "is their indeterminacy" (Rogers 143), and suggest that they must target "the most advantageous 
contradiction in society" (Holt 63). Barbie along with Madonna reflects a postmodern performance of identity, expressing a "pastiche personality" (Rogers 143). Sarah Jessica's Parker character, Carrie Bradshaw, as one of those identities with "pastiche personality", discusses relevant cultural problems and uses fashion to express her own indeterminacy. According to theories of postmodernism, ambiguity can be a feature of postmodernist cultural icons. Although for style icons there must be a consistency in such range of options, otherwise followers might lose a sense of their understanding.

In Barbie Culture Mary F. Rogers argues that No icon represents only one dimension or axis of a culture. Instead, icons become such because of their versatility, thick folds of meaning, adaptability to diverse individuals' needs or interests, ultimate ambiguity, and open-ended nature. In a sense, then, a cultural icon is paradoxical. At one and the same time it evokes commonality and difference. It offers a shared point of reference for society's members while adapting itself to the cultural differences built up among them. (3)

Themes of ambiguities, as those that occurred in the analysis of style icons, are thoroughly discussed in Chapter 6 as a justification of this point of mechanism of functioning of style icons, which are not strictly determinative. They can appear as universal yet individual, portray and encourage democratization yet advocate elite companies, they portray one type of women on the screen (single girls) but in real life they lead another lifestyle (married women). Rachel Moseley notices how Hepburn was described as "boyish, but still a girl" and “fragile, yet strong" (“Growing Up", 217). And while some followers might refer to one part of the style icon's image, others can share the values embodied by another side of the image.

\section{CONCLUSION}


Relating to the theories discussed above, a style icon can be viewed as a specific kind of a cultural icon due to similarities of their features and conditions of their functionality, but with a primary emphasis on fashion as a medium for their establishment in culture. Narrating myth is an essential condition for the existence of an icon, either a cultural, celebrity or style icon. Icons are instantly recognizable images, which are shared and appreciated by wide groups of people due to the narratives that they perform in their works and media portrayals. The construction of cultural icons as well as style icons includes a wide web of products associated with them and involves active practices of consumption in order to emulate or relate to the icon. No cultural/style icon represents only one set of values, but is required to be indeterminate and ambiguous. Moreover, this ambiguity as a feature of postmodern culture emphasizes that icons become embodiments of culture and fill the need of their admirers of a role model to relate to. 


\section{Chapter 3}

\section{Methodology AND THEORETICAL FrAMEWORK}

In order to find answers to the main research questions, one of the key techniques of analysis was visual analysis that observed iconic outfits and the narratives they represent. By building on Roland Barthes theories, Jackie Stacey's work in psychoanalysis and semiotics, and Richard Dyer film study and 'star' theory, I examine how the films, film stills and photographs of Audrey Hepburn and Sarah Jessica Parker determined their status as style icons.

Since my main discussion focused on these two female style icons I researched the films and television productions that helped them achieve that status. The images for these films are still represented in various media, and sometimes function on their own, distinct from their original context, such as the Roman postcards of Hepburn's image from the movie

\section{Roman Holiday.}

My analysis of Hepburn includes her most famous and popular roles in Roman Holiday (1953, dir. William Wyler), Funny Face (1957, dir. Stanley Donen), and Breakfast at Tiffany's (1961, dir. Blake Edwards), which exemplify Hepburn's iconic status and relationship of fashion and lifestyle in the fashion capitals of Rome, Paris and New York, respectively. These particular movies are chosen for the research as they represent not only her rise and establishment in the Hollywood star system and her fashion looks but are also connected with the Cinderella narrative. Handyside explores Hepburn's connection to European cities, emphasizing that the actress was promoted "as different" in comparison to her other American contemporaries, she was presented mostly as "European" and her most significant transformations, connected to the Cinderella motif, occur there (288).

The image research includes an examination of influential magazines like Vogue and Harper's Bazaar. Vogue has a reputation of being the most authoritative in the fashion 
industry and "firmly belongs to a tradition which links fashion with status, class and wealth" (Konig “Glossy Words" 205). As an example of Vogue's status as a fashion authority, a Ukrainian fashion designer, Anna K, launched a series of humorous T-shirts, sold in Colette in Paris, called "Fashion Dictionaries", which included the "Fashion Icon" T-shirt. The t-shirt reads "Fashion Icon - 1. Status which has to be approved by Anna Wintour" (see figure 8). Anna Wintour has been an editor-in-chief of Vogue magazine since 1988.

Other images that I analyze are taken from photography books such as "Audrey. The 60's" and "Audrey in Rome", which includes the paparazzi pictures taken of the actress during the years when she worked and lived in Rome. It is an important source, as the book (published by her son) represents images that are considered to be candid and off-screen, but they are vital in establishing her style icon status. Also, the text gives examples of how the off-screen looks of Hepburn either supported or contradicted her on-screen images.

With the case of Sarah Jessica Parker, I am going to focus particularly on the episodes of her seminal TV-show Sex and the City (1998-2004), where her character Carrie Bradshaw discusses fashion and its role in her life in episodes such as "A Woman's Right to Shoes" (Season 6, Episode 9) and "What Goes Around, Comes Around" (Season 3, Episode 17). Because there are so many episodes to consider, I do not apply an explicit visual analysis. Rather, I discuss SJP's connections with fashion. I analyze the role of Vogue magazine and Harper's Bazaar, two most important magazines in the fashion industry, which exemplify how the actresses' image was presented to the masses.

I am going to analyze what both actresses are wearing at a certain points of the plot, so that the particular look is best associated with the narrative that is represented on the screen, whether it is the character's ride on a Vespa motorcycle or how another is walking the streets of New York. Also, I am researching how consistent the styles were on-screen and off 
-screen to see if they complemented/contradicted each other and what messages they were conveying.

\section{METHODOLOGY}

In his book "Iconology. Image. Text. Ideology", W. J. T. Mitchell writes, "The critical study of the icon begins with the idea that human beings are created "in the image and likeness" of their creator and culminates, rather less grandly, in the modern science of "image-making in advertising and propaganda" (2). In his research, Mitchell looks at "the ways that images in the strict or literal sense (pictures, statues, works of art) are related to notions such as mental imagery, verbal or literary imagery, and the concept of man as an image and maker of images" (2). Mitchell looks at how theories of art (including iconography), language and the mind are connected to social and cultural values. Using a similar approach, I examine how images of style icons relate to cultural standards and ideals. Since style icons function first of all as images that are emulated by their followers, the idea of "likeness" is very applicable to my research through the ideas of identification and consumption of female viewers. Aspirations that style icons embody are mental images for their followers and their looks become referential to the narratives they perform.

Semiotic Analysis and Mythologies. As one of the research questions of this thesis is to examine myths that are constructed in the image of style icons and their personalities, semiotic analysis helps to unveil myths. Mike Parker in his research on cultural icons wrote, "The idea that layers of meaning gradually accrue to a symbol justifies a semiotic analysis of these layers and clearly adds knowledge to how modern iconic forms are perceived" (54). In his research of cultural icons, Parker was unveiling cultural meaning that icons embodied with the help of this approach. I also analyze layers of meanings, despite their fashion authority and aspirational ideas that are covered by style icons. 
Images convey messages as much as words do, they become a foundation for discourse and cultural contexts. As Mitchell notes, "they stand as referents for words" (60). However there is a system of how images can be read. One of the most common contemporary techniques is a semiotic analysis of signs and signifier/signified, denotation/connotation. Since I research movie stills and photographic images (visual signs) of style icons, both set in studios and in the streets, they send a message depending on the contexts, in which fashion is also used as a language to communicate those messages.

Signs have levels of meanings, which are denotation and connotation. As provided by Michael Emmison and Philipp Smith, "denotation is the simple, obvious, literal or commonsense meaning of a sign" (75), while connotation is a meaning that "occurs when denotation interacts with the dominant cultural values associated with the sign and the attitudes, feelings and emotions of audiences/users" (75). Connotations are socially constructed, ideological and mythological, although they appear to be natural. If an image of a woman in a long black dress, with a beehive hair-do, long cigarette holder, and heavy jewellery (denotations) is placed in a realm of fashion imagery, it instantly gives a connotation of an image from the movie "Breakfast at Tiffany's". Audrey Hepburn and her heroine Holly Golightly, and the aspirations of a better life, elegance and timeless chic also come to mind. Within the context of tourism, the image of Holly Golightly connotes New York City, the Tiffany's Store on $5^{\text {th }}$ Avenue, leisure and a fun lifestyle. In cinematic discourse, this image provides a foundation for the context of cinematography of the 1960s, actors, storyline and Truman Capote.

Semiotic analysis provides a base for the structuralist theory of mythologies by Roland Barthes. In myth "the tridimentional pattern... the signifier, the signified, and the sign" (Barthes 223) operates. Barthes claims that myth is produced to consumption through connotations, the myth is "conveyed by a discourse" (217). Storey clarifies that "By myth he means ideology understood as a body of ideas and practices, which, by actively promoting 
the values and interests of dominant groups of society, defend the prevailing structures of power" (121). Barthes states that "photography, cinema, reporting, sport, shows, publicity, all of these can serve as a support to mythical speech" (218). By myths in my research, I am going to explore not only well-known archetypical narratives known from childhood, but also narratives that are being created with the help of films and television and repeated over and over again for their establishing.

Both Audrey Hepburn and Sarah Jessica Parker's images operate within the archetypical conventions of feminine nature, in order to be relatable and likable. Before they stand out, firstly they have to fit in the system of conventional models of behavior that are presented through archetypes. Female archetypes represented in cinema usually depict a woman as the mother, the wife, the seductress/vamp/femme fatale, or the virgin (Nichols 399-405). Did the actresses exploit these archetypes or were they obliged to create new roles outside of the box in order to be consolidated in mass culture? Fashion can be considered as their first and most important tool in creating the myth along with their iconicity, which helped them to stand out.

Film stills as images that circulate in magazines and on the Internet, have a great value for finding answers to the research question. I take into consideration main narratives and connotations that are performed in film and then live beyond the screen. Opening scenes, key plot turns and final scenes (where a heroine usually ends up with a fairy-tale scenario of finding her "Prince Charming") and what they were wearing are important elements in building a mythological construct of style icons that gained their status within the film and fashion industries.

A Feminist Lens. A feminist theoretical framework is employed in the examination of Audrey Hepburn and SJP particularly when discussing female style icons, female roles and 
stereotypes. Moreover as a female researcher, I might apply my personal judgments as a female viewer.

Jackie Stacey's publication on Hollywood and female spectatorship has clear connections to what is observed in the creation of a style icon. She conducted research based on interviews and responses of middle-class white British women who had been keen cinema-goers in 1940s and 1950s. From the interviews, Stacey singled out three main discourses - escapism, identification and consumerism.

By escapism Stacey understood "not only escaping into luxury of the cinema and the glamour of Hollywood film, they were also escaping from the hardships and the restrictions of wartime and post-war Britain" (qtd. in Storey 141). She refers to Richard Dyer and comments that he "highlights the connections between pleasure and the historical and cultural locations which produce the particular forms of utopian sensibility" (Stacey 92). Locales of Audrey Hepburn's films and her connections to European cities and her fashions there create this type of escapism for viewers who would later copy her looks in order to embody that type of escapism from quotidian life. The importance of associative locations was mentioned by Douglas B. Holt as one of the conditions of iconicity. As the outcome of escapism, Dyer and Stacey notice "community" (93) as a sense of belonging and communal interests as I have discussed in my literature review in terms of creating a cultural icon. Hollywood overall is perceived as "offering an escape to a materially better world" (98) through signifiers luxury, desirability and glamour, so opposite from post-war British reality. This aspirational and imaginative escape is a very important aspect of creation a style icon and mythological promise of a better life.

Her second discourse is identification. Identification traditionally was acknowledged as "the means by which women collude and become complicit in their own oppression" (Storey 141). In film studies the term "identification" would generally refer to "sympathizing 
or engaging with a character" (Stacey 130). However, Stacey explains that stars "can generate fantasies of power, control and self-confidence, fantasies that can inform the activities of everyday life" (qtd. in Storey 141). As seen before, identification is a strong mechanism in creating cultural icons as described in the article about cultural iconicity of Frida Kahlo, where Irma Dosamantes - Beaudry observed identification processes in the same way as Stacey does - through references to Freud as a starting point (4). Once a person has entered adulthood and detached from their parents, they still have a need of an anchor that serves as an example as well as provides emotional support, recognition and validation (Dosamantes-Beaudry 10). Many women would find those anchors in screen narratives.

Stacey notices that from her research and interviews of women, there are contradictory feelings that spectators usually experience regarding Hollywood stars: "on one hand, they value the difference for taking them into a world in which their desires could potentially be fulfilled; on the other, they value similarity for enabling them to recognize qualities they already have" (128). This observation also relates to the style icons and myths that they create, when they either play in the normative realms of allowed female behavior or they stand out, thus creating desires for viewers. Fashion is a key element to draw this approach of identification for viewers to identify themselves with their style icon, which helps achieve visual similarities.

As "extra-cinematic identificatory practices", Stacey notes pretending, resembling, imitating and copying, where the last one "involves an intersection of self and other, subject and object", when "in front of a reflection of herself, the spectator attempts to close the gap between her own image and her ideal image, by trying to produce an ideal image" (167). Women make or purchase clothes, and style their hair and make up similar to their favourite actresses in order to look like them. A screen representation is seen to be ideal and aspirational, thus a fan through copying or following styles attempts to become as close to the 
icon as possible. Stacey mentions this process as a bridge to her final discourse, which is consumption.

Consumption, as a third discourse, is the process of not only purchasing garments seen on the screen, but concerns "producing oneself as a desirable object, it also offers an escape from what is perceived as the drudgery of domesticity and motherhood" (Stacey 238) that define femininity at a given time. While industries were creating commodities that have connections to the Hollywood movies, like cosmetics, fashion and even furnishing, the female spectator appears to be "a consumer of idealized images of femininity on the screen" (Stacey 183). Adding to existing companies that were building their clientele based on the desirability of cinematic identifications in the 1950s (like Max Factor), style icons go further and themselves become part (whether as producers or just "the face") of those companies. One of the greatest examples is Audrey Hepburn as the face of Givenchy, as discussed in this MRP. Contemporary actresses that are claimed to be style icons by the media, include Blake Lively as a face of Gucci perfumes, Penelope Cruz as a face of Lancôme, Marion Cotillard as an ambassador for Dior, and Monica Belucci as an ambassador of Dolce \& Gabbana. L'Oreal Paris, a French cosmetics company that often sponsors international film festivals (such as the Cannes Film Festival, Toronto International Film Festival, Odessa International Film Festival) is affiliated with such movie stars as Blake Lively, Jane Fonda, Jennifer Lopez, and Laetitia Casta. Such practices not only establish movie stars in the fashion and beauty world, but give validation to the fashion houses in their attempts to be affiliated with cinema.

The rise of Audrey Hepburn occurred in the early 1950s, and in terms of a timeline, her rise as a Hollywood star coincided with the three discourses of female spectatorship of the 1950s as analyzed by Stacey. Rachel Moseley's book “Growing Up with Audrey Hepburn" also is based on interviews of British women who admired the actress in the 1950s, 1960s and 1990s. She takes Stacey's psychoanalytically informed approach to investigate 
how and why Audrey Hepburn has appealed to women by bringing "some insight into the role played by subjectivity in determining the meanings women make of media texts" (Moseley 26). As is noticeable in Moseley's research topic, women themselves make meanings of texts. With style icons, no matter how actively media might discuss and impose certain personalities as style icons, unless there is a connection between an icon and a recipient, one might not gain the status of an icon.

"Star" Theory. Jackie Stacey, discussing "Identification", speculates about how stars become role-models for their viewers and encourage their desires. She writes, "Stars serve as normative function... contributing to the construction of the ideals of feminine attractiveness circulating in the culture of that time" (152). Additionally for screen stars as style icons some "unattractiveness" can play its part in helping to let more people to identify themselves with a character, since not everyone is an embodiment of beauty ideals. According to Stacey, for young women "Hollywood stars seemed to embody a perfection of desirability which they themselves felt they could never hope to achieve" (110). While screen stars can be viewed as idealized beauty objects, style icons expand beyond these borders, sometimes even emphasizing their peculiarities and making these features as trademarks. Nevertheless, the style icons examined in this paper are screen stars in the first place. Within her "Consumption discourse", Stacey discusses that stars become "commodities within the Hollywood film industry and, in addition, their names become commodities in the fashion industry in Britain as they are used to describe particular styles" (203) and that "Hollywood sold its stars as icons of feminine attractiveness, whose beauty could be replicated through the purchase of particular commodities” (206). For instance, Audrey Hepburn's look from Breakfast at Tiffany's is very recognizable and is often reproduced as a Halloween costume, which exemplifies Stacey's argument and relates to my research. 
Celebrities are considered to conceptualize the "inner wants on the parts of the mass of people" (Dyer 20) and are "symbols by which we narrate, negotiate, and interpret our collective experience" (Butler Breeze 337); they are "seen to determine society" (Barry 251). Richard Dyer is considered to be one of the most influential stars' researchers and he provides a framework for analyzing a star system. He sees them as "Stars as Social Phenomenon", "Stars as Images" and "Stars as Signs", where he also examines their production and consumption. He writes that, " a star image is made out of media texts that can be grouped together as promotion, publicity, films and commentaries/criticism" (68). By promotion he refers to the "creation/manufacture of a particular image or image-content for a particular star" (68). Within the realm of publicity, a more "authentic" image is promoted through its "escape" from the Hollywood's imposed image as stars' personal lives, dramas and attempts to appear disconnected from their habitual presentation. For example, the singlegirl image of Hepburn on-screen contradicted her off-screen image as a married woman with children. Dyer provides the example of Marilyn Monroe's "attempts to be considered something other than a dumb blonde sex object" (70).

Films and TV-shows are vehicles for stars. Dyer breaks down this vehicle and its provision of: "a) a character of the type associated with the star", "b) a situation, setting or generic context associated with the star", “c) opportunities for the star to do his/her thing" (70) such as opportunities to either show other sides of talents or consolidate in the industries that might benefit from the partnership. Criticism and commentaries "are placed on the side of the audience - the consumers of media texts" (Dyer 71) This argument provides justification why the spectatorship theory is important in this research, as the formation of a style icon is revealed to be a production of viewers and recipients through their collective needs. Even if the media attempts to establish their protégé as a style icon, unless a receptive community accepts a person as such, this icon will not be truly considered and validated. 


\section{CONCLUSION}

In this chapter it was observed how theories of mythology, based on semiotic analysis, spectatorship theory and the examination of 'stars' help to unveil the narratives and functionality of style icons. Semiotic approach is used to see the meanings behind the signs, connotations that build a mechanism of mythologies narrated through the screen. Myths are performed constantly and in such way are established and appropriated in culture. Jackie Stacey's discussion provides vital understanding of how women watch and relate to screen stars through escapism, identification and consumption. Overall screen stars and style icons are signs and images created by the film industry, who function as embodiments and representations of certain types of behavior and reflect the normative cultural discourses, needs, beliefs and desires of their viewers. 


\section{Chapter 4}

\section{Audrey Hepburn, The Ultimate Icon}

Audrey Hepburn's rise to fame and personal story is quite similar to that of her film heroines: that of a poor girl who is transformed into a beautiful feminine ideal. Even though she was born into the noble family of a Dutch Baroness, she was poor during World War II when the Nazis occupied Europe. She had no privileged connections in Hollywood, but was claimed as a new Hollywood princess after her first major movie. In this chapter I introduce the actress, analyze three of her films, and find out themes and narrative on which her style iconicity must have been based.

The actress was born as Audrey Kathleen Ruston on May 4, 1929 in Ixelles, a district of Brussels, Belgium. From a young age she had been taking ballet classes and was dreaming of becoming a ballerina. Following her parents' divorce, she moved to England with her mother and during the war they moved to the Netherlands. As her son recalls, "she survived by eating turnips and boiled tulip bulbs until the liberation" (Dotti 13). Whether it is true or not, this legend is circulated in her biographies, and I find it to be quite an interesting detail a future actress had to digest flower roots which led to her personal flourishing as an actress and as a woman later. After gaining professional ballet training, she picked up minor acting roles, but her bigger acting breakthrough happened with a Broadway performance in Gigi, which she had not been sure she could execute as she had not received professional training. But the French novelist Colette knew "c'est Gigi” (Wasson 7) and insisted.

Her major Hollywood breakthrough, following international success and winning the Oscar, happened in 1953 with her role as Princess Ann of an anonymous European country in Roman Holiday (directed by Willam Wyler). This work is very important in analyzing Hepburn's introduction to viewers, as well as the start of creation of the myth of Audrey Hepburn, which followed her ascendancy in the Hollywood star hierarchy and later on 
becoming a style icon. It is important to mention that Hepburn's rise to fame and establishment in Hollywood occurred in a western, post-war cultural context, when women started reconsidering their social position.

\section{ROMAN HOLIDAY}

The film Roman Holiday starts with the announcement that Princess Ann is visiting the European capitals of London, Amsterdam, Paris and Rome. She is shown in a carriage, wearing a hat, and a blazer with a brooch and white gloves. Then she is shown in another jacket with pearls, hat and gloves. She wears gloves all the time in formal affairs and, as in Rachel Moseley's research “Growing up with Audrey Hepburn” is noted, "wearing of gloves by women in the summer preserved white skin, in differentiation from those of lower social classes" (14), who were exposed to sun during outdoor labour. One of the women who took part in Moseley's research said “I was taught when I was a child that you weren't dressed unless you wore gloves, summer and winter" (14). This little detail is referential to ideas of race, class, and gender. Femininity, according to Skeggs, "has been coded historically as middle-class and white and black women coded as sexual and deviant" (thus not feminine)" (qtd. in Moseley, "Growing Up" 15). Also it has its associations with Dyer's iconography of white as a colour of purity - and absence of sex.

The next scene is a ball, held in the palace to honor the princess. Princess Ann is wearing a big white ball gown with cute bows on lapels of her dress, a tiara, diamond jewelry and the gloves are all the way to the shoulders. While performing an official ceremony of "meet and greet" with international ambassadors and elite, she takes off her white shoe to rest a tired foot. Her foot is shown three times. Then she loses the shoe and cannot put back on. And while greeting the guest, she manages to find a shoe under a voluminous skirt of a gown. She is definitely uncomfortable in her shoes, which is taken as a literal visual allegory of the idiomatic expression and gives us a hint of future rebellious behavior of Princess Ann (see 
figure 9). When she sits back on the throne, the shoe is still on the floor, but she is unwavering, while her entourage is staring at it trying to avoid embarrassment. But one of her councilors takes her to dance and the problem is solved. In this episode Hepburn looks like a traditional European royal woman.

The next scene is in the Princess' bedroom, where she is getting ready to sleep but is unhappy with her look in a long nightgown (see figure 10). "Why can't I sleep in my pajamas? I'm not a hundred years old!' After her helper reads her the list of duties for the next day, she has a hysterical seizure and a doctor has to give her an injection. Then she looks out the window, hears the music from the party at the river and runs to the closet. The next scene is where she is walking out from the closet, dressed in a A-line full skirt to the midcalf, white blouse with long sleeve and a bow, she takes her gloves and escapes the palace. She falls asleep on a bench near the Old Forum, where Gregory Peck's character Joe Bradley sees her. Even in her sleep she is condescending to him, while he thinks she has had too much alcohol. After their discussions, she ends up in his house for a sleepover. She asks for "a silk night gown with rose buttons", but receives pajamas, that she desired not a while ago. This night attire can be symbolic of a new and democratic way that Princess is going to explore the following day. While a nightgown was old-fashioned and depressing after sleeping in pajamas, a whole new world is going to open up.

The next morning she is dressed up as the night before. After leaving Joe Bradley, she buys new sandals as a symbol of her new life for the day. Then she gets a haircut, cutting her hair short, which is a big twist in the story line and her character's attitude: "This is not an ugly duckling transformation... This is a transformation from Ann's conformist self (a girl with traditionally long, traditionally "feminine" hair") to Ann's true self." (Wasson 24). She looked so "cool" (as said by the barber) that he invites her out to dance at the Tiber that evening. After leaving the salon, she goes to Piazza di Spagna, her sleeves are rolled and she 
keeps this look until the end of the movie (see figure 11). This look in a skirt, simple white shirt and sandals has become iconic, because in it she has lived the most exciting parts of her life. On the Spanish Steps, sitting and eating gelato, she meets Bradley again and confesses that she wants only "to do whatever I like the whole day long... to sit at a sidewalk café and look in shop windows, walk in the rain, have fun", something that a Princess cannot afford experiencing. Wasson comments that "What Audrey offered - namely to the girls- was a glimpse of someone who lived by her own code of interests, not her mother's, and who did so with a wholesome independence of spirit" (23). Bradley takes her to bar at Pantheon, where they drink "champagne for lunch?" ride the Vespa around town on a background of major Roman sightseeing spots, visit the Coliseum and, most notably, the Mouth of Truth monument. These images are the most significant for this movie and have become a signifier of an aspirational idea of a "Roman holiday". As White suggests: "Shot in the most photogenic locations... [this film] purveyed an enchanting, if sentimental image of Italy, and represented a free and effective publicity campaign for Italian tourism" (132). These images are still circulating today as postcards, souvenirs and posters of the movie, as well as for the promotion of the city of Rome.

Due to its wide dissemination, her outfit from the movie has indeed become iconic in terms of instant recognition in relation to the movie and the romanticized idea of a Princess on adventure behind it. As an example, for the commercial for Galaxy Chocolate in 2013, Hepburn's costume from the movie was recreated for the computer generated actress, because in modern culture it has become a signifier of that aspirational and romanticized notion of Roman holiday and dolce vita, even though it was filmed in a rural Italian town. Regarding the technical part of creating this outifit, Wasson would write that Edith Head: had worked especially hard on Roman Holiday, and ingeniously, camouflaging Audrey's many physical irregularities. The list of alterations seemed to go on 
forever: Edith broadened Audrey's shoulders wide enough to frame her face, she disguised Audrey's spindly neck with jewels and scarves whenever possible, she decided against sleeveless blouses for the sake of Audrey's toofrail arms, and she selected an especially long dress to keep Audrey's gangly legs from the camera. Because it directed one's eye away from Audrey's problematic torso, the full skirt Edith designed helped a great deal to restore equanimity to the rest of girl's frame, and with the slimmer belts Edith made especially, she could downplay Audrey's awkward waistline. (32-33)

These details emphasize the fact, that for the style icon it is necessary to be aware of one's body shape and imperfections to achieve the desirable and culturally acceptable ideal, despite personal peculiarities.

When she asks Bradley to go to the party at the river, she makes a Cinderella comment about leaving the party before midnight and the carriage turning into pumpkin. This explicit comment works as a reference of her own to the Cinderella story, a key trope in feminine culture for the aspirational princess' transformation, finding a Prince Charming and acquiring a fabulous wardrobe. When they get to the party, she dances with a barber, he again slightly changes her hair at the front, and then she is exposed by royal security agents and a massive fight starts there, which ends with her and Bradley jumping into the water and then a kiss. She does leave after the party without leaving her shoe, but only because this story is an inverted Cinderella story, of a princess-turned-into-a-regular-girl, where she plays her rules of her own games, not giving a man an opportunity to be searching for her.

In the final scene, at the press conference, she appears in a white lacy New Look suit, white shoes, a hat, with a choker on her neck and pearls in her ears. This is the last time she sees her suitor, and they have a warm goodbye. What is notable, is that later this dress was modified by Edith Head for the Oscar ceremony when Hepburn received her Oscar for this 
role (Luu). The screen garment, that had strong associations with the story of a Princess Ann, was taken out of the film context and put in another context, no less glamorous or successful. This is how Audrey Hepburn was crowned as a new "Princess of Hollywood". As Handyside notes, "Roman Holiday plays on the similarities between the female cinema star and the princess: both a public icons of idealized femininity" (290). This observation relates to how the on-screen garment, associated with a princess myth, operates in an off-screen setting, thus making the images of an actress and her character merge into one mythical, successful, popular and idealized character. Fashion here is a mediator of this aspirational narrative of success and social mobility.

\section{FUNNY FACE}

The film Funny Face was filmed in 1957, after the film Sabrina (1954, dir. Billy Wilder), which also exploited the Cinderella story of her character Sabrina Fairchild, a chauffer's daughter, finding her rich and affluent husband, played by Humphrey Bogart. The preproduction process of Sabrina connected Hepburn with Hubert de Givenchy, whose wardrobe played an important part in the visual transformation of her character.

I decided to analyze Funny Face, because the images from this film have become iconic and are referenced by contemporary artists (like Beyonce for her video "Countdown" or Michael Jackson's look of black trousers with white socks), which emphasizes the visual power of Hepburn's fashion choices in the film. Her first appearance as Jo Stockton in this movie is at the ten-minute mark. She is working in a bookstore, where fashion editors and photographers come for a photo shoot. She is dressed very imperceptibly in a black turtleneck, grey waistcoat, brown grey long skirt. She is explicitly against anything fashionable, calling magazines "chi-chi and unrealistic approach to sell impression". As photographer Dick Avery notices her beauty, he recommends using her as a model for new Parisian fashions. Jo is lured to the editorial office to bring them books, but is persuaded to be 
a model and follow them to Paris. She agrees only with a plan to meet a philosopher. As soon as she agrees, the editor's assistants are trying to undress her. This is the first ritual in her transformation.

Transformation is one of the main narratives in most Audrey Hepburn movies. From poor and uneducated, or too intellectual and unattractive girls, her characters become popular, affluent and desirable women, and this process was emphasized by Hepburn's stylish looks. However, Rachel Moseley points out that in Hepburn's movies, the process of "growing up and acquisition of status is told precisely through their clothes" ("Dress, Class and Audrey Hepburn” 116). Hepburn's film transformations are presented mainly as performances, they are thoroughly filmed and are given a lot of screen time, as with the hair cut in Roman Holiday and all the fashion adventures of Hepburn's heroine in Funny Face.

On her arrival in Paris, Hepburn wears a black turtleneck, ankle-length trousers and a brown trench coat. They sing a song, "Bonjour Paris," and the image of Audrey Hepburn, cheerfully exclaiming the song title, is circulated around the internet as a reference to the world of fashion, luxury and allure, which is followed by excitement and pleasure (see figure 12).

A famous dancing scene from a bar, when Hepburn is wearing a "Beatnik suit", dressed all in black with white socks has become one of the most iconic scenes of the actress (see figure 13). The reference of this outfit by other artists (see figure 14) or its featuring in advertisements such as Gap, create another level of iconicity due to instant recognition. She was also wearing this outfit at the meetings with the French philosopher in the film. On one hand, this look is contrasted with the glamorous and bright side of the fashion world and opposes the philosophy of the fashion editor in the film, who encourages her readers to "think pink!"; on the other hand, this look is classic and safe, it has become a uniform for fashion insiders, who wear black on a regular basis. Probably, the ambiguity connected with the 
visual pleasure of the scene, has helped this look to achieve iconic status. Elizabeth Wilson argued that this costume was "an oppositional dress" of the 1950's, claiming "The beatnik's use of black came from existential fashions of post-war left-bank Paris, although black had long been one signal of anti-bourgeois revolt" (186). She adds that it was Hepburn, whose "gamine looks, short black hair, doe eyes and ballerina slippers translated an ersatz existentialism on to film" (187). So despite the universality of the look, as it seems today, in the original context, Audrey Hepburn's look was the embodiment of a subculture of the 1950s and made her fit into non-mainstream grouping as much as she appealed to the general public.

Fashion fittings and a photo shoot occupy a long duration of screen time in Funny Face. Not only do they provide the main context of the film, but also a personalization of the transformation narrative of Hepburn's character. For every look, the photographer Dick Avery coaches her, telling her what to do and imagining a story behind the shot. During the filming of a shot in a white full-skirt dress with floral motives and holding a white pigeon, she said "I am a Princess at the ball. And the bird is really a Prince Charming!" So Princess narratives appear again here in her own commentaries, like in Roman Holiday and in the Cinderella reference (see figure 15). During the preparation for the fashion show, Hepburn cheerfully signs and dances with the editor-in-chief of the magazine, who she considered to be an enemy in the beginning. They even dressed very cohesively to each other - white and beige blouses, black trousers. This scene can be interpreted as a visual sign of Hepburn's character to already be one of them, from the fashion world as their visual representations become similar to each other (see figure 16).

Finally, at the fashion show, viewers can observe what transformation has occurred with Hepburn's character as she models the gorgeous Givenchy gowns very comfortably. As Handyside points out, "the Givenchy clothes allow her to become spectacle: they reveal a 
beautiful femininity that had been hidden before" (294). She becomes an object by all the glances of spectators. In the 1950's, models were considered ideals of femininity and in this film, Hepburn becomes one (Radner). But when she walks out in a wedding dress and realizes that the man of her life is not there, she runs away. Then Dick finds her at the chapel, where they had a photoshoot. They hug and kiss which leads to a happy ending (figure 17). Even though she used to be a free spirited, anti-glamorous girl, through the fashion discourse she has found her feminine inner self, love and a man. If in the beginning of the movie she was always frowning and grumpy, in the end she was happy and smiling, as this transformation was a "discovery of her true essence" (Handyside 296). This also has been happening in Paris, a city that has had a long history and authority in the fashion world as a "site of prestige and sartorial excellence" (Rocamora 34). The fashionable context of the city itself presents a validation of her transformation process and is reinforced even more.

Cinderella and Pygmalion Narratives. The Cinderella story as one of the primary narratives of Hepburn's movies, has been addressed by numerous researchers, such as Rachel Moseley, Gabrielle Finnane, Peter McNeil, Vicki Karaminas, Stella Bruzzi, and Fiona Handyside. Moseley describes a Cinderella story as a "tale of aspiration and social mobility through stylish transformation," adding that it has been "an enduring staple of feminine popular culture" ("Dress, Class and Audrey Hepburn”, 109). I would add that the Cinderella story also requires the necessary finding of "Prince Charming," in the embodiment of a wealthy and powerful man. This story is narrated both explicitly and implicitly in most of Audrey Hepburn's movies, as well as in her personal life.

The universality of this narrative in the creation of a style icon can be found in other examples. Grace Kelly's personal story, for instance, reinforced this narrative bringing it to real life. Kelly was a Hollywood actress, who married the Prince of Monaco and became a real princess herself. She gave up her acting career in order to dedicate herself to her family, 
but it is obvious that once she achieved a new social status and position, she did not need to go back to work. However, she would still occasionally pose for fashion magazines like Vogue. She is also an acclaimed style icon, in both popular and academic circles. In 2010 the Victoria and Albert Museum held an exhibition "Grace Kelly - Style Icon". The curators of the exhibition raised the question, "What is it that makes Grace Kelly a style icon, nearly 30 years after her premature death?” (“Grace Kelly: Style Icon”). The importance of the Cinderella story becomes a proof of its importance as a mechanism of creating a princess myth in order to be established in the realm of style icons.

The Pygmalion narrative requires personal transformation not only through dress, but also education and manners. The narrative is performed in one of Hepburn's movies, My Fair Lady. It is based on George Bernard Shaw's play Pygmalion, which was inspired by the myth of a sculptor falling in love with the statue that he created. In the play, a flower girl is transformed into a lady, who is presented to high society as a duchess by the professor. This narrative requires social mobility, attained through training and respectable visual representation. Implicitly this narrative can be noticed in Hepburn's film Breakfast at Tiffany's, in which her character Lulumae is transformed from a village girl into the Manhattan "cocktail sophisticate” (Handyside 292) and upscale call girl Holly Golightly. One man at the famous party at Holly's apartment told Paul Varjac, her friend, how she used to be a simple village girl but then he taught her how to speak and behave. This episode is rarely discussed in terms of Hepburn's transformation but it is important to mention its presence as this narrative becomes important in style icon formation.

The difference between the Cinderella and Pygmalion narratives is that in the Cinderella story, social mobility requires the influence of a wealthy man. Meanwhile, within the Pygmalion narrative, after a woman has been transformed, there is no turning back to her "initial self," and she is now capable of functioning and gaining self-actualization without a 
man. These two narratives can intersect, as in Funny Face, or can function on their own. The images from Hepburn's movies have become instant signs of these narratives, embedded in popular culture. They reinforce Barthes' mythologies due their constant reproduction and cinematic references. They are seen as "naturalized" (Barthes 242) as they are repeated again and do not cause any doubts in their validation.

\section{BREAKFAST AT TIFFANY'S}

The opening scene of the movie, when Audrey Hepburn is in a long black column dress, with beehive hairdo, pearls, gloves, signature big sunglasses, white shawl in her hands and croissant and coffee, has become one of the most iconic scenes in her career (see figure 18). She looks at the Tiffany's display in the window and walks home. This look is disseminated in movie posters, postcards and posters, online images, book covers and referenced in numerous pop culture sources, as well as commercials. This look is also a popular Halloween costume, which is easily reproduced due to simplicity of the look and its instant recognition. This image as a sign, discussed by Mitchell, has become a symbol of aspirations for luxury and free thought.

While her light-coloured outfits in Roman Holiday were signifiers of her class and purity, the black dresses in Breakfast at Tiffany's had opposite symbolic meanings. Sam Wasson writes that the colour black held symbolically "charged intimations of power, sexual knowing, and reversals of traditional passivity" (128) due the cost of black dye and its historical connection as a colour widows wore (as sexually experienced women). For example, Queen Victoria dressed solely in black gowns after her husband, Prince Albert passed away in 1861 (Gullickson 202; Wasson 127; Wilson 188). In the film, Hepburn wears other famous black dresses. One is worn in the scene when she meets her new neighbor Paul and is getting dressed in an elegant knee-long black dress, with feathers at the bottom, a wide-brimmed hat with a scarf on it. She flirts with him, asking him rhetorically "How do I 
look?" This image (see figure 19) has also been disseminated over many fashion blogs, inspiring confidence and reflecting the pleasure of a ritual of getting ready to go out. Another black dress is worn at the famous party in her house. This time it is paired with a big necklace and earrings (figure 20). Notably, she is the only woman at the party wearing black. Holly not only entertains at her party, but also is talking about how to marry one of the richest men in America. At this point we can see the connection and visual association of an aspirational feminine idea, connected with a finding of a wealthy man.

At one point Holly and Paul decide to spend the day “doing whatever we haven't done before" (see figure 21). This conversation reminds me of Princess Ann in Roman Holiday, and her approach to spend time with her loved one, having fun and getting new experiences. In those scenes, Holly is dressed in a double-breasted orange coat and fur hat (see figure 22). The silhouette of the dress is very 1960's and is very similar to the coats that Hepburn would later wear in her private life. They go to Tiffany's (where she says her famous quote "I think it is tacky wearing diamonds before I am 40"), they go window shopping, to the library, she makes him steal a mask from a cheap store, then they run home and then they finally kiss. The bright colour of the coat is referential to the fun times that the couple experiences together, their easy-going and cheerful dynamic and contrasted to strict black dresses that she would wear for her meetings with men.

Another choice of colour, in the context of her opposite from the usual restrained behavior, was pink. She and a wealthy Brazilian businessman Jose are coming home from a party, when she is dressed in a baby pink sparkly dress with a tiara and pink shoes (see figure 23). She looks like a fairy from children's books. She receives a telegram of her brother Fred's death and becomes hysterical. She has a mental breakdown and breaks the furniture. She was wearing pink, just like a child, and she was acting immature. This is a rare time we see Audrey Hepburn wearing pink. In this scene the color is quite discredited as it has strong 
associations with her mental problem. The connection of Golightly and a child was noted by researchers, who wrote that the "beehive... and a fur helmet... have the exaggerated style of outfits donned for a masquerade, suggesting the high jinks of a child mimicking the adult world" (Finnane). Although Hepburn's character was an adult woman, she was presented as immature and childish, which enabled viewers to put this character in one box of conventional female roles. Neither a wife/mother, nor mistress/femme fatale was associated with Holly Golightly due to the genuine performance by Hepburn, who herself in a personal life at that time had a husband and a child.

In the last scenes, she is wearing a neutral colour palette, black narrow trousers and a beige sweater (see figure 24). In the final scene in the taxi she changes from one outfit to another and applies her make-up. Her transformation is simultaneous with their discussion about love and life. She is wearing a classic beige trench coat, when she realizes that she is also in love with Paul and wants a regular, in some way, restricted life, unlike her free spirit and constant partying. The scene of a romantic kiss under the pouring rain (see figure 25) also quite often recreated in pop cultural texts, as in the TV-show Gossip Girl (2007-2012), which also was heavy on costumes and aspirational fashion narratives (see figure 26). The importance of costumes in Breakfast at Tiffany's is noted by Moseley in terms of the numbers of scenes in the movie, when Hepburn's character is going out or coming back home, on the stairs or in the hall of her house, "where her silhouette and the details of her dress can be viewed to the best advantage" ("Trousers and Tiaras", 41), so that the emphasis for the viewers is given and they don't have to search for additional visual sources.

What was revolutionary about the costumes in Breakfast at Tiffany's is that Holly Golightly could not actually afford wearing French haute couture costumes by Givenchy. Costume designer Rita Riggs would comment, that it was "a breakthrough" in film (qtd. in Wasson 129), when a signifier (an outfit) did not refer to the signified (wealth): "There is no 
real way of explaining how Holly would get that dress. At that time, only the very wealthiest American women would have European trousseaus. A regular girl couldn't afford that" (Wasson 129). Still, it reinforces the aspirational potential of style icons and their influence upon their followers.

Givenchy. One of the main requirements for style icons to achieve their status is observed to be their involvement in the fashion industry and their having good relationships, even friendships with the designers, due to the fact that style icons as personalities are allowed to enter this world of fashion from within. This is a part of the consumption chain, where an icon takes part with a producer's privileged role.

I stress the importance of the couturier Hubert de Givenchy in creating a style icon of Audrey Hepburn, by dedicating a separate part of this chapter to him, because his role is vital on many levels. Moreover, the connection and friendship between Hepburn and Hubert de Givenchy is another example of the Pygmalion narrative functioning in the "real" life of the actress, as well as on screen.

Legend suggests that Hepburn wanted an actual French couturier to produce her costumes for the film Sabrina, so she went to Paris to meet Christobal Balenciaga. But he was too occupied by his work, and that referred her to an emerging designer Hubert de Givenchy. Givenchy from his side recalled, that he had expected to see another Hepburn, Katharine, but then a petite girl showed up at his atelier. She had to convince him to work with her in Hollywood (Rubenstein 29; Wasson 38-40). After this collaboration, as Handyside points out, "designs by Givenchy became a standard requirement on a Hepburn film contract from 1956 onwards" (290) and he also designed clothes for her private life. This fact is quite explanatory of why Hepburn's photographs in the streets are reminiscent of her film stills. Sam Wasson writes, “Audrey would become the muse Givenchy had been waiting for, and he, the Pygmalion she needed to bring her to life" (41). This poetic expression is referential to 
the narrative of Pygmalion transformation that I have discussed earlier. Her style transformation with the help of the designer helped the actress to reach that iconic status. Even in Givenchy's memoirs he would point out that "the change from the little girl who arrived that morning was unbelievable" (Moseley 37), so fashion transformed a little girl into a woman. Hepburn in her essay about costumes on film, in her own words declares, "In a certain way one can say that Hubert de Givenchy has "created" me over the years" (Hepburn, 10). Their names would come together in fashion discourse. From 1957 she has been a face for Givenchy's perfume and in the early 1960's, she regularly modeled Givenchy's clothes for Vogue and Life magazines. "Givenchy clothing created a smooth, uninterrupted image of Hepburn as having a personal style based on European haute couture" (Handyside 290) which was a total contrast with the pin-up photographs associated with stars at the time, such as Marilyn Monroe, Jayne Russell or Doris Day.

The Givenchy style reflects paradoxes in Hepburn's play on feminine/masculine, mature/childish characteristics: "While it creates Hepburn as the idealized woman surveying her own body and bringing it forth as ornamented surface, the clothing also has further contradictory connotations of modernity and masculinity" (Handyside 297), and also "came to epitomize the new woman: refined, ironic, and intellectually provocative" (Dotti 97). The couturier's clothes created the discussion of Hepburn's look within the cultural context of 1950-1960, when she was contrasted with other ideals of beauty and style, and also there is a discussion going on in her own personality and personal style.

A New Beauty Ideal. The 1950s in post-war beauty and body ideals is associated with two iconic figures of Marilyn Monroe and Audrey Hepburn. However, an interesting observation was noticed by Moseley, that "Monroe as "for men" and Hepburn as "'for girls' or women" ("Growing Up with Audrey Hepburn" 112) in terms of addressing audiences and arousing their sexual attraction or platonic admiration. Marilyn Monroe has become not only a sex- 
symbol, but a symbol of sex, embodiment of male desires: big hips, big breasts, sensual mouth, soft voice and innocent eyes. Richard Dyer comments that her image "can be indicated as the spread of Freudian ideas in post-war America" (36), as a sublimation of sexual desires, accumulated over war period.

In the 1950's Audrey Hepburn's rise to fame in terms of her body shape was contrasted with this epitome of femininity and Marilyn Monroe's curvaceous body. Hepburn body was petite, flat-chested, she had a short hair cut. She combined qualities of boyish and feminine features in one body. And by "boyish" Moseley refers to "a stylishness which signifies naturalness, freedom and pre-sexual" ("Growing Up with Audrey Hepburn”105). It is also connected with her age, as "she is understood as both grown up, and yet very young compared to other stars" ("Growing Up with Audrey Hepburn" 105). Handyside suggests that "Hepburn's youthful looks and her less "womanly" body made her easier to identify with for French viewers than idealized stars such as Grace Kelly and Marilyn Monroe” (297). Even the flat shoes that she was wearing, which in that period was "advertised as footwear for the young" (“Growing Up with Audrey Hepburn” 105) was contrasted to the high heels that Marilyn Monroe wore in order to emphasize her sexuality.

In terms of her signature style, "the flat shoe, a little masculine, was another one of Hepburn's trademarks, a look that was halfway between American preppy and French gamine" (Dotti 41). It is said that "this style was adopted by another Hepburn (Katharine), who used it to affirm the almost androgynous power of her character; on Audrey, though, it was a message of undisputed femininity" (Dotti 41). This gives us another layer of senses that can be seen in Hepburn's flat shoes, either androgyny or "undisputed femininity". Who asserted that flat shoes are a message of undisputed femininity? Other researchers (e.g. Handyside; Moseley) would argue that Hepburn was "boy-ish" and her body was emphasized as "androgynous and modern" (Handyside 297) through her clothes. So whether, it is 
feminine or not, this discussion can only reinforce the idea of ambiguity of a cultural (and here, style) icon, which is so necessary for its validation.

Comparing Hepburn and Monroe in terms of their bodies as their connection to social status, Moseley states that "Hepburn embodies class in Bourdieu's sense" ("Growing Up with Audrey Hepburn" 126) and speaks it through her body. In another article she states, that Hepburn's body was "key to her embodiment of restrained, European classiness" ("Trousers and Tiaras", 48) as well as her "youthful looks and her less "womanly" body", placed in European locations on screen/ context and "made her easier to identify with for French viewers" than idealized Hollywood stars (Handyside, 297). Meanwhile Monroe is described by Skeggs, quoted in Moseley, as such, "[In Some Like it Hot (1959)] she appears as if naked -this a body unfettered, uncorseted, uncontrolled, sexual. She represents excess - the undisciplined female body which signifies low social status" ( "Growing Up with Audrey Hepburn”126)

Hepburn's body can be viewed as a bridge from the 1950 to the 1960's, as Moseley puts it, it can be "understood as "modern, new different", appealing to girls growing up put of the frilly feminine 1950s and into 1960s youth culture" ("Growing Up with Audrey Hepburn” 129). In 1960, a new valuation of the body occurred, which was tightly connected with movement. Also movement is a feature of youth and escape from the traditional domestic setting of a woman. Movement is depicted and in such things as fashion styles and fashion photography. Even modeling, as movement on a catwalk transfers to a new level, which from slow, fluid migration has turned into active performance. Coming back to the flat shoes of Audrey Hepburn, they also were a first sign of this shift to movement as a value, that were providing her with "mobility and activity" ("Trousers and Tiaras" 45), which was represented in the dancing scene of Funny Face. 
For the style icon of Audrey Hepburn, the main elements of her iconicity as observed in this chapter, are strong repetitive narratives that are presented in her works and that transcend to her life. Her body and her looks are also carefully curated for visual representations that are cohesive and repetitive and that become embodiment of new cultural values, appearing on the turn of the decade, that on one hand contrast dominant beauty ideals, but on the other are more attainable and achievable to be emulated by viewers, who identify themselves with the actress. I will discuss more of these mechanisms in Chapter 6, when I compare Audrey Hepburn with Sarah Jessica Parker to discover how both of these women have been established as acclaimed style icons, and embody similar values. This comparison will affirm the universality of a mechanism of creation of a style icon in our culture. 


\section{Chapter 5}

\section{Carrie Bradshaw/Sarah Jessica Parker: Style Icon.}

Carrie Bradshaw is a fictional character created by writer Candace Bushnell and portrayed in the TV-show Sex and the City (SATC) by Sarah Jessica Parker (SJP).

Throughout the six years that the show was on, SJP and her character merged into one personality in people's perception, and fashion journalists and academic scholars (e.g. Bruzzi; Church Gibson; König; Warner) have asked the question: "Where does SJP begin and Carrie end?" (Byers; Krieger 46). Thanks to her character, for whom fashion was a primary tool in establishing her identity, SJP has become an acclaimed style icon. In this chapter, I am going to analyze what has helped the actress to achieve this status and how she is maintaining it today, 10 years after the last episode of the show was broadcast.

Sarah Jessica Parker was born on March 25, 1965 in the small town of Nelsonville, Ohio. Her personal story represents both the "rags to riches" myth (Warner, "Fashion on Television" 112) and Cinderella narrative ("Sarah Jessica Parker: Real Life Cinderella", People, October 2000). SJP had a difficult and poor childhood, but hard work has brought her fame, a successful marriage and the opportunity to wear haute couture gowns. Warner notes that, "SJP's success is articulated through dress - specifically through the "conspicuous consumption" of "real couture" ("Fashion, celebrity and cultural workers" 384). Conspicuous consumption is a term that was introduced by Thorstein Veblen in late nineteenth century. He claimed that middle- class women display wealth and social status through their dress as "it has this advantage... that our apparel is always in evidence and affords an indication of our pecuniary standing to all observers at the first glance" (103).

Before Sex and the City, SJP performed on Broadway and in Hollywood productions; however the TV-show with its strong emphasis on fashion helped her to gain iconic status. Moreover, she has since been exploiting the work results of the costume designer of the 
show, Patricia Field, in her personal star construction, and has continued to participate in the fashion industry during and after the show's broadcasting.

\section{SEX AND THE CITY}

The TV-show premiered in 1998 on the cable channel HBO. Carrie Bradshaw is a sex columnist who writes a weekly column for a newspaper. She calls herself "a sexual anthropologist". In the first season, Carrie is not overly explicit and outspoken about fashion, she even goes out to meet her boyfriend, "Mr. Big", wearing jogging pants and sneakers (Season 1, Episode 12). But later on, fashion and shopping (consumption practices) become an integral part of the show.

In the first episode, Carrie is dressed in muted and neutral colours, black, gray, blue. She talks directly to the viewers, wearing a grey oversized trench coat, in which she looks like a detective investigating a crime scene. The cultural context of the show is postmodern and post-feminist (see figure 27). Later, in a nightclub scene, she is wearing a leopard printed corset, but with a black cardigan to mute it down (see figure 28). Nevertheless, she points out that New York is a city, where "women work, pay taxes and they pay $400 \$$ for Manolo Blahnik’s strappy sandals" (Season 1, Episode 1). As Helen Warner mentions, “the specific namecheck of Manolo Blahnik in the prologue signals, to a self- selecting fan base, the premium which would ultimately be placed on fashion within the narrative" ("Fashion on Television” 1). Blahnik, the prominent shoe designer, is mentioned very often throughout the TV-show: Carrie walks the streets of the city with Manolo Blahnik shopping bags, and he is has given special status, as his name has become a synonym for the shoes generally. "They are not just shoes, they are Manolos!" declares Carrie when her footwear is stolen at a party in season 5. In another episode, when she is mugged on a side street, the burglar yells at Carrie "Give me your Manolos!", which indicates not only the burglar's fashion competence but also the value of the brand in fashion discourse. 
In SATC shoes become a symbol and connotation of numerous meanings. Shoes are the signs and their meaning "depends rather on its relation with all other marks in a dense, continuous field" (Mitchell 67). In the context of feminine culture, shoes can be seen as a direct reference to Carrie's Cinderella myth. In the original fairy tale, Cinderella finds her Prince Charming through the glass slipper that she loses at a ball. In a controversial episode, in which Carrie admits to her suitor that she has "a substance abuse problem - expensive footwear" (Season 1, Episode 5), he leaves her \$1,000 after having slept with her. She does not know how to react to this gesture as she is not a prostitute, but she probably spends it on shopping. In this episode, she was trying to purchase Dolce \& Gabbana shoes, but her credit card was declined. She meets "a friend", whose reputation is questionable, and she gets Carrie the shoes using her "boyfriend's" credit card. Here, a man is seen as a source of acquiring expensive material goods, although the characters of the show appear to be independent and free women. In the feature film Sex and the City (2008), Carrie's engagement to her Prince Charming is also performed through shoes, royal blue Manolo Blahniks (see figure 29). This episode also gives us allusions to the Cinderella narrative and its connection to the shoe and finding a man.

Another theory has been introduced by Helen Richards, who researched Carrie as a "visible flaneuse for the postmodern era" (147). Discussing the nineteenth century concept of the flaneur's habits and behavior, and figuring out the parallels between the flaneur as writer and Carrie as a journalist, Richards highlights their relation to sex and fashion, pointing out that shoes are her "equipment needed for walking" (149) and "Carrie's feet - clad in designer shoes - are her main mode of transport around the city" (149). This representation of Carrie is linked to her obsession with shoes in a functional way, not only through a consumerist approach and conspicuous consumption. Although, one might question why Carrie chose high-heels and not flat shoes that provide easier and more comfortable mobility, one might 
respond that Carrie's high-heeled shoes signify a higher social status, an aspirational detail relevant to the middle-class women the show was targeting (Arthurs; Bruzzi; Church Gibson; Warner).

The fashion on the show gains more central emphasis with the second season. Carrie's silhouettes and accessories become more consistent. She usually wears either A-line skirts, with an accentuated waist that becomes a signature silhouette, or body con dresses. If she is wearing a straight, mini or pencil skirt or pants with funny tops, her waist would be accentuated as well, either baring it or wearing a belt or a purse (see figures 30-32). She is accessorized with unusual brooches or hair bows; floral accents became her signature in the second and third season. Overall her aesthetic is very ironic and bohemian (see figures 33-42) with a mix of textures, colours and accessories.

Jane Arthurs in her article "Sex and the City and Consumer Culture: Remediating Postfeminist Drama" argues that this bohemian aesthetic "epitomises the reconciliation of bourgeois with bohemian values in the aesthetics and lifestyle that Sex and the City expresses and promotes"(91). By bohemian values she sees sexual freedom and attitudes to female sexuality, active consumption and self-expression. Carrie's self-expression and her originality is represented through her colourful and mismatched outfits, which are often contrasted with the apparel of other women, who she places herself in opposition to: like Natasha, her ex-boyfriend's new wife, or family people, whose baby parties she is obliged to attend. They are dressed in white or gray/black colour schemes, and usually embody traditional values. Through her fashion, Carrie expresses her values, such as freedom, leisure and love for fashion as opposed to restrictions, domesticity and an orientation to family.

As noted in my research questions, I questioned if there is a social need for style icons to appear in culture. Sex and the City was the first show on cable TV that was open about sexual relationships and practices (Arthurs). David Brooks, as referenced by Arthurs, 
introduces a new class fraction that replaced the Yuppies of the 1980s_- "bourgeois bohemians" (qtd. in Arthurs 86). This new fraction found its reflection and a necessity of role models in SATC's main characters, who embodied these new values.

Sexual permissiveness, that in the bohemian movements of the 1960s was articulated with radical anti-capitalist political values, has been re-articulated to conform, not only with the materialist priorities of consumer culture, but also with the emancipatory politics of the 1970s and 1980s. One effect has been to free white, middle-class women from the sexual constraints required by bourgeois respectability (Arthurs 86 ).

Carrie Bradshaw, along with her friends Samantha, Charlotte and Miranda, embodied four different types of women: bohemian, guilt-free and promiscuous, a relative traditionalist and a strict career woman. SJP's character is the most complex and the hardest to define in one word as she represents a bricolage of various types of women with various features. She is ironic and doesn't take herself seriously, she is self-conscious, smart and witty yet neurotic, she is stylish but sometimes looks like a clown. Through her undefinable and complex character, she is an embodiment of the "postmodern self" (Warner, "Fashion, celebrity and cultural workers" 389). This allows viewers to identify with her because she possesses many traits, even if contradictory, that anybody can find in themselves, too. As Jackie Stacey relates: "The spectator's own identity is replaced through her imaginary identification with her ideal" (197).

The postfeminist cultural context and sexualized freedom of women of the 1990s provides an epistemological base for the show as it "works through the problem of establishing the boundaries of respectability" (Arthurs 92). On one hand women share many of the same freedoms as men, but still meet double standards, which the heroines discuss and argued about. Women can have not only extra-marital sexual relationships, but also can 
perform and discuss sexuality freely and openly. Sexual practices and constant changes in partners are observed as regular, still women can be given names for their behavior. Naomi Klein, quoted by Jane Arthur, states that the show "is simply part of a wider cultural trend, one that at its most broad can be described as postmodernism, a commodified aesthetic in which irony is a central component" (91). In this cultural context, SJP's style iconicity is based through the ironic and eclectic visual representations, where individuality and selfexpression are important values of personality of postmodern period.

Consumption. Shopping and consumption practices are portrayed as one of the central activities for Carrie Bradshaw. Quotes such as "Shopping is my cardio" or "I like my money right where I can see them, hanging in my closet", while discussing investment opportunities on the New York stock exchange (Season 6, Episode 1), are widely disseminated in social media, such as Pinterest (see figures 43-45). As seen from these quotes, shopping has substituted Carrie's primary life functions, such as exercise or budget planning. She is not responsible with money. Over the series she meets domestic problems with roof/pipes problems or investments, which she could not address, but then would go and spend $\$ 400$ on a pair of shoes. In one episode, where her footwear was stolen at a party, she was justifying herself and comparing that choice of attire is as important as the decision to have a family, she even pretended to get married with herself in order to get new shoes as a gift. The episode was named "Woman's Right for Shoes" and exemplifies Carrie's attitude and all-consuming approach to shopping and the acquisition of goods.

Helen Warner discusses that the shopping scenes on the show can be observed as "a space to discuss the broader themes within the series: specifically, gender, identity and relationships" ("Fashion on Television" 63). In the show random encounters can happen in a fitting room, such as when Carrie meets Natasha and their underwear is reflective of their 
personalities, or how Carrie had a panic attack due to her fear of getting married (confronting the normative gender roles and idealized femininity) in a wedding salon.

Thus, shopping as a common practice for the women and heroines of the show, became a process of easier identification of viewers with the character. The more they consume, as their icon, the closer they become like her. Moreover, consumption as an outcome is argued by Stacey to be the final step in a relationship of female viewers and their favourite stars (207): “The replacement of self with ideal subject position is effected through the fantasy of consumption; thus the spectator and star are linked, not through the purchasing of clothes, but through the gazing and desiring of the female spectator/consumer who imagines her ideal's choice of commodities" (197). Here, shopping becomes not only the habitual process, but also a fantasized activity in the consumerist culture. These fantasies operate as mental images of W.J.T. Mitchell in order to be similar to their icon. Sarah Jessica Parker's own involvement with consumers' practices will be discussed in Chapter 6, such as disseminating her stylistic influence on the postcards and stationary company Hallmark, advertising Gap, launching her own perfume, clothing and shoe lines.

Vogue Girl. Vogue magazine, which is considered to be the ultimate authority in the fashion world (Konig, Matthews David), plays an important role in building an iconic status of SJP. In the TV-show Carrie makes statements such as, "When I just came to New York and I was broke, sometimes I would buy Vogue instead of a meal. I felt it fed me more" (Season 4 Episode 2). This phrase can be often encountered in the fashion blogs despite its literal absurdity, but due to its aspirational value. One episode was fully dedicated to Carrie, trying to write a column for Vogue magazine, "A Vogue Idea” (Season 4 Episode 17). She enters the editor's office in a pin-stripe asymmetrical dress with a vintage brooch, wearing nude pumps. She looks professional, still with her individual twist (see figure 46). In the background her voice is saying "One of the most relevant and provocative magazines on the 
newsstands today, at least for me, Vogue". When her paper is criticized and declined, another editor and herself make comments, personifying Carrie and Vogue, in a way that Carrie herself is validated as fashion authority. One editor tells her "Vogue is about vision. You are kooky and have vision". As they get drunk in the office, Carrie says, "I didn't have my breakfast and size 2, which makes me perfect for Vogue!" Interestingly, this episode premiered on February $3^{\text {rd }} 2002$, while SJP first appeared on a cover of the actual magazine for the February 2002 issue. This case exemplifies the blurred boundaries of reality and hyperreality. Hyperreality as a concept was introduced by the French philosopher Jean Baudrillard. It is one of the features of postmodernism, where the real and fictional are blended together so that there is no clear distinction between where one ends and the other begins (Oberly). Carrie's character merged with the actress into one media personality, but also stresses the role of the magazine in building SJP's iconic status.

The actress SJP appeared on the covers in 2003, 2005, 2008, 2010 and 2011 (see figures 47-52). Carrie's fashion expertise is also expressed in the episode, when she explores the Vogue closets and finds the shoes, she excitedly exclaims, "Do you know what these are? Manolo Blahnik Mary Janes! I thought these were an urban shoe myth!” Here shoes again come up as a referential point of her knowledge and authority. Moreover, in 2011, SJP wrote an introduction for the book "100 shoes", published by The Costume Institute of Metropolitan Museum of Art.

Later in her career in 2012-2013, when SJP guest-starred in another TV-show, Glee, her role was as an editor-in-chief for Vogue Online, Isabelle Wright, where she hired Kurt Hummel, another fashion-obsessed teenager with a "kooky" personal style to intern there (see figure 53). In 2014, she co-chaired with Anna Wintour, editor-in-chief of Vogue, an exhibition for the Metropolitan Museum of Art's "Charles James: Beyond Fashion". In the "Late Night with Seth Meyer" show, where she went with Wintour, to promote the exhibition, 
she was dressed exactly as Carrie Bradshaw would dress, a yellow floral dress with A-line broad skirt and a bright blue cardigan (see figure 54). This shows that SJP deliberately exploits the fashion legacy of her fictional character today.

Another involvement with fashion authorities was noticed by Helen Warner, who connected SJP with Diana Vreeland, who used to be an editor of both Vogue from 1963-1971 and Harper's Bazaar from 1936-1962 (387). SJP "paid an homage" to Vreeland in the photoshoot for the Harper's Bazaar magazine (see figure 55), where she directly references colours, the pose and the visual aesthetic of Diana Vreeland's famous portrait. In the article their similarities are illuminated, such as being referred to by initials (DV and SJP), their similar choice of vocabulary ("vulgar") and "aligning herself with Vreeland as an arbiter of taste" (Warner, "Fashion, celebrity and cultural workers" 387). This consistent association with fashion authorities obviously has played its role is establishing SJP's own fashion authority, that is deliberately emphasized in different types of media. As she gets older and can't simply play the feckless ingénue, it makes sense that she would align herself with established older fashion authorities like Vreeland.

All of these affiliations with authorities do position style icons above regular consumers, because they are involved in the production and dissemination of fashion. They are presented as an elite level of society, as discussed by Veblen and Simmel. They provoke aspirations and cause desires within the lower classes and fans to emulate them, so that they visually appear at a higher level. While this mechanism of fashion's trickling down discusses the processes of fashion, it is important to point out that today one does not have to be born in a high-class strata, but can visually achieve social mobility through fashion. Style icons have demonstrated that process, visible in their own fashion transformations that embody the narratives of transformation and self-improvement. 
In this chapter it was observed how narrating myths and through fashion helped SJP to achieve the status of a style icon. Advocating high-end brands and being connected with the most influential fashion magazines, established the actress as a fashion influence. Acting on the verge of the centuries, SJP represented new cultural values of the post-feminist period and a new social class, "bourgeois bohemians". In a similar fashion to Audrey Hepburn, she also performs a Cinderella and "rags to riches" narratives through fashion. This example proves the importance of this mechanism in creating a style icon. 


\section{Chapter 6}

\section{Style Icons: Themes and Narratives of Iconicity}

In this chapter I am going to present the outcomes and themes that emerged from the research that reflect how style icons are created and function. Significant themes included: ambiguities in narrative (e.g. universality and individuality; democratization and elitism; married woman versus single girl), an icon's mutual involvement in consumption, and the consistency of on-screen and off-screen imagery in the circulation of style icons.

\section{THEMES OF AMBIGUITIES}

As discussed previously, ambiguity is one of the necessary conditions that must be included in the construction of a cultural icon and style icon. As Rogers noted, an icon's "indeterminacy" (143) makes them powerful. Douglas Holt argues that to succeed, icons must target "the most advantageous contradiction in society" (63). As discussed in Chapter 2, Rogers suggests that "No icon represents only one dimension or axis of a culture... At one and the same time it evokes commonality and difference" (3). In the following sections, I am going to present what commonalities and differences can be observed in cultural and style icons.

Universality vs. Individuality. The theme of universality was observed in the literature discussing the styles of Hepburn and SJP. Their looks are quite flexible. Although they each possess a distinct look, this look can be applied in different contexts. For example, Audrey Hepburn "could just as easily passed for a teenager at a Beatles concert, a first lady on an official visit, or a beautiful airline stewardess" (Dotti 81). Though her image distinctly reflected the time period she was from, it could be applied and represented in various forms and activities and still look appropriate. Sarah Jessica Parker's looks were similarly transferable: the way she dressed could be adopted by any woman for a casual walk around the city, to go to the art gallery opening, to a fashion show or family gathering. 
The universality and mass appeal of these actresses can be observed in the example of both of their advertising in GAP (see figures 56, 57). Gap is considered to be one of the most universal and confirmative apparel companies (Byers; Krieger 60-61) in terms of their simple styles, models and colours. Byers and Kriger discuss the position of SJP in the context of her uniqueness, that had been established through the TV-show, and the universality of the company: “The GAP's endorsement by ...SJP... gives them a certain credibility, but also reinforces the star's status as unique, iconic fashionista, able to bestow her cool and chic upon regular GAP shoppers" (60). Although SJP seems to be original and not like everyone else, the company reinforces her status (hiring her as image) as many people can identify with her, which on the other hand reinforces her universality emphasized by the fashion market. Combining all that what I have discussed earlier, Byers and Krieger sum this up in one sentence, "The Gap ad draws on the mythic imbrications of SJP and Carrie Bradshaw: the city, the fantasy, and other wordliness, (...), the quirky style -...- that is at once her own and yet somehow imagined to be universal" (61). In addition to this, designer Patricia Fields who created Carrie's look for the show stated that "Carrie can relate to as many types of people as possible" (Byers and Krieger 61). To the same extent Gap used the image of Audrey Hepburn from Funny Face wearing her "Beatnik uniform" to promote skinny black pants in 2006.

Although it can be viewed as impossible for the actress to wear the brand, this case exemplifies her own universal form of presentation expressed through attire. Moreover, the brand for its own validation relies on the values and aesthetic principles that Hepburn embodied: simplicity, classiness and attainability.

Democratic vs. Elite. These cases from The Gap advertisements not only exemplify universality, but also show how the actresses reflected democratization. Even though they both advocated high-end brands and wore haute couture, their looks can be easily emulated. What was innovative with Hepburn in the 1960s was that her screen characters were dressed 
elegantly and simply. Despite her associations with haute couture houses, this simplicity of her looks "meant that they could be easily sourced or made, through adapting patterns, by young women who admired her style" ("Dress, Class and Audrey Hepburn” 118). This democratization also provides a visual social mobility for the masses. By emulating their favourite star they could look as good as her even if they did not possess the same material access. Moseley states that in terms of models of femininity, "Hepburn emerges as remarkably available and attainable star" (117). This attainability reinforces and empowers her status of a style icon that appears to be easy enough to imitate.

The factor of democratization contradicts the arguments of Dyer and Stacey, who stated that stars are unattainable and that their glamour is not achievable. Stacey writes, "For some young women, Hollywood stars seemed to embody a perfection of desirability which they themselves felt they could never hope to achieve" (110). But these authors were mainly discussing old Hollywood glamour, which Audrey's look opposed. I suggest that this opposition helped her to achieve her iconic status. Many Hollywood divas of the 1930s and 40s can be remembered as marvelous actresses, but their images became difficult to emulate and reproduce, therefore their style iconicity on Hepburn's level couldn't be achieved. Her singularity in the realm of Hollywood helped her to stand out and at the same time to be accepted by viewers as "one of them". At the same time in the cultural context, democratization became a trend. It was a time when prêt-a-porter and mass produced fashion emerged and was established as normative form of fashion (Wilson 12, 174).

The democratization of fashion can also be observed in SJP's critical approach to fashion. Helen Warner discusses how the actress promotes fashion to be "accessible for every woman" ("Fashion, celebrity and cultural workers" 385) and that all woman should participate in fashion. Although fashion processes start from creation and trickle down to consumption, most people are situated at the end of the chain. Meanwhile in order to be a 
style icon, one must take an active participation in production. This has been exemplified not only by Hepburn but by SJP: In 2005 she released her perfume lines; in 2007 she launched her first clothing line "Bitten"; and in 2014 she created two shoe lines, "SJP" for Nordstrom. This can be observed also in the activities of awarded "fashion icons" such as Rihanna or Pharell Williams, who received his award Fashion Icon by CAFDA in 2015 ("Pharrell, 2015 Fashion Icon"). Icons not only become "faces" and ambassadors of the companies but they all become affiliated with various fashion brands. For example, Rihanna and Pharell designed lines for River Island and Adidas respectively, and were positioned on a creative side of the consumption chain. They work not only as images, but seem to invest intellectual potential through their designs. Moreover, they position themselves as "tastemakers" as they are "responsible for producing the symbolic value of fashion" (Warner, "Fashion, celebrity and cultural workers" 386). What is even more important is that all of these fashion icons create democratic, relatively cheap, mass marketed and accessible lines and products.

Single Girl vs. Married Woman. The female normative roles in the 1960 s were shaken by the introduction of a new model of a feminine type called "A Single girl" offered by Helen Gurley Brown, who in 1962 wrote a book "Sex and the Single Girl” (Radner). Hilary Radner writes that this ideal continues "to dominate feminine culture". It depends on "seemingly impossible and delicate balance between self-gratification and social control" (Radner). This model includes freedom from dominant gender stereotypes, which in fashion photography is represented through movement and activity. The "single girl" is young and, obviously, single. Even if she is married, her value is presented by "what she does rather than by whom she belongs to" (Brown 89 qtd. in Radner). She has a career and is an active consumer. Hepburn's heroine Jo from Funny Face is named to be the embodiment of this model (Radner), as well as Holly Golightly (Finnane). Although Hepburn's characters find their true love in the end of the movies, they still act according to the behavioral pattern of single 
girls, they are not domestic and passive females. In her real life in Hepburn was married to Mel Ferrer from 1954 to 1968, and to Italian psychiatrist Andrea Dotti form 1969-1982. She was very family-oriented and in 1967 she gave up her acting career, taking up roles only occasionally in order to devote herself to the home and her humanitarian work. This example of Hepburn shows that even though she dedicated herself to her family, she was valued and famous for what she had achieved herself, not through the establishment of her husbands.

In the case of SJP, her character in Sex in the City also embodies Brown's “single girl" due to her social status, position, activity and consumption. Moreover, Arthurs argues that the show's character' single state is "rather a necessary precondition for their central preoccupation-sexual relationships and how to achieve sexual satisfaction" (85), so being single, despite all conventional stereotypes, becomes a narrative and base for building her image, which is seen in a positive view. Also it is promoted with a positive appraisal. In one episode “They Shoot Single People Don't They?” (Season 2, Episode 4) after Carrie’s unflattering portrait is placed on a cover of New York Times with caption "Single and Fabulous?" (see figure 58), the character's discussion over the episode revolves around the issue of the shame of being alone and faking happiness with a man for his satisfaction. Notably, SJP was wearing pink pants in the beginning of the episode and a pink dress in the middle of the episode, when she went out partying. According to Veronika Koller's investigation of the colour pink, it has cultural associations with femininity in the Western world and has strong links to notions of "romance", "softness", "love", "delicacy" and "dreaminess" (405). The conclusion of the episode showed that SJP's character Carrie was single "single and fabulous", but not hopeless to find her love. Desirable aspirations of fabulousness and looking the best has been connected with being single, as a reflection of a new model for women. This episode is ambiguous in terms of the manifestation of singleness, but still dreaming of love and romance. 
Despite this, in real life, just as Hepburn, SJP has been married to the actor Matthew Broderick since 1997 and they have three children. So while in real life, SJP is tied to atraditional feminine gender role (a wife and a mother), her on-screen alter ego committed to one man only by the end of the lifespan of media production of Sex and the City. Still, SJP is known for her work, but not as "Mrs. Matthew Broderick" and falls under the characteristics of a single girl. This ambiguity of the family statuses of style icons provides a discussion and disconnections for their iconic establishment. Notably, Hepburn's images after she had fully committed herself to the family are not considered to be iconic. She is remembered and referenced for the period when she played single girls, but was married.

Consumption. A style icons' participation in the fashion industry promotes active consumption for their fans and those who receive aspirational messages from them. Mary F. Rogers, discussing Barbie as a cultural icon, stated that "monitary expenditure" and "small social worlds building up around the icon" (6) are a big part of formation of icons, as it requires active involvement from fans. Since the construction of a cultural icon "involves a dense web of products identified not only with [an icon] but also with other corporate sponsors and popular culture" (95), style icons can expand their influence in other industries, but the emphasis will still be on their stylistic specialties. This can be exemplified by the Galaxy Chocolate advertisement that recreated Hepburn's look from Roman Holiday, and SJP's collaboration with Hallmark, a company that produces postcards. Still those postcards reflect her style in fashion, a bit eclectic, yet with emphasized femininity in its design (see figure 59). Through the dissemination of their stylistic features, the style iconicity gets its validation in culture due to the repetitive nature. Just as a myth that is being recreated many times, the visual representations of style icons are consolidated and "naturalized".

As discussed previously by Stacey, consumption and the fantasy of it is one of the principles of female viewership, after escapism and identification. She states: 
The spectator's own identity is replaced through her imaginary identification with her ideal. This replacement of self with ideal subject position is effected through the fantasy of consumption; thus the spectator and star are linked, not through the purchasing of clothes, but through the gazing and desiring of the female spectator/consumer who imagines her ideal's choice of commodities. (197) Consumption as a practice is a prevailing value for style icons and the mechanism of pushing sales further in order for consumers to achieve the desirable visual embodiments of mythological success, social mobility and personal validation in a social context. Consumption establishes the authority of style icons, popularizes their fashions and Mitchell's idea of "likeness" of an image through purchasing whatever was created by an icon is achieved.

On-Screen vs. Off-Screen Representations. The discussion of on-screen and off-screen representations is declared as one of my research questions. According to Christine Gledhill, stars' "offscreen lifestyles and personalities equal or surpass acting ability in importance" (xiv, qtd. in Beltran 74). Such lifestyles seem to be more authentic and thus desirable and attainable. Aside of how style icons are created on the screen, how they appear in real life and how it is related to their cinematic appearance is what matters in the construction of their iconicity.

Similar to how the scholars ask where does Carrie Bradshaw begin and SJP end, writers question Audrey Hepburn's film and real world personalities (Dotti 106) and state that "the difference between Hepburn, the female star performing iconic femininity, and her character, also performing this idealized femininity, is extremely blurred" (Handyside 293). These blurred lines can be observed in an edition that Audrey Hepburn's son, Luca Dotti, published in 2012. The book "Audrey in Rome" features her photographs taken in the streets 
of the Italian capital, the city where her rise to fame started and where she moved to devote herself to her family.

Through an analysis of the images (see figures 60-69), it is noticeable how her looks off-screen were carefully constructed and correlate to the aesthetic she presented in her films. Firstly, it is connected to the fact that Hubert de Givenchy created her outfits for her personal life. Secondly, her son writes,

Mamma was never caught off guard by photographers, at least not while doing anything worse than wearing a sleepy expression late at night in a club. Aided to her training in classical ballet, she naturally displayed impeccable composure on every occasion. Even so, she can’t be given full credit for her dignified appearance. In those days, actors and photographers often developed friendships. My mother had her favourites, to whom she gave exclusive shots in exchange for impeccable images. Her favourite shot were those taken by Pierluigi Praturlon (Dotti 13)

So here we observe from the insider's source that the "real-life" images were as managed as the on-screen appearances. Moreover not only the looks, but also the background and scenery is very reminiscent of her film stills. Photos of Audrey with her mother, and more importantly, with her husband (see figure 66) on the Spanish Steps give a reference to the famous image of her and Gregory Peck from Roman Holiday, when they decided to spend the day together. The coats, dresses and shoes in which she is depicted in the photographs are very reminiscent of her outfits for Breakfast at Tiffany's. These instances are highly representative of the hyperrealistic tendencies of Hollywood that started in the 1950-1960s, when the real and fictional became blurred together. One particularly elegant style of Audrey Hepburn is carried out through various medias and through this consistency and recognition, it allowed the actress to achieve her status. This consistency is linked to Barthes' 
mythologies, which themselves are repetitive and thus are perceived to be normative. This aspect of building an iconic status is very important. Jeffrey Alexander, who researched the concept of celebrity icon as a sign, refers to the carefully managed appearance of the actress on the screen and her actions and the values she embodied off screen. He states "The ringing reassertion of the unity of surface signifier and depth-signified comfortability confirms that Audrey Hepburn and Holly Golightly constitute a true sign" (327). This means that for a true style icon, there must be not only a glossy surface but strong and appealing narratives (myths) that are accepted in the cultural discourse.

With SJP, similar tendencies can be observed but with minor differences. During official and promotional events, parties, red carpets, TV-appearances and magazine spreads SJP borrowed the style of her character, Carrie Bradshaw, which reinforces the consistency of her style (see figure 70). Nevertheless paparazzi images taken in the streets of New York do not represent her carefully curated looks. She can look disheveled, wearing jeans, parkas, and Uggs. This can be justified by SJP's promotional democratic approach to fashion consumption. Describing the actress as one of "style icons of the century", Simone Werle describes, "in her private life SJP prefers clean, straight lines. For daywear she likes to be casually dressed in jeans, shirts, and plain boots. She admits she never really felt at home with Carrie's delight in experimental dressing. Only on the red carpet does the 5'4', actress make an exception" (136). The red carpet is still valued as the most valid context for a carefully curated look due to its elitism and separation from masses. However, SJP's looks in the street are neither iconic, nor recognizable and have no connection to her status in the fashion industry. In the meantime, today stars have become very accessible through social media, as a source of reaching out to their fans. SJP's private Instagram is as usual and democratic, as her looks in the streets, very casual and not precisely managed. 
Cultural Icons and Style Icons. Since another question of my research questions was if cultural icons and style icons can be interchangeable notions, from my overall investigation, we can observe that cultural icons such as Audrey Hepbrun can become style icons. Both types of icons share similar features and conditions of functioning. However, for style icons fashion is primarily a tool that helps them to embody and perform cultural norms and values. The style icon is a more narrow concept, and is mostly applicable to certain groups of fashion enthusiasts. So if both of these concepts fall under all the categories of cultural icons, we might say that style icons become "cultural icons" in certain subcultures, but not in a broader context. At the meantime, cultural icons can become style icons with the condition of a distinct look and when the image transcends the object, exemplified by Frida Kahlo (discussed by Irma Dosamantes - Beaudry) or James Dean (analyzed by Parker). Sarah Jessica Parker, for example, would not be considered a cultural icon by those who did not watch the show and is not actively participating in the consumption of her name. She becomes a cultural icon for the particular group of people who have an interest in the show or her personality; a reminder, that collectivity is one of the conditions of iconicity. This question can be addressed in further research through interviews and finding out the opinions of different focus groups of broad cultural discourses.

\section{AREAS FOR FURTHER RESEARCH AND IMPLICATIONS}

This project attempted to give the first explanation and discussion of a style icon. In order to have a strong focus, the paper was based on the research of two screen stars - Audrey Hepburn and SJP. Although they are very different in their styles, representations and time periods, there were similar themes that occurred in the research, such as similar ambiguities, consumption and mythological narratives. It would be interesting to analyze further how politicians, musicians and models become style icons. Are the same requirements as narratives, ambiguities, support from fashion authorities, consumption practices included in 
their formation? And if the requirements are the same, then what are the narratives? What is the medium for musicians to become style icons? Do their songs, music videos, or live performances reinforce their authority in fashion?

Without a deep immersion in this research hyperreality as an occurring theme emerged a couple of times, first with the instance of Hepburn's dress from Roman Holiday in which she later received her Oscar; then with SJP appearing on a cover of Vogue at the same time when her character Carrie tried to get a job at the magazine; and then with the discussion of merging of on-screen and off-screen images. Since Baudrillard's concept of hyperreality was not claimed as a theoretic framework for the research, it would be interesting to analyze how these tendencies of Hollywood influence started and are continued today, especially with the rise of "reality-TV" and blogs, and how those "real" people and their images gain influence and those stars become style icons.

Breakfast at Tiffany's introduced a new approach of dressing a star, when protagonist Holly Golightly could not afford to wear French haute couture costumes by Givenchy and a signifier (an outfit) did not refer to the signified (wealth). How this film spanned a tendency for designers to create costumes that would not correspond with the character's financial situation, could be an area for further research in terms of what aspirational cloud of senses costumes on film create. The same mechanism was used in creating Carrie Bradshaw's wardrobe in Sex and the City, when a journalist was not able to afford all the designers' clothes and expensive shoes that she was wearing. However it only reinforces the potential of style icons and their influence upon the followers as well as constant consumption of goods.

While Fiona Handyside provided a thorough research of the role of European cities in the creation of Audrey Hepburn's iconic and star status, by marketing her as a new, unconventional and “different" star (287), New York City also played a big role in Hepburn's career. Her Holly Golighly has become a symbol of New York. In one scene she even 
explicitly declares her love to the city. In the same way, New York is considered to be "a fifth character" in Sex and the City and Carrie Bradshaw confesses in her love for the city over six seasons of the show, such as in the episode I Heart New York (Season 4 Episode 14).

Considering that associative locations play an important role in building a cultural icon, as an area of further research it will be interesting to research specifically the role of New York City and its cultural capital in the process of creation of style icons.

Hepburn and SJP are critically acclaimed style icons through their affiliations with fashion magazines and the industry. However, with the help of interviews of focus groups, it could be researched if the opinion of fashion authorities matches the opinion of people who are indeed the projected followers and consumers of style icons. A question to explore is: Who are considered to be the contemporary style icons of the $2010 \mathrm{~s}$, not from only from mere curiosity but because style icons embody cultural values. And by observing specific personalities, it can be easier to understand the culture.

\section{CONCLUSION}

By providing a cultural context for the development of the style icons Audrey Hepburn and SJP, the research in this study revealed a great need for style icons in culture. Style icons often oppose a dominant set of ideals and norms and come to reflect new social values through the fashions that they wear. For example, Audrey Hepburn and SJP rejected male fantasy ideals and appealed to women because their fashions were easy to emulate. Because their colours and silhouettes were so consistent, it was easier for women to follow their looks and achieve similar styles with cheaper copies.

Style icons become cultural icons in a narrow sense, if conditions of their functioning are met, such as instant recognition—when the image transcends the subject, and the icon achieves a visual shorthand. Style icons and cultural icons are reproduced in durable images that live in the collective unconscious. They embody myth and constantly represent mythic 
narratives through their creative work and fashion choices. Moreover style icons have strong associations with certain locations, which reinforce their consumption influence.

In order to be consolidated into culture, style icons represent various ambiguities; they are not strictly determinative. In the cases of Hepburn and SJP, the research revealed that universality made them appealing to large groups of people. At the same time, they were individuals, and fulfilled the following 'iconic' conditions: durability and reproducibility, instant recognition by large groups of people, and the embodiment of cultural narratives and myths. For example, in the 1960 s, the culture demanded a democratization of fashion. As an icon, Hepburn started the trend of making style attainable. Even though she wore elite hautecouture, her overall character promoted accessibility, an important quality in a style icon who must become emulated by followers and encourage their fashion consumption.

Icons not only encourage consumers to buy fashionable clothing but are themselves consumed as images. An icon's followers are not only encouraged to spend money to look like the style icons, but also to be involved in a dense web of style creation and production that is affiliated with them. Style icons themselves must participate in the creative side of the production chain in order to establish their authority and appeal to consumers.

The style icons Hepburn and SJP, as examined in this study, are also significant for promoting the enduring success narratives of the Cinderella and Pygmalion stories. Through their on-screen and off-screen style, these figures repeat and recreate key tropes of feminine culture that generate aspirations for a better life in their consumers. The films of Hepburn and SJP prove that success, transformation, finding your true self and true love is attainable, and that personal style makes it possible.

It is a dense web of myths, imagery, products and personalities that creates a cultural fashion narrative, and this research reflects only the beginning of a movement to construct a theory of style iconicity. 


\section{Appendix: Figures}

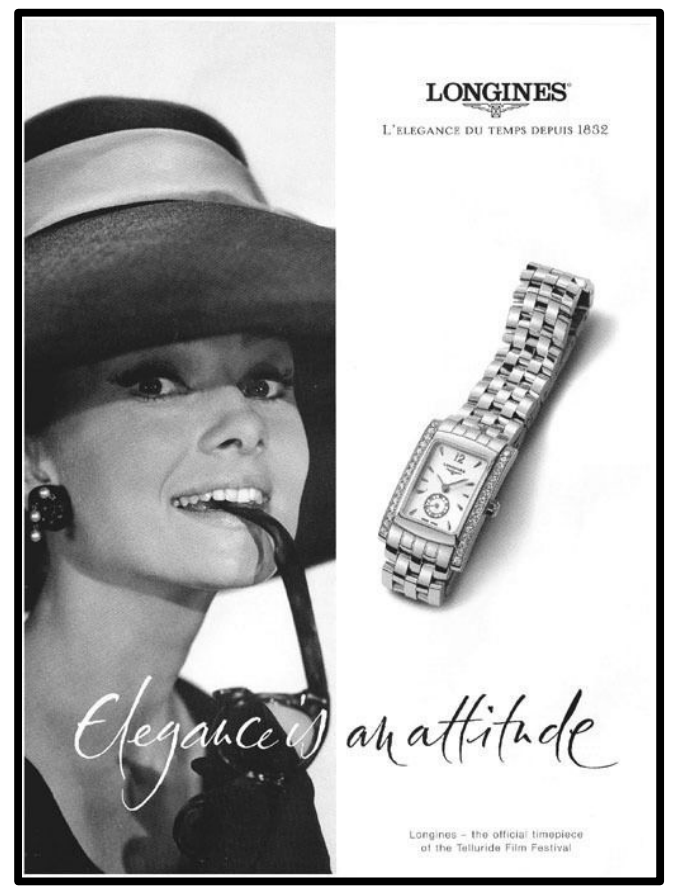

Figure 1. Audrey Hepburn advertising Longines (2001).

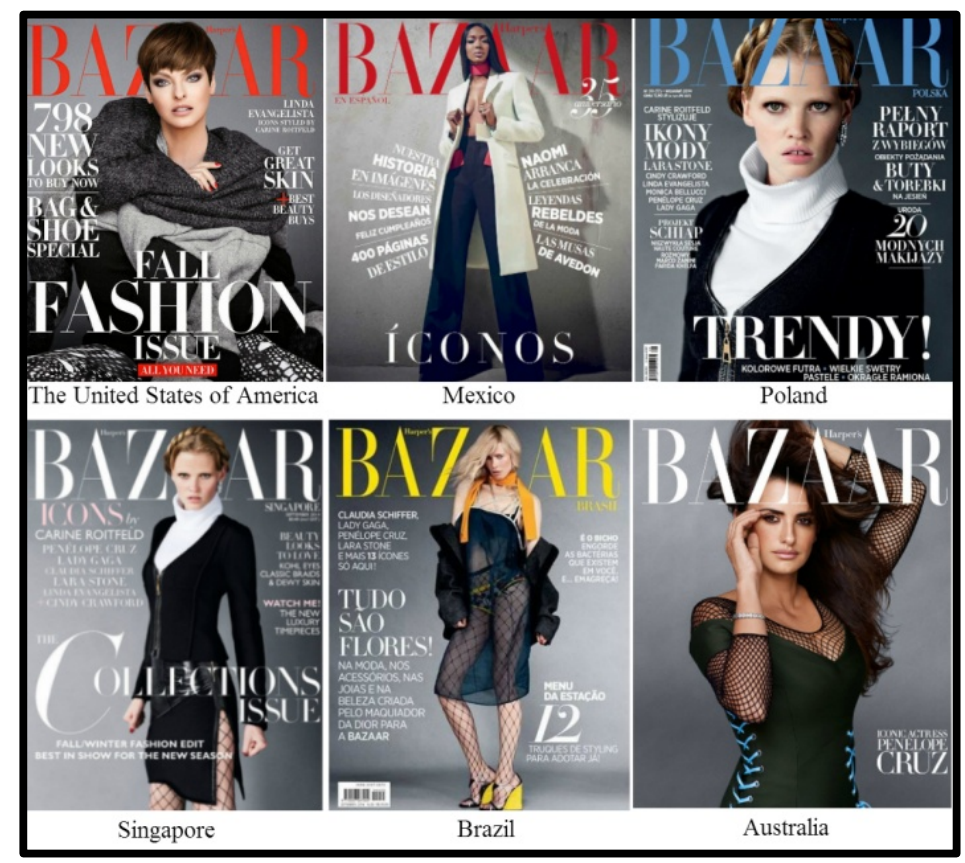

Figure 2. International covers of Harper's Bazaar magazines, September 2014. 

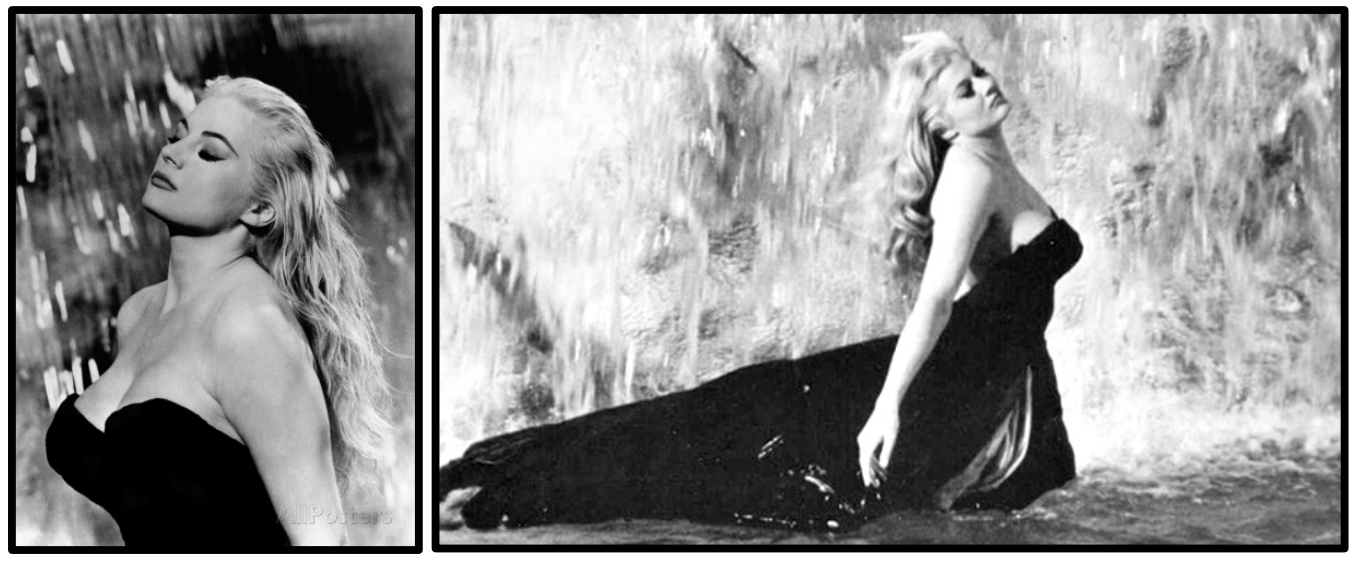

Figure 3. Anita Ekberg in Federico Fellini’s “La Dolce Vita” (1960).

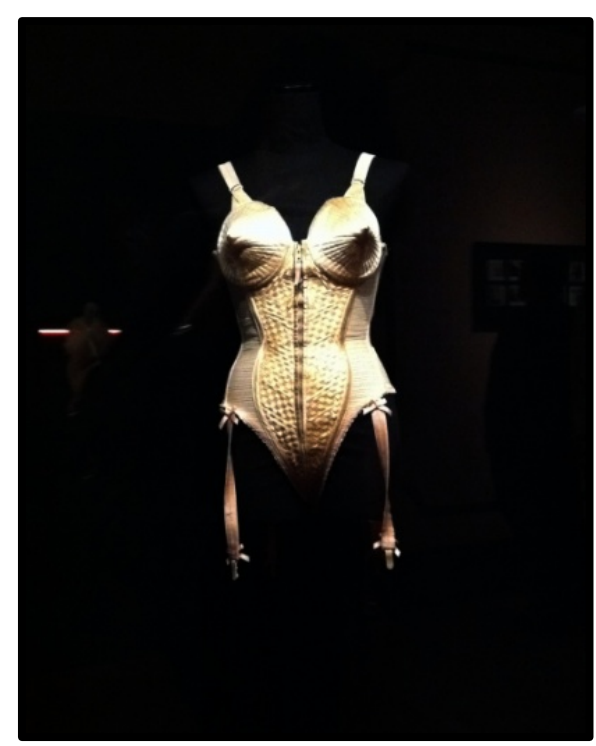

Figure 4. Madonna's bustier by Jean Paul Gaultier for "Blonde Ambition Tour" (1990).

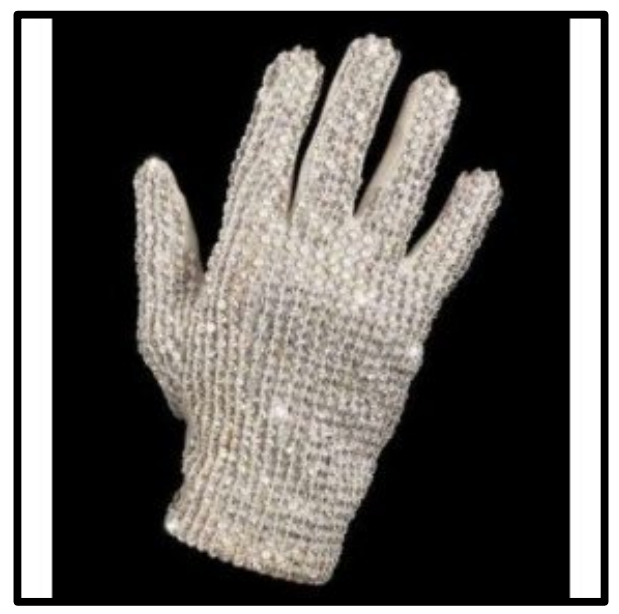

Figure 5. Michael Jackson's sparkly glove. 


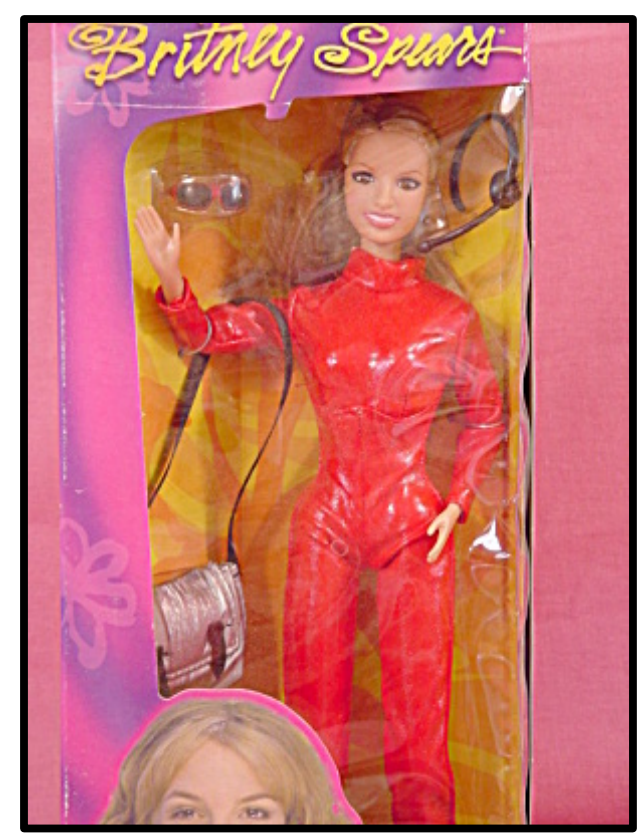

Figure 6. A doll of Britney Spears in a costume from "Oops!..I did it again" music video (2000).

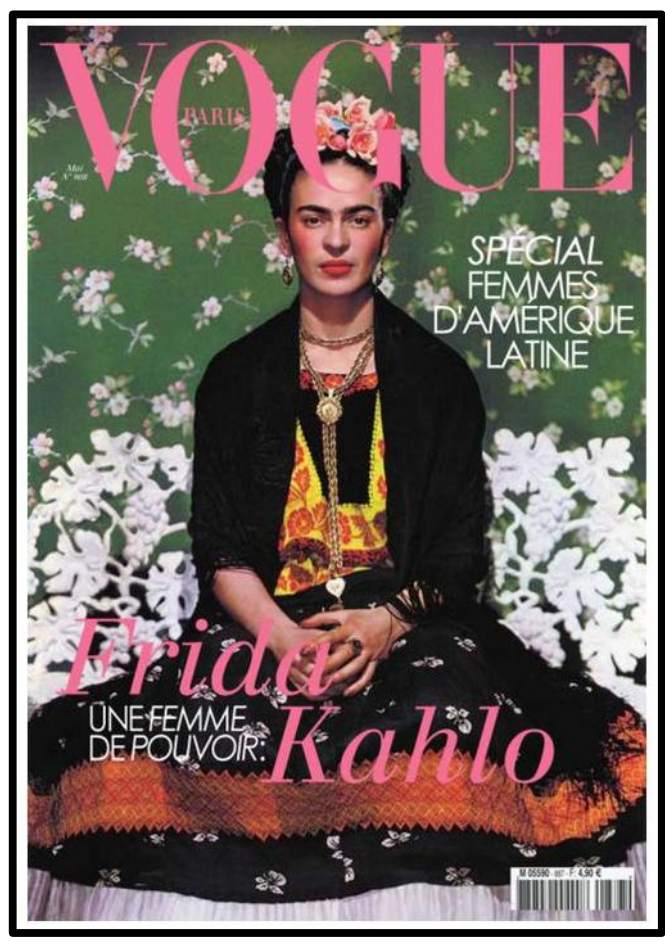

Figure 7. Frida Kahlo on the cover of Vogue Paris, 1939. 


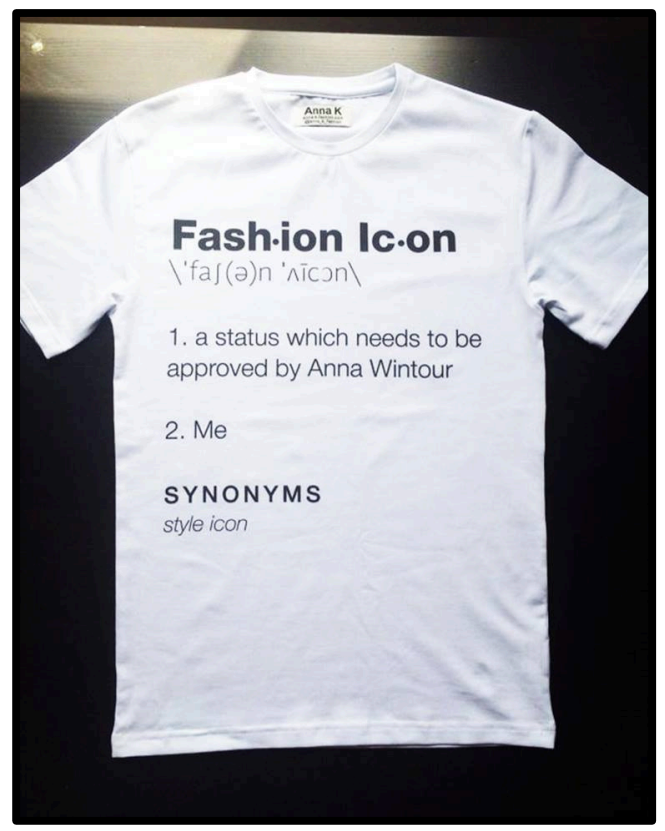

Figure 8. T-shirt by Anna K from her line "Fashion Dictionaries", 2014.

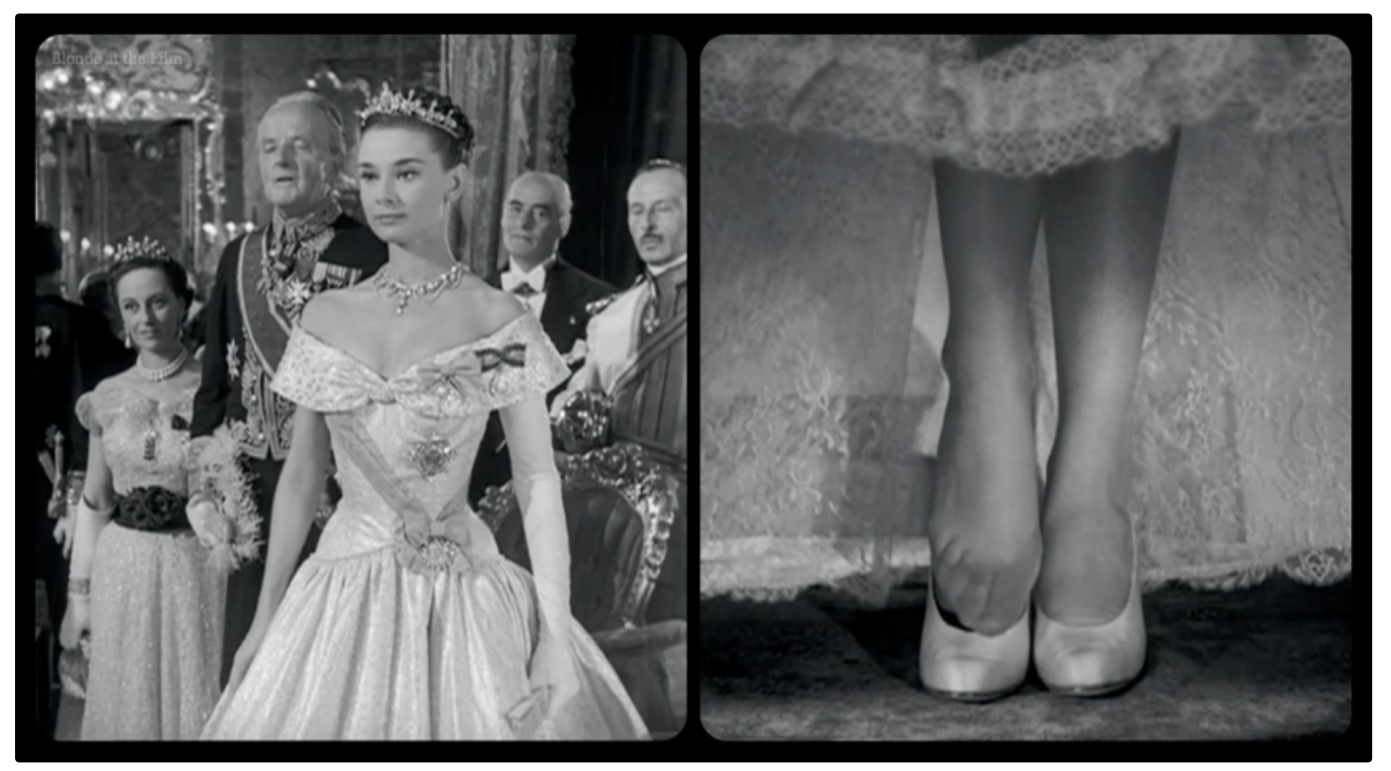

Figure 9. Audrey Hepburn as Princess Ann, a ball scene, Roman Holiday (1953). 


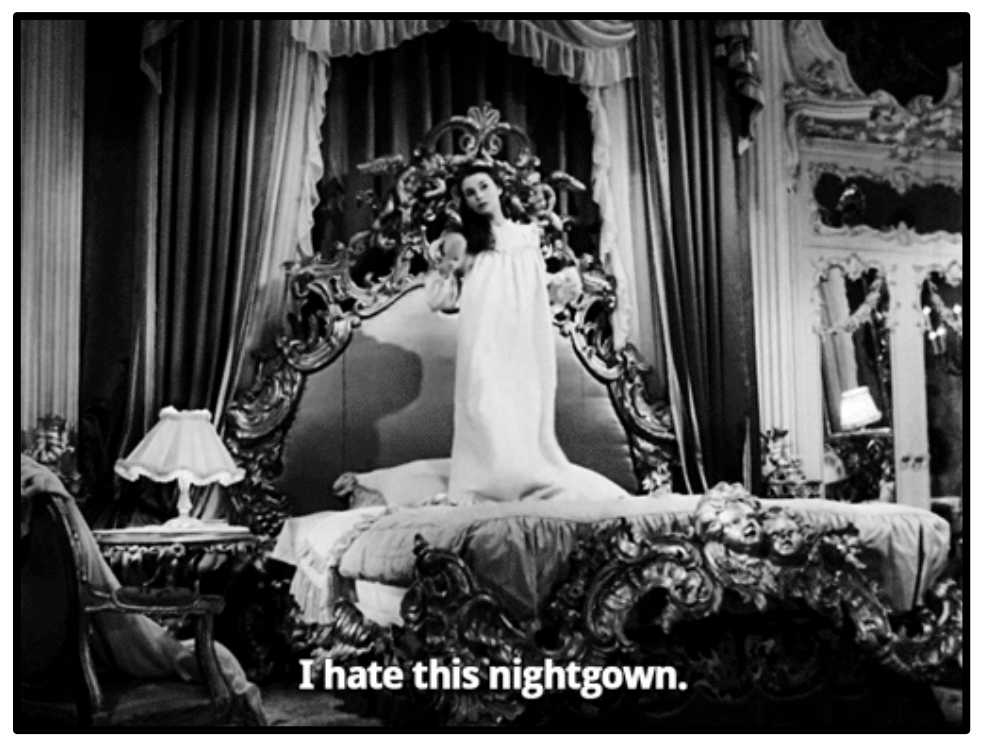

Figure 10. Audrey Hepburn as Princess Ann, in her bedroom before going to sleep, Roman Holiday (1953).

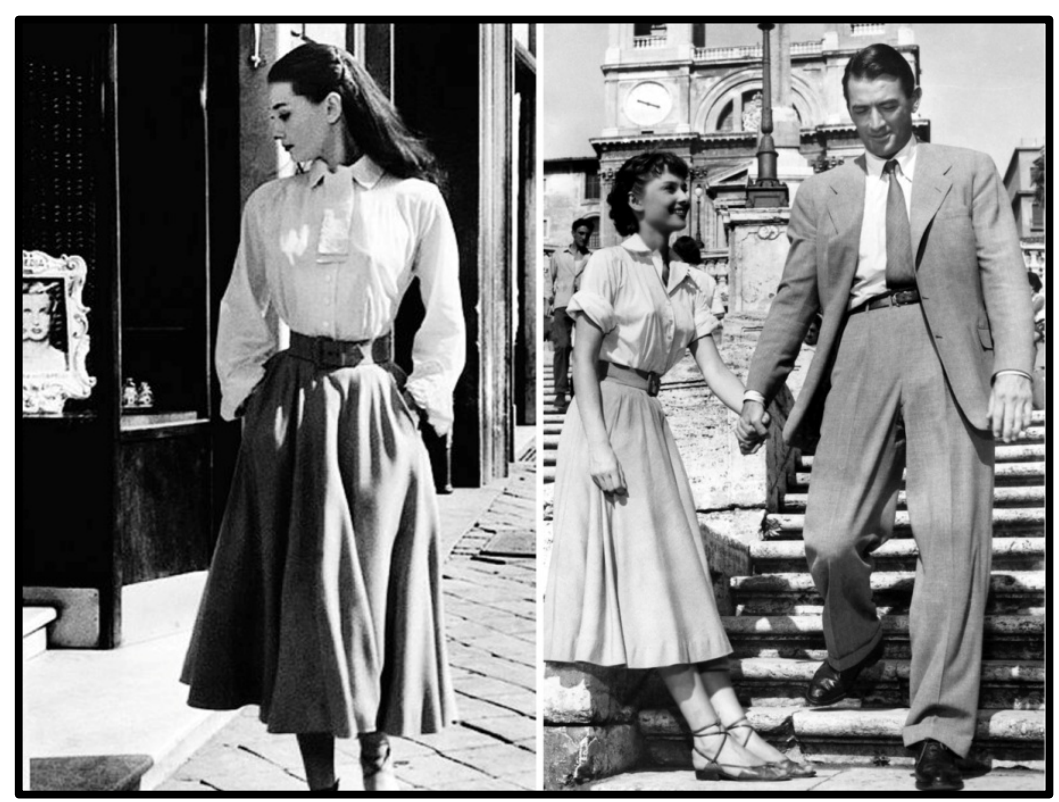

Figure 112. Audrey Hepburn in Roman Holiday (1953), before and after a hair-cut.

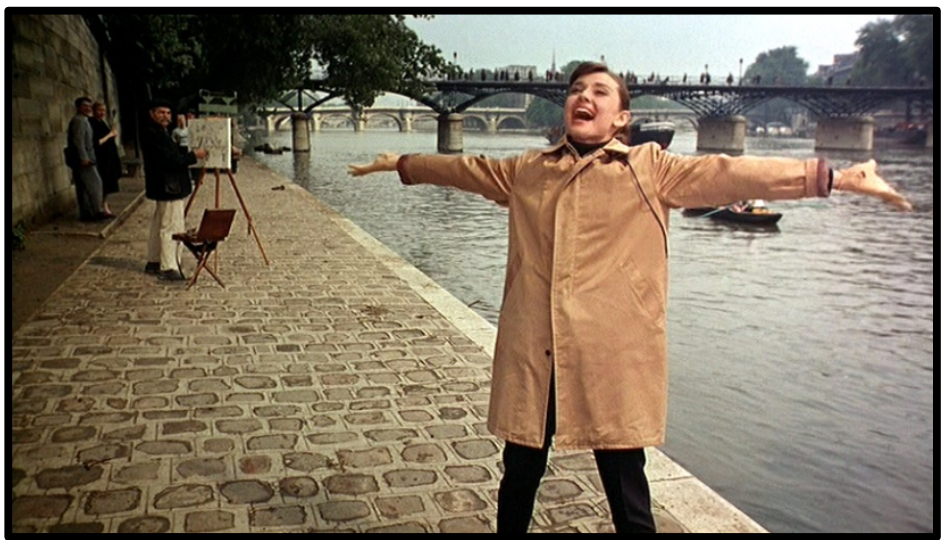

Figure 12. Audrey Hepburn in Funny Face (1957), singing "Bonjour Paris.” 


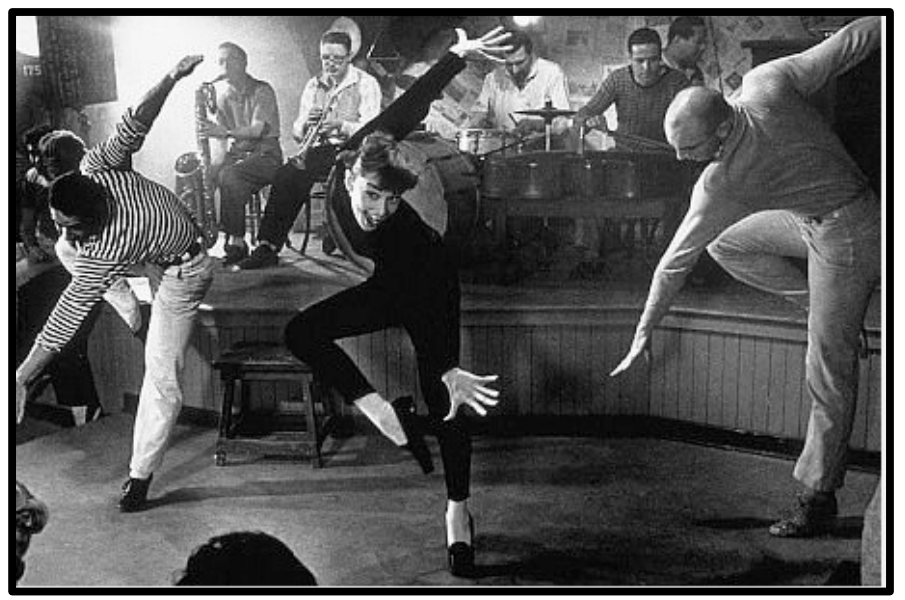

Figure 13. Audrey Hepburn in Funny Face (1957), dancing scene.

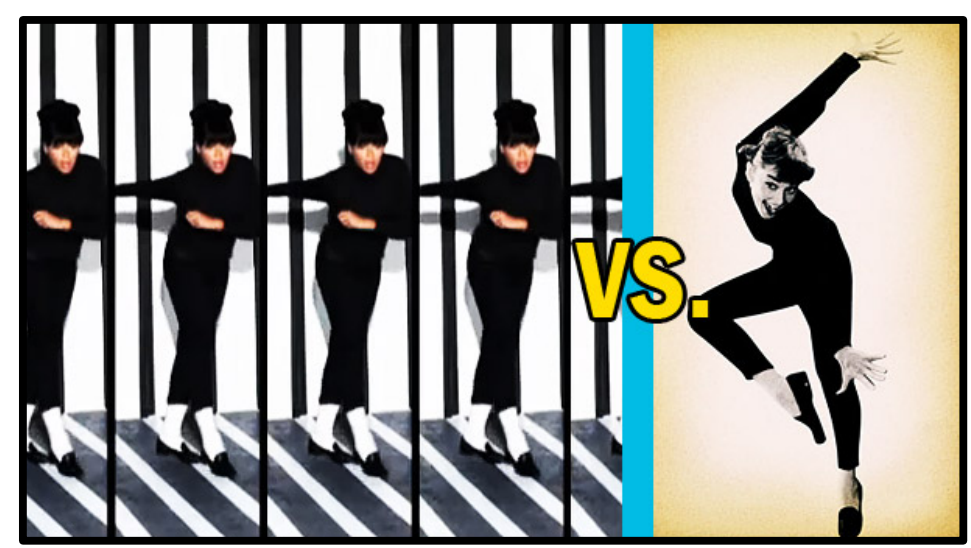

Figure 14. Beyonce from her music video "Countdown” (2011) is compared to Audrey Hepburn in Funny Face (MTV.com).

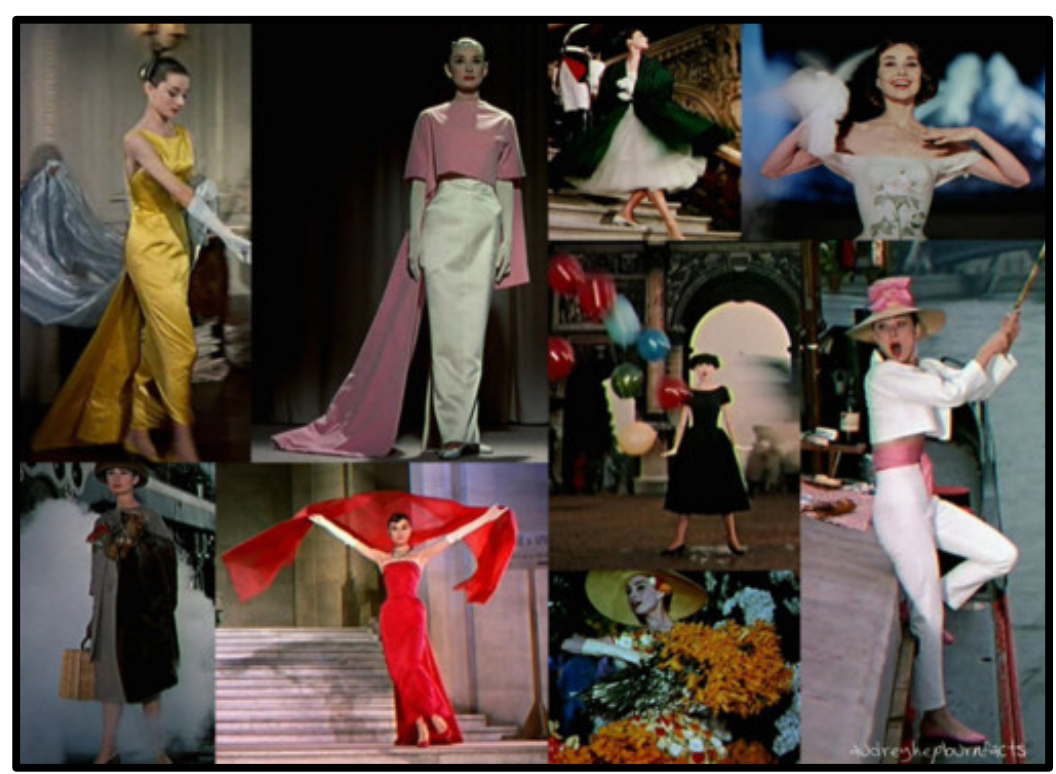

Figure 15. Givenchy costumes for Audrey Hepburn in Funny Face (1957). 


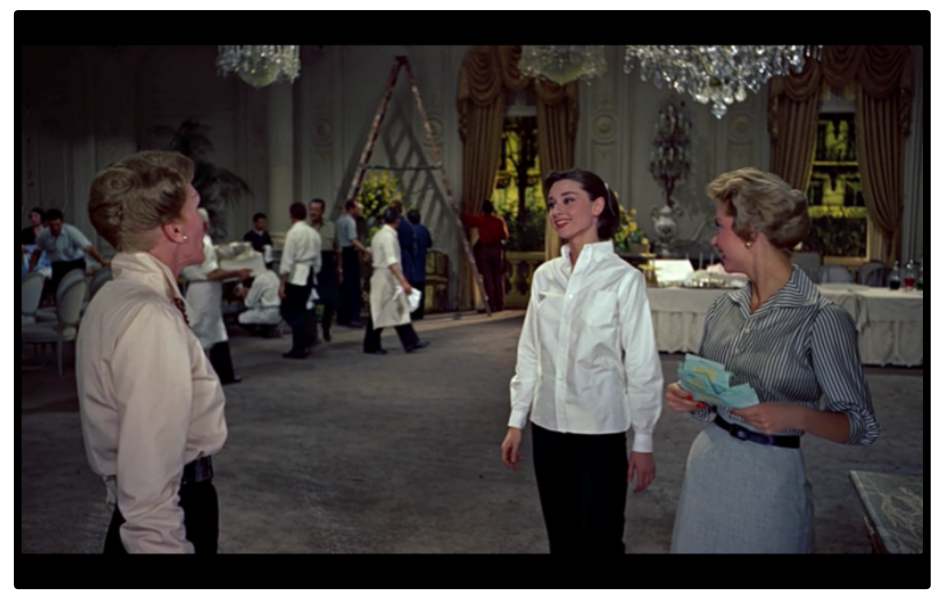

Figure 16. Audrey Hepburn in Funny Face (1957), dressed similarly as editor-in-chief of the fashion magazine Quality.

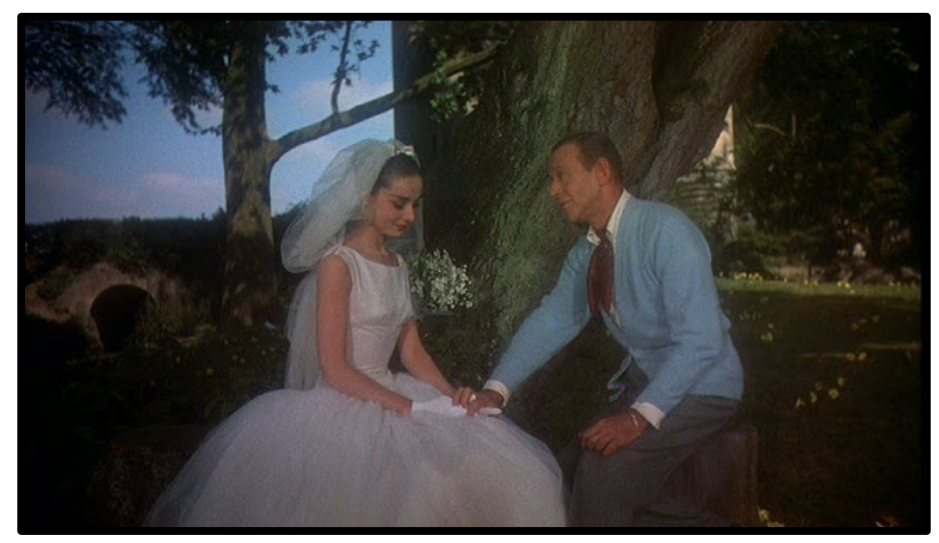

Figure 17. Audrey Hepburn in Funny Face (1957) with Fred Astaire.

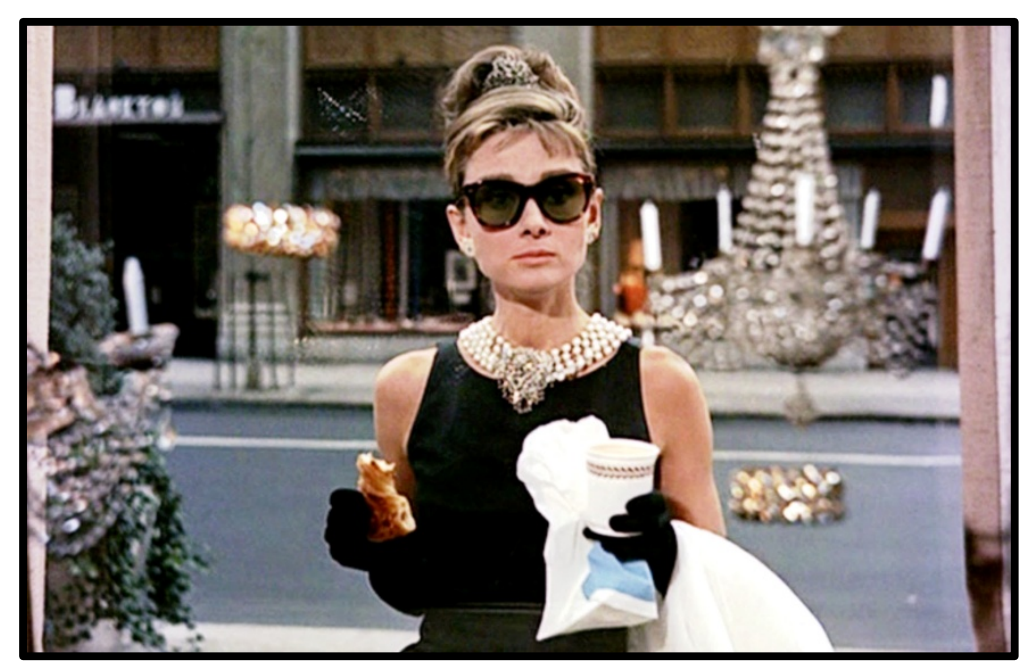

Figure 18. Image from the opening scene of Breakfast at Tiffany's (1961). 


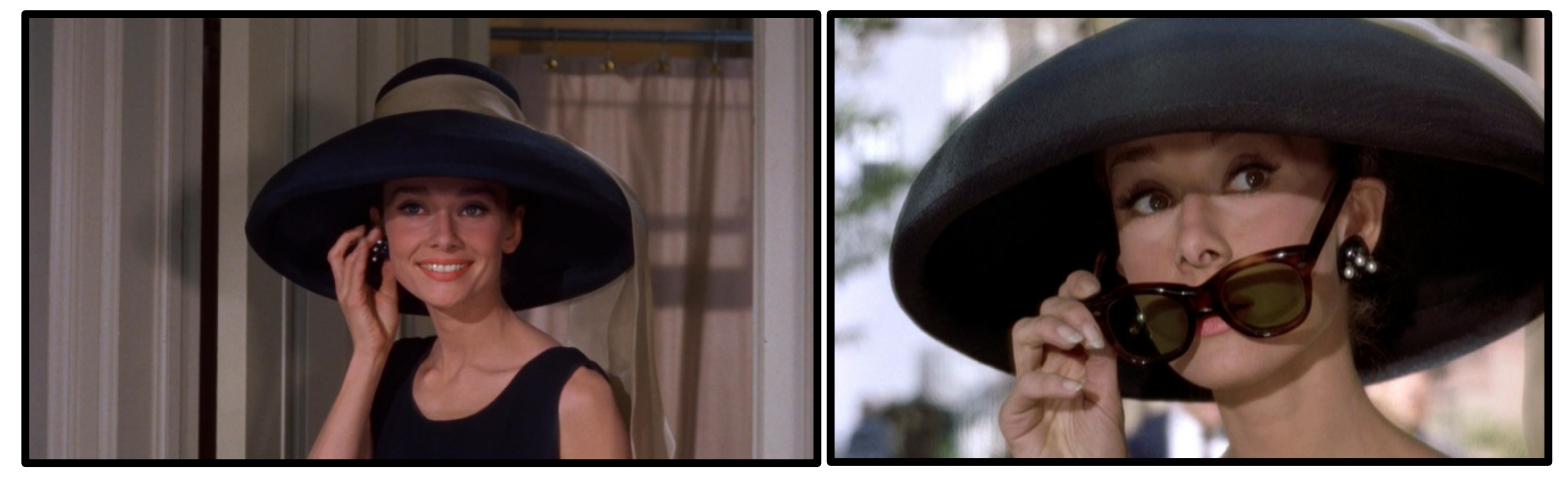

Figure 19. Audrey Hepburn in Breakfast at Tiffany's (1961).

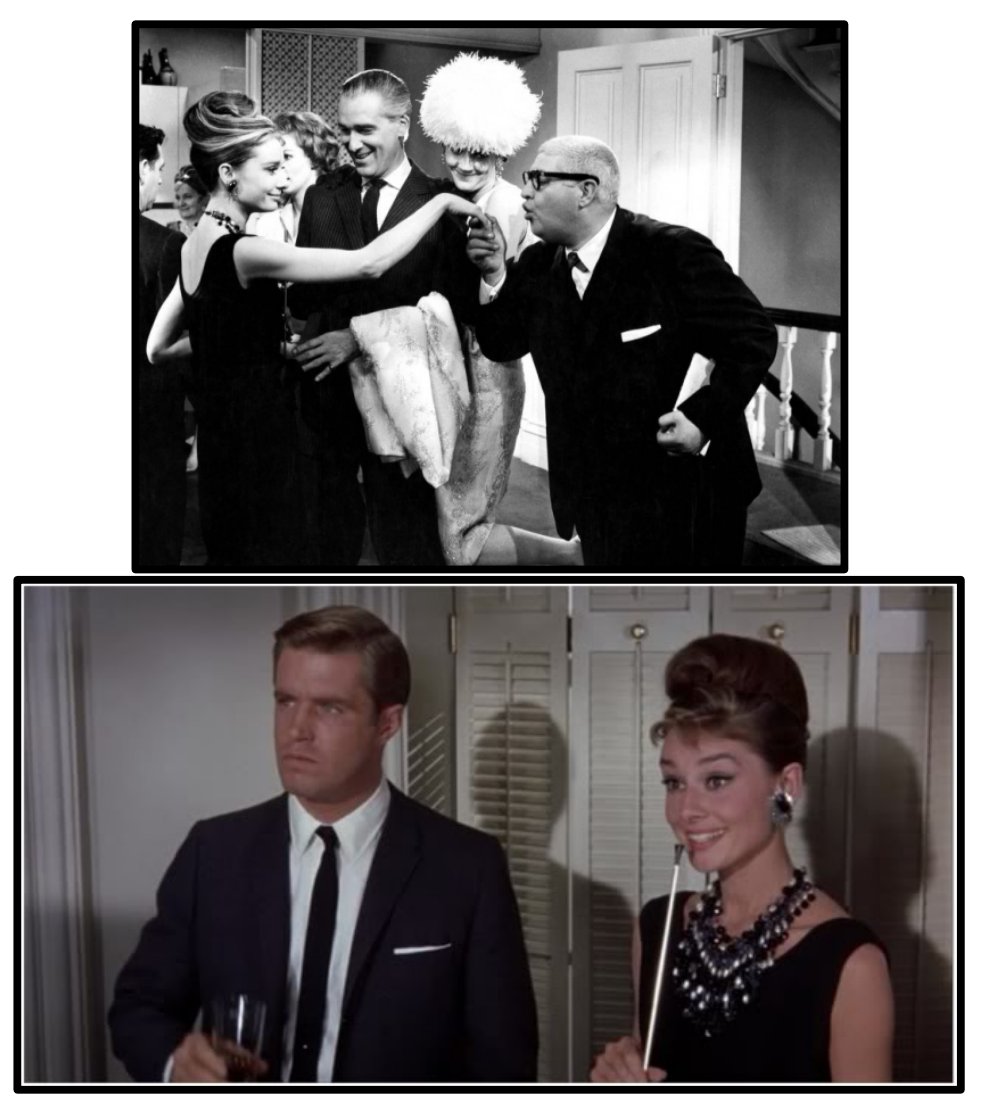

Figure 20. Audrey Hepburn in Breakfast at Tiffany's (1961), party scene. 


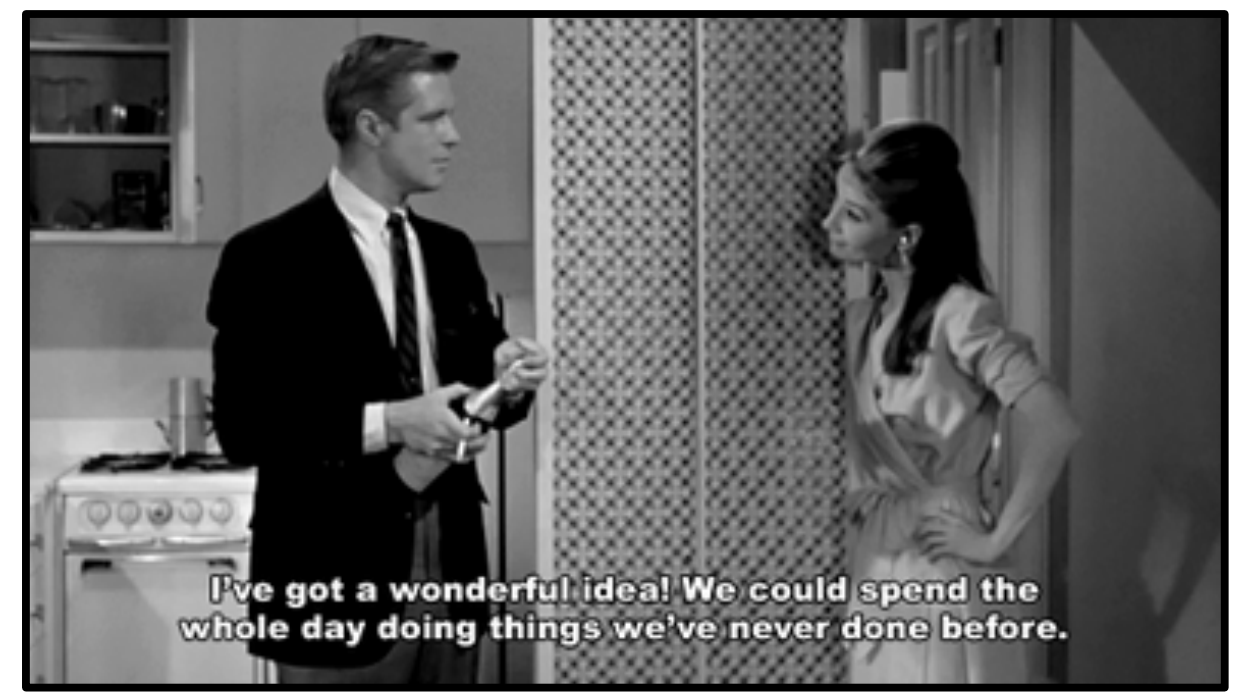

Figure 21. Audrey Hepburn and George Peppard in Breakfast at Tiffany's (1961).

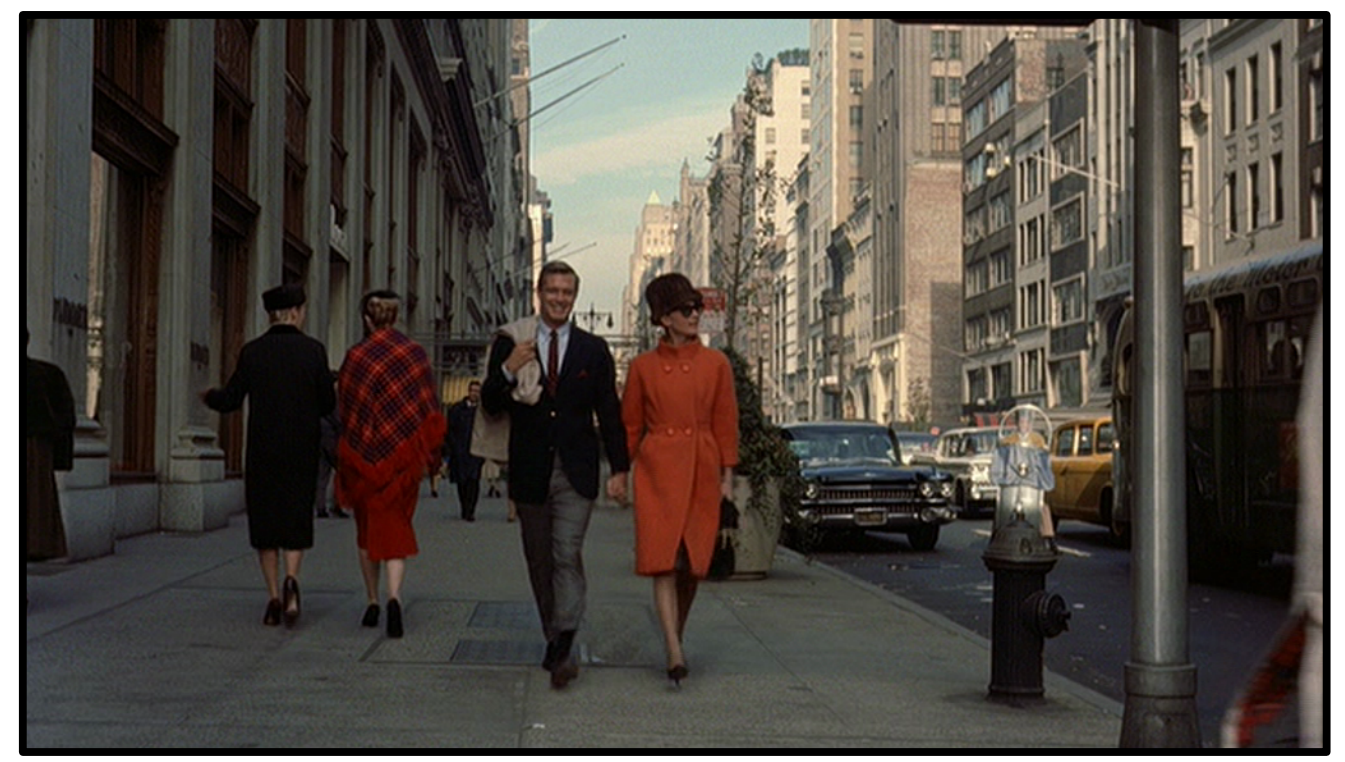

Figure 22. Audrey Hepburn and George Peppard in Breakfast at Tiffany's (1961). 


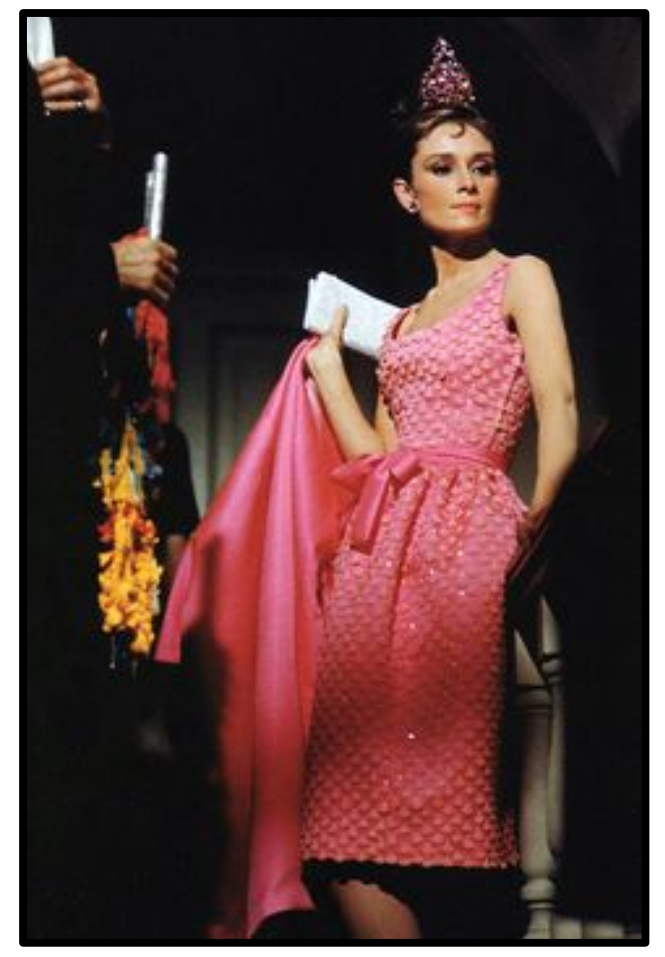

Figure 23. Audrey Hepburn in Breakfast at Tiffany's (1961).

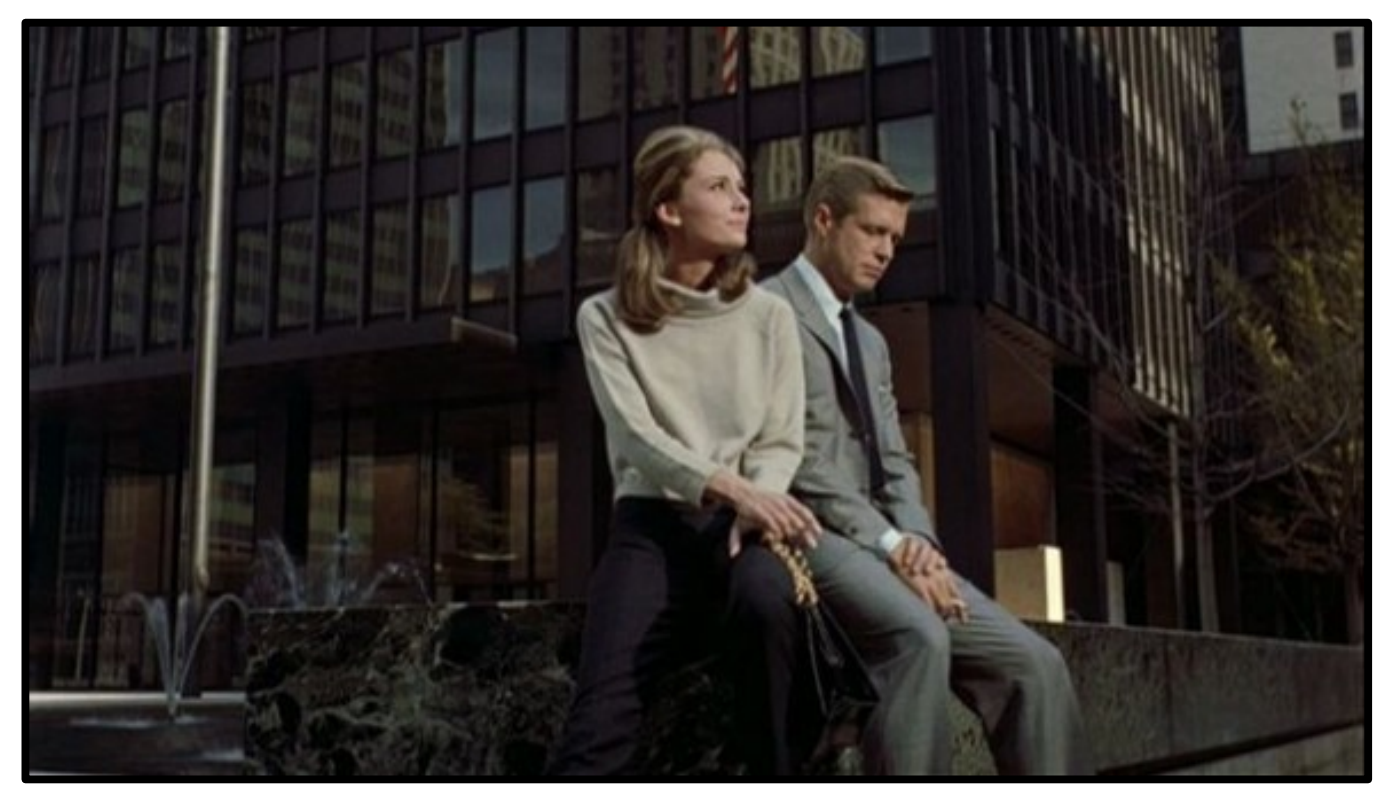

Figure 24. Audrey Hepburn and George Peppard in Breakfast at Tiffany's (1961). 


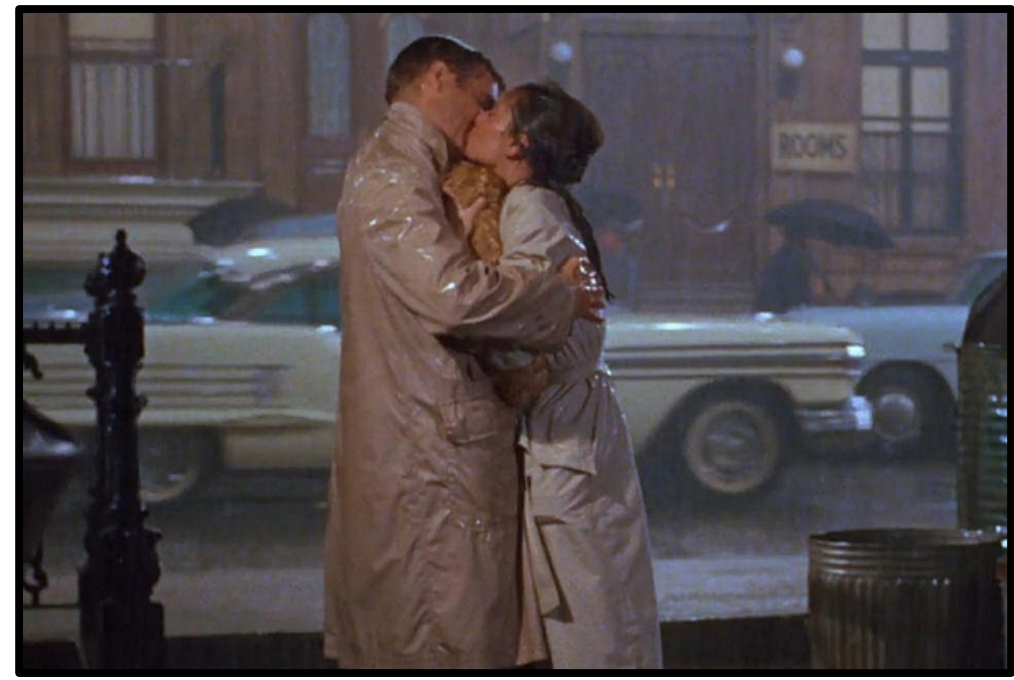

Figure 25. Audrey Hepburn and George Peppard in Breakfast at Tiffany's (1961).

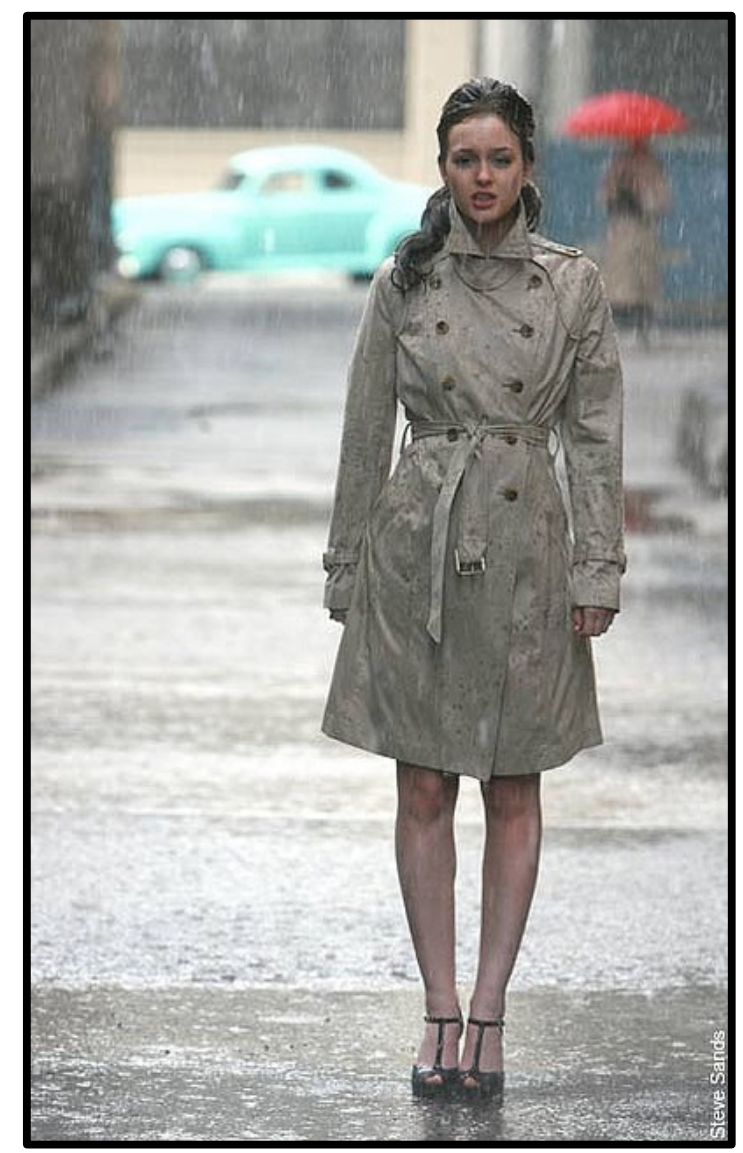

Figure 26. Blaire Waldorf (Leighton Meester) channeling Audrey Hepburn in Breakfast at Tiffany's (1961) in a dream scene. 


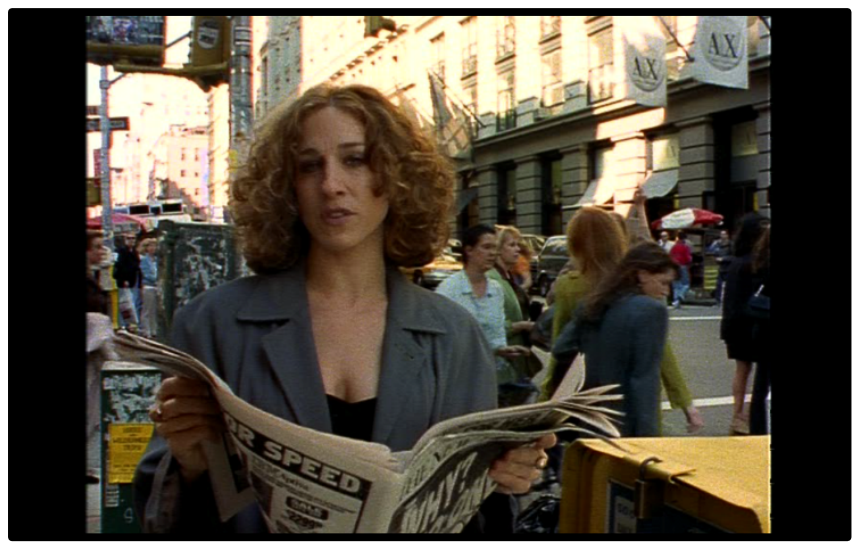

Figure 27. Sarah Jessica Parker as Carrie Bradshaw in the pilot episode of Sex and the City.

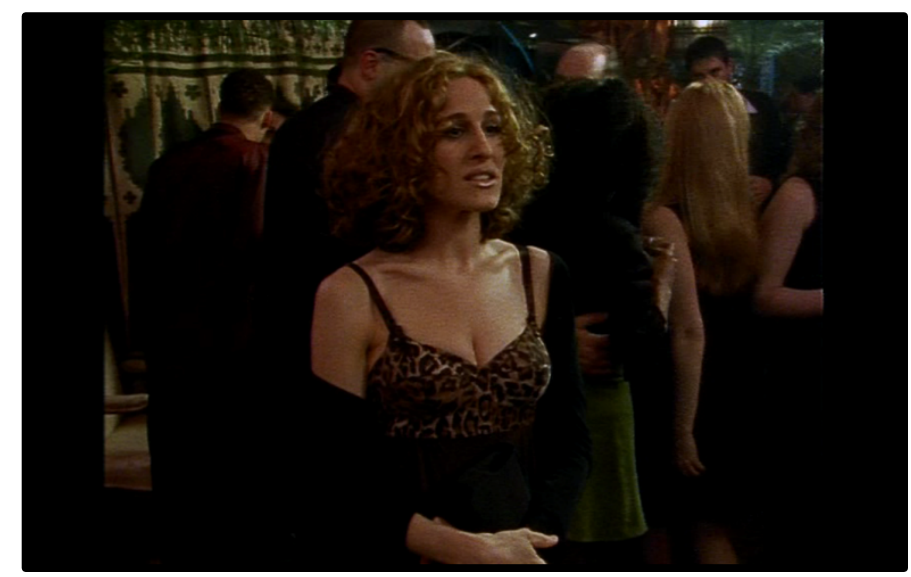

Figure 28. Sarah Jessica Parker as Carrie Bradshaw in the pilot episode of Sex and the City.

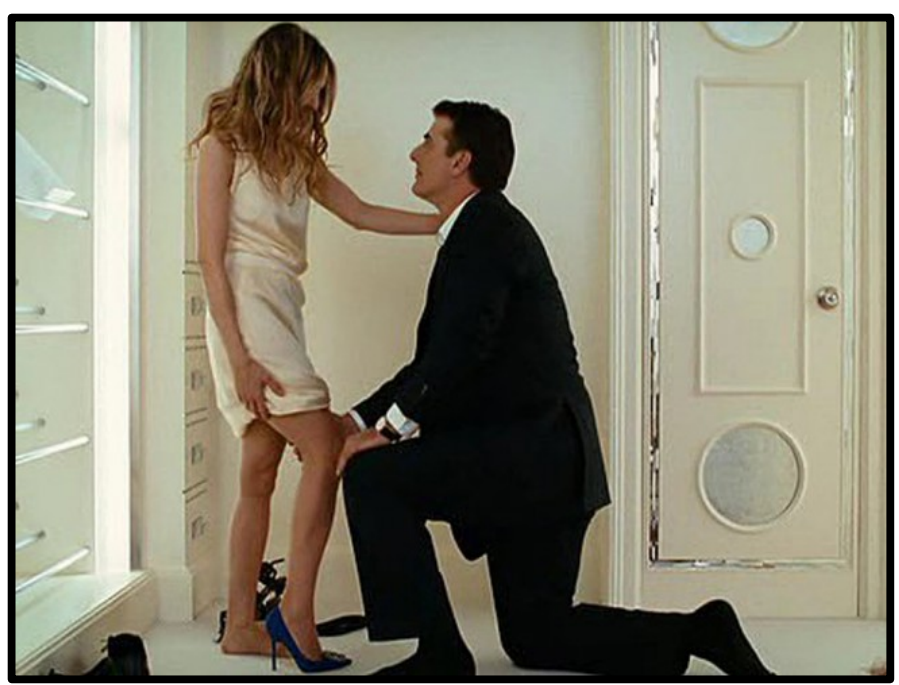

Figure 29. Sarah Jessica Parker as Carrie Bradshaw gets engaged to Mr.Big in film Sex and the City (2008). 


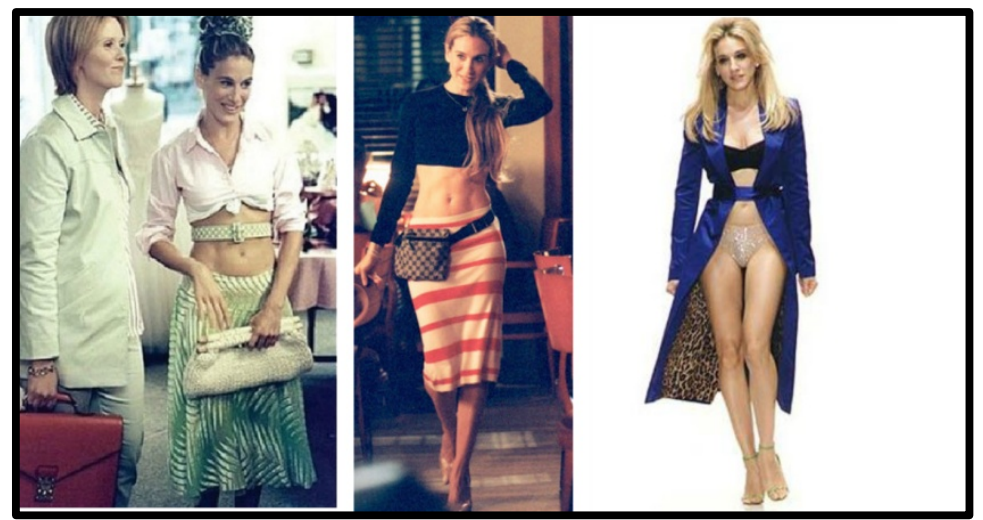

Figure 30. Sarah Jessica Parker as Carrie Bradshaw in Sex and the City (1998-2004).

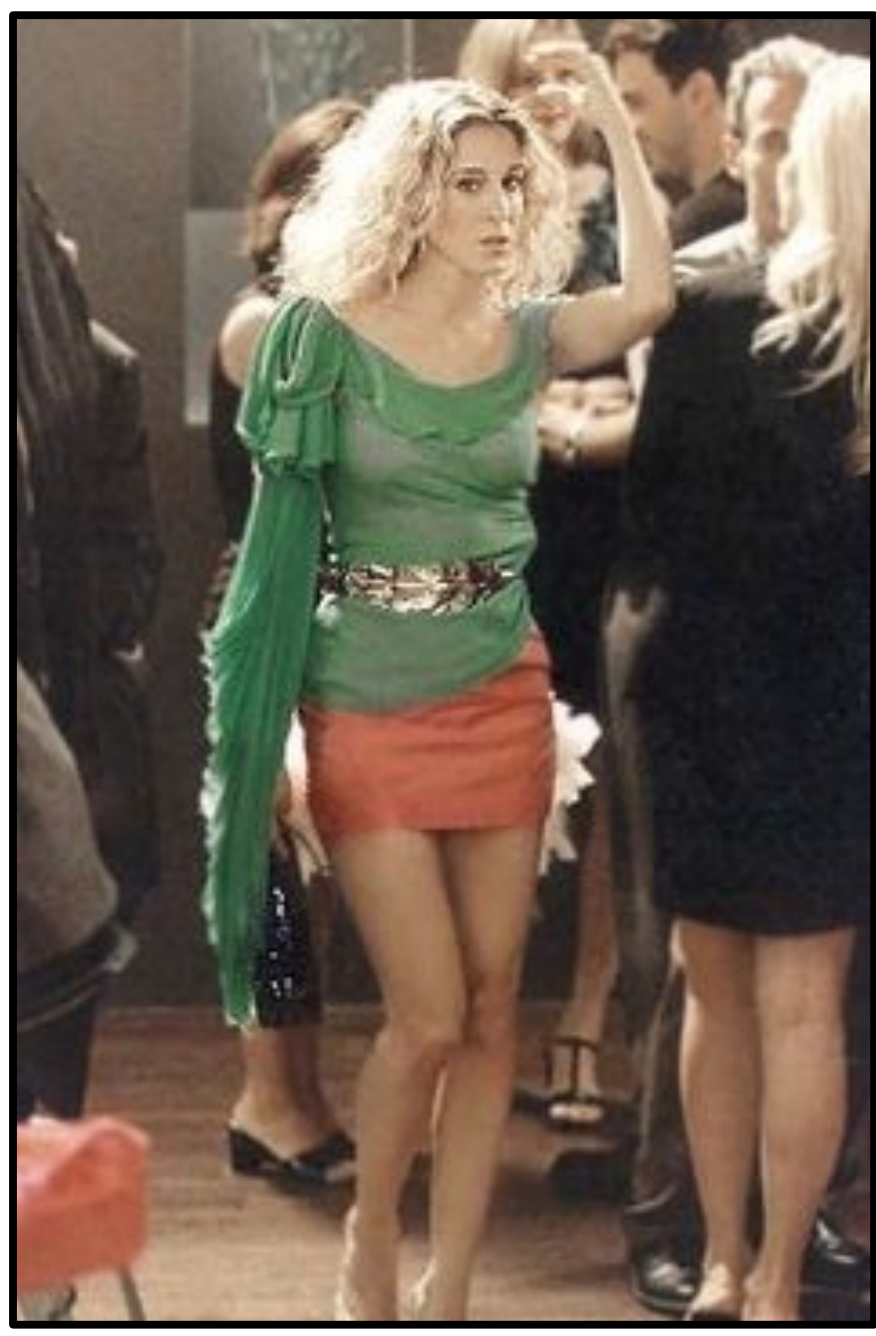

Figure 31. Sarah Jessica Parker as Carrie Bradshaw in Sex and the City (1998-2004). 


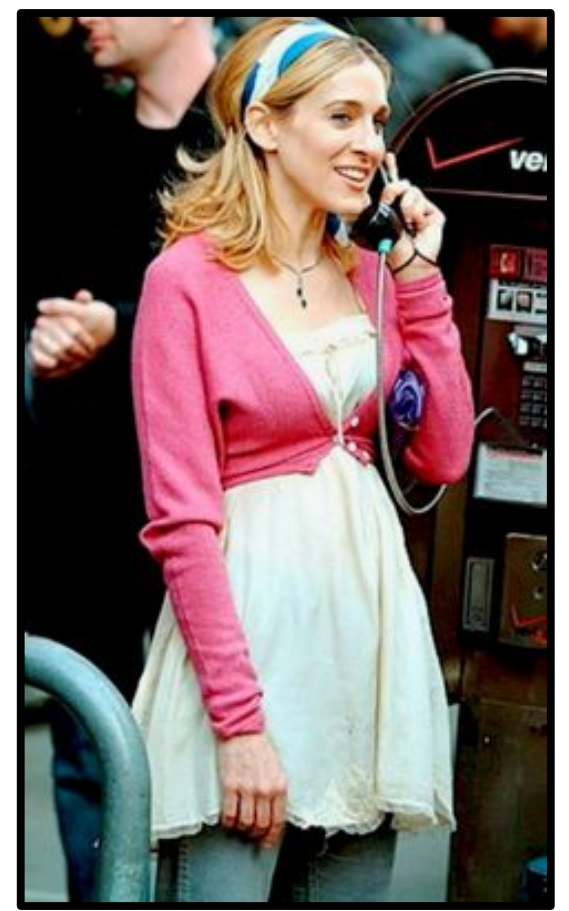

Figure 32. Sarah Jessica Parker as Carrie Bradshaw in Sex and the City (1998-2004).

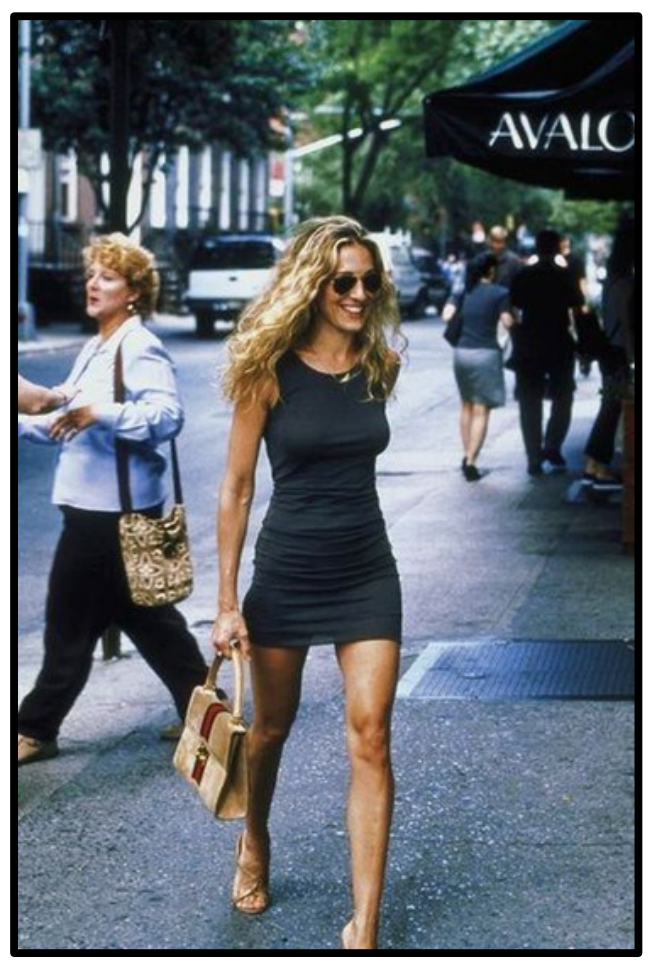

Figure 33. Sarah Jessica Parker as Carrie Bradshaw in Sex and the City (1998-2004). 


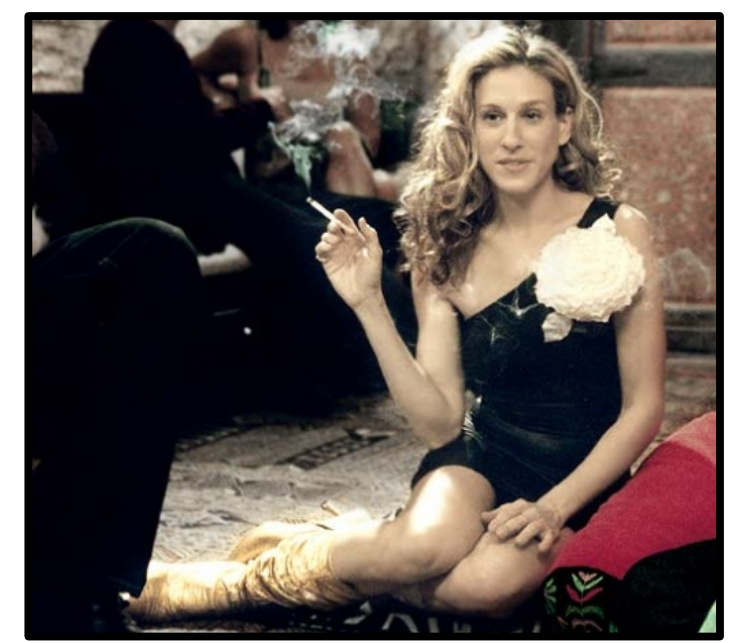

Figure 34. Sarah Jessica Parker as Carrie Bradshaw in Sex and the City (1998-2004).

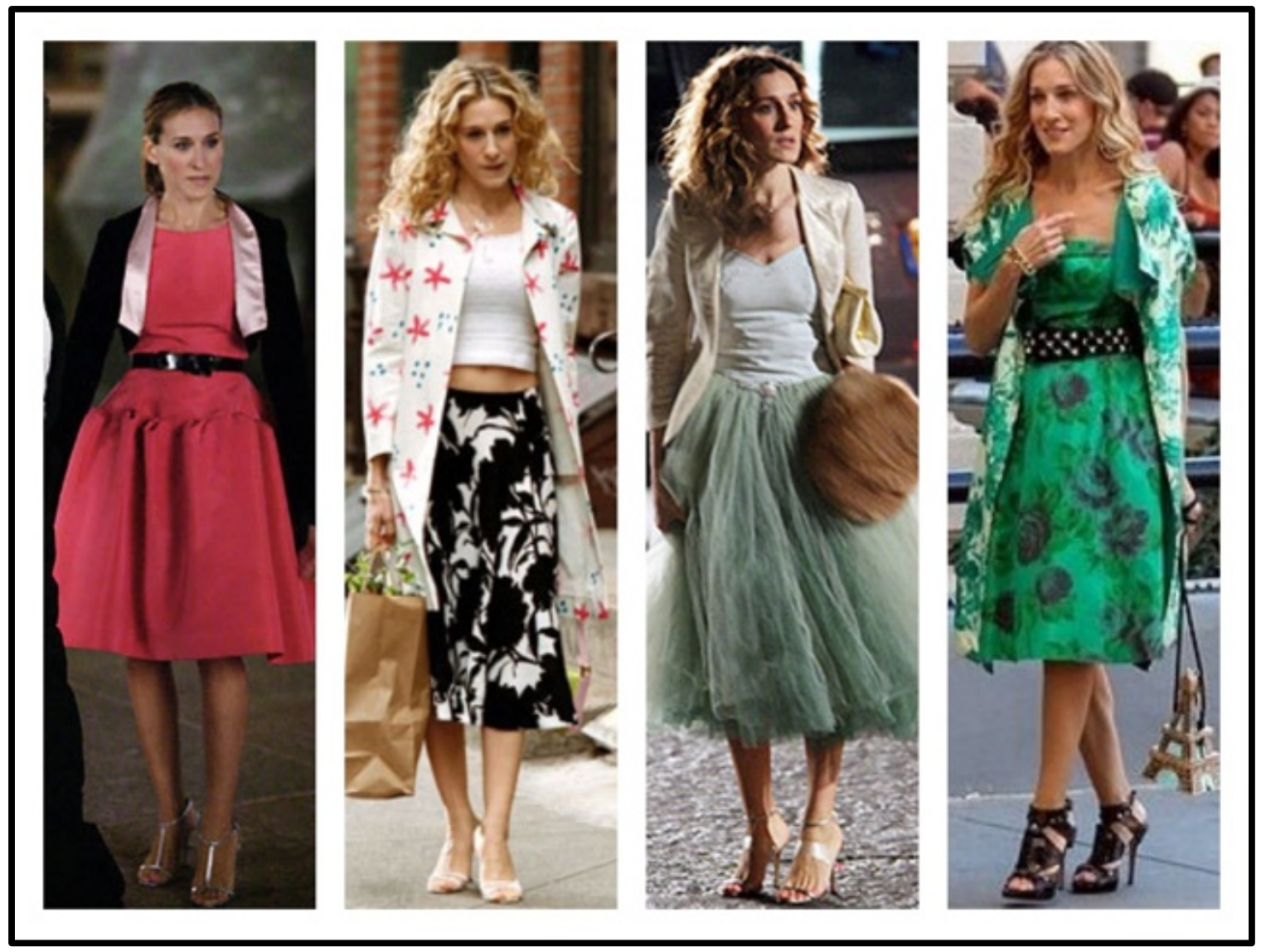

Figure 35. Sarah Jessica Parker as Carrie Bradshaw in Sex and the City (1998-2004). 


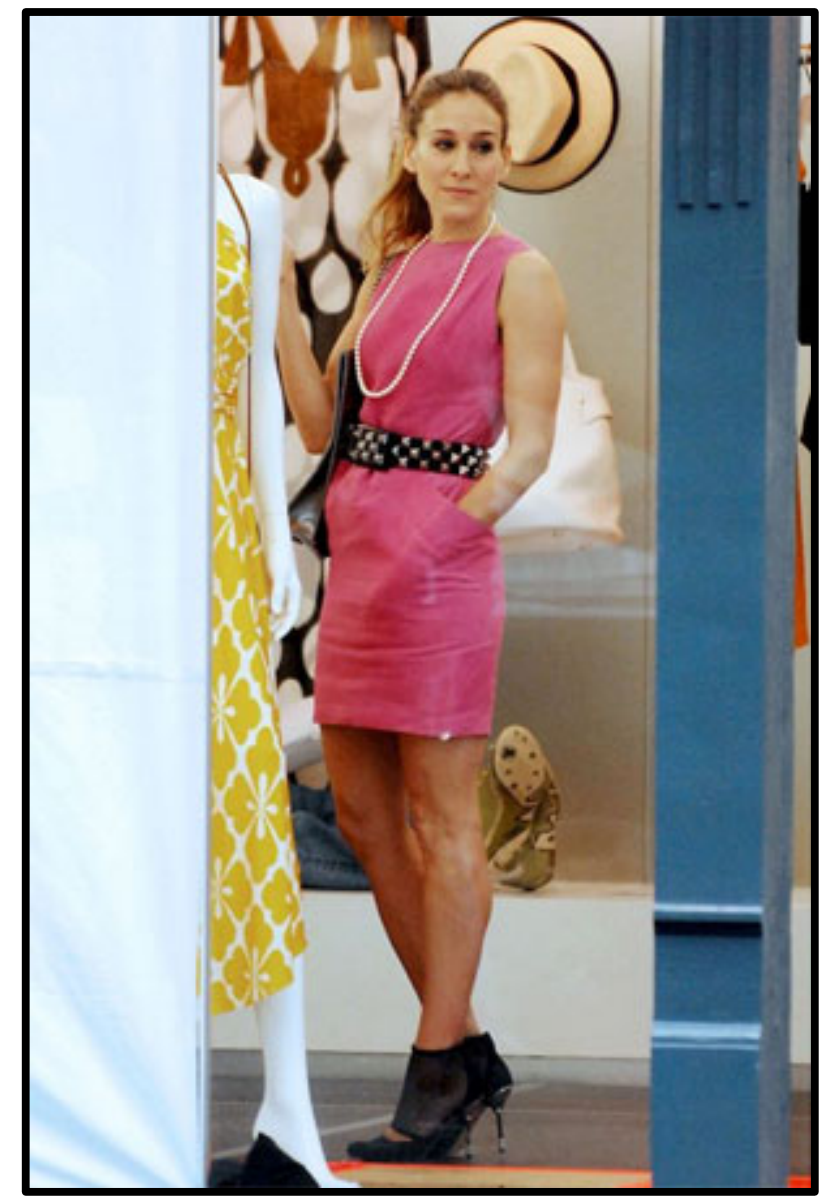

Figure 36. Sarah Jessica Parker as Carrie Bradshaw in Sex and the City (1998-2004).

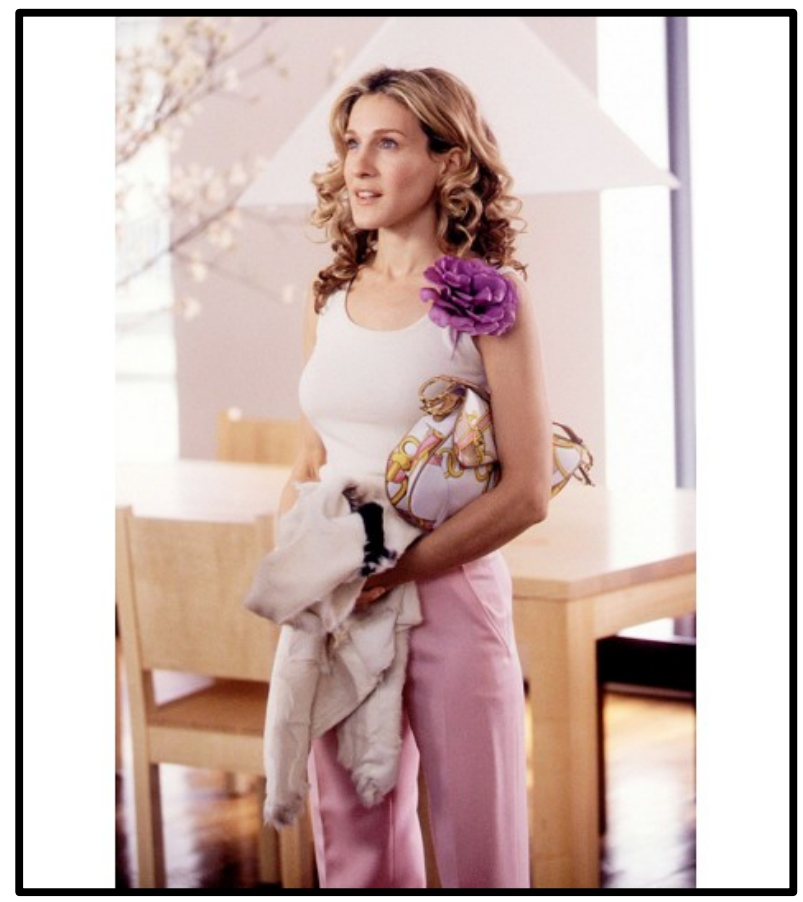

Figure 37. Sarah Jessica Parker as Carrie Bradshaw in Sex and the City (1998-2004). 


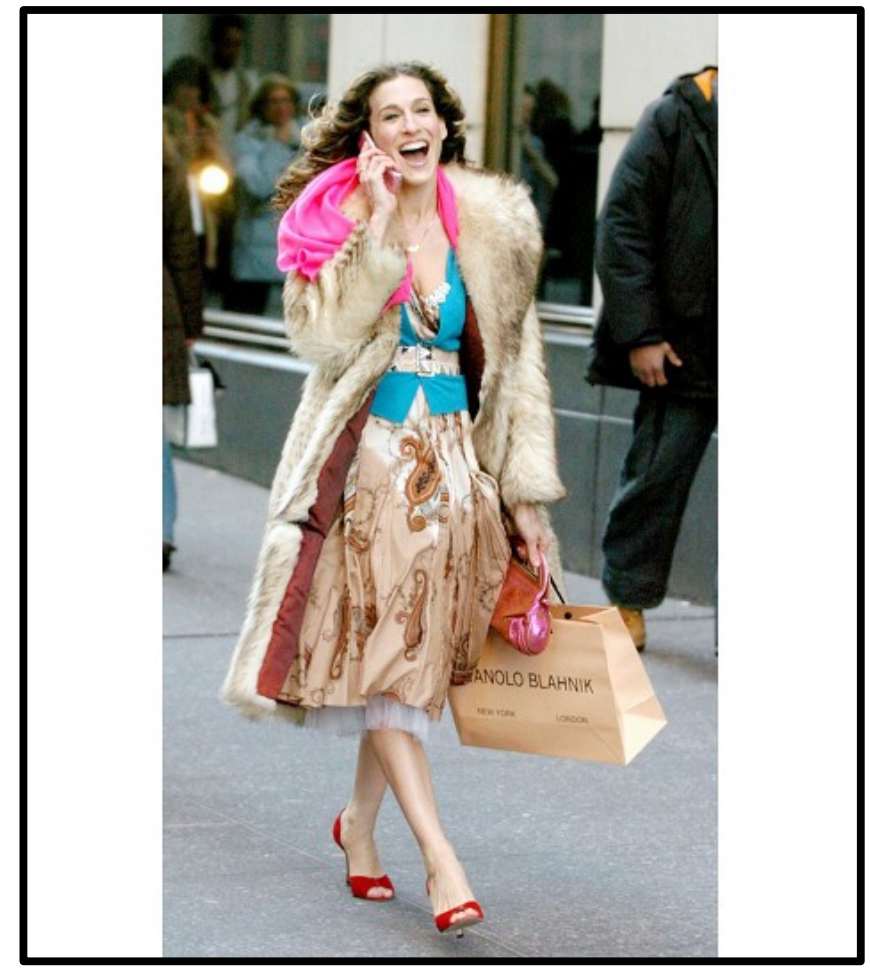

Figure 38. Sarah Jessica Parker as Carrie Bradshaw in Sex and the City (1998-2004).

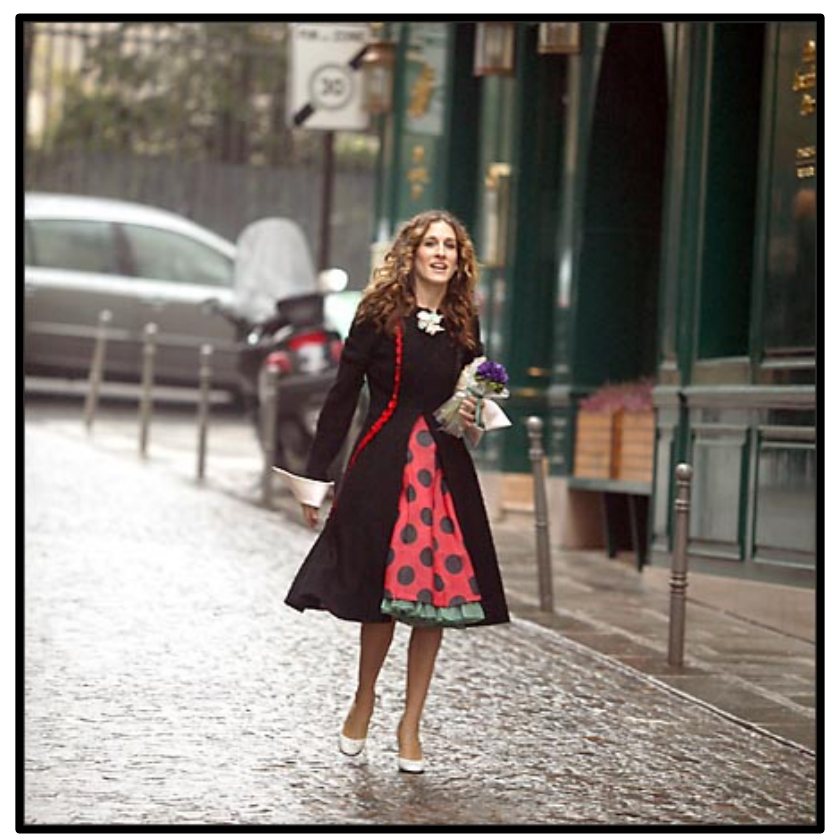

Figure 39. Sarah Jessica Parker as Carrie Bradshaw in Sex and the City (1998-2004). 


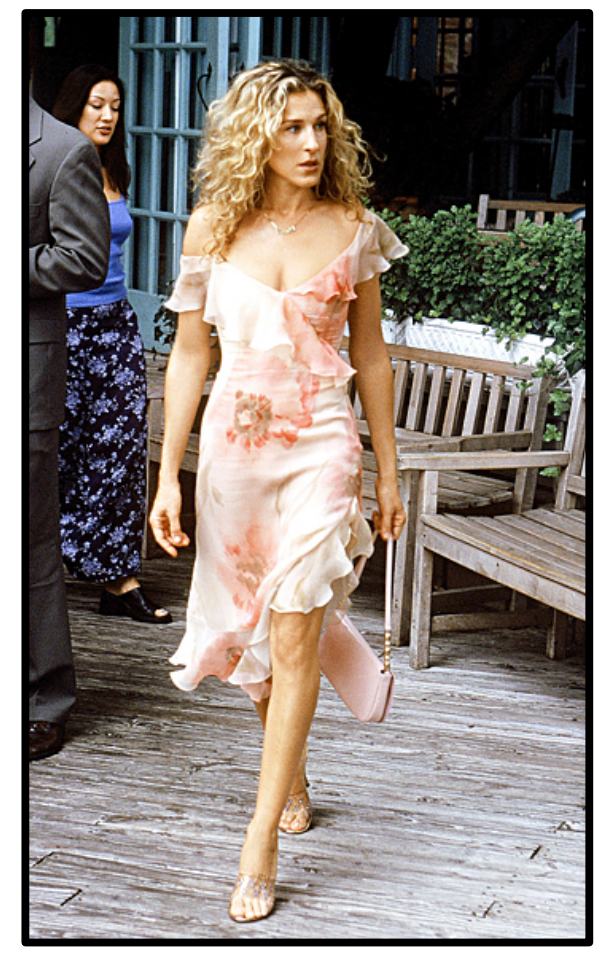

Figure 40. Sarah Jessica Parker as Carrie Bradshaw in Sex and the City (1998-2004).

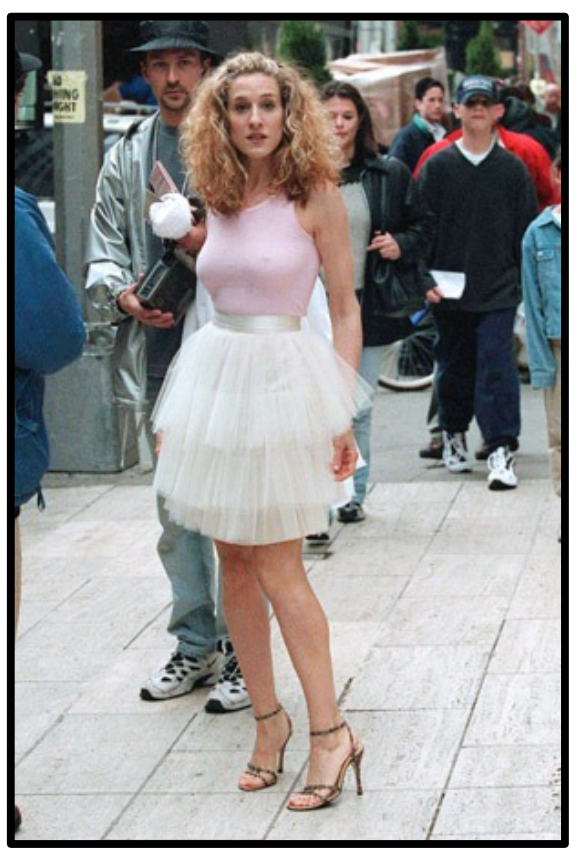

Figure 41. Sarah Jessica Parker as Carrie Bradshaw in Sex and the City (1998-2004). 


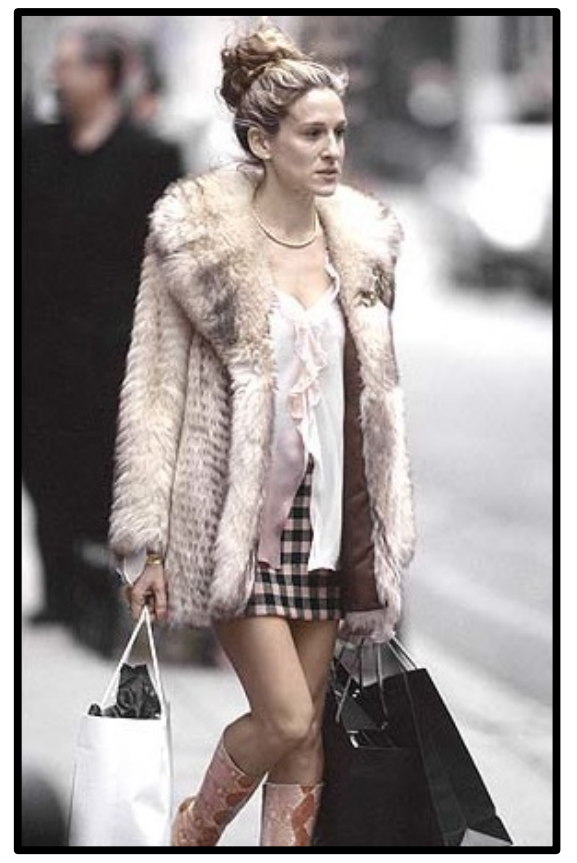

Figure 42. Sarah Jessica Parker as Carrie Bradshaw in Sex and the City (1998-2004).

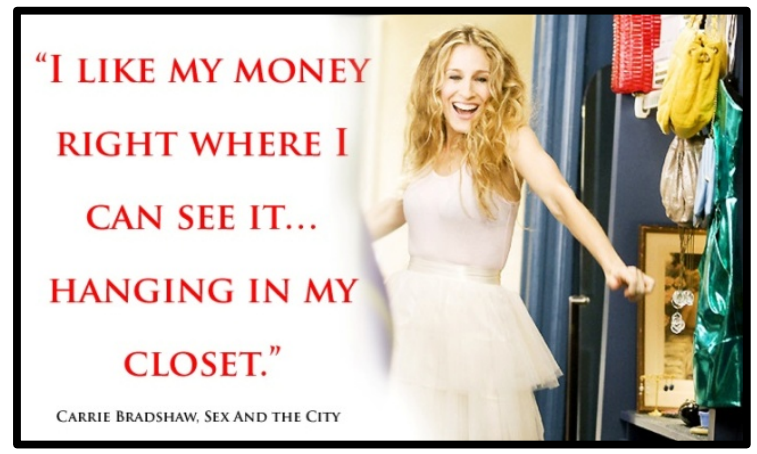

Figure 43. Quote by Carrie Bradshaw regarding her investments. Season 6 Episode 1.

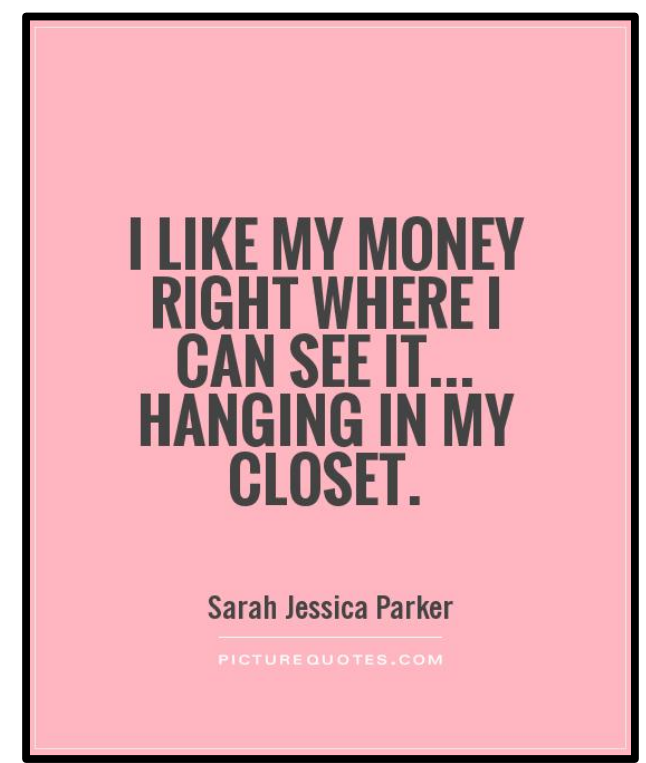

Figure 44. Poster with a quote by Carrie Bradshaw regarding her investments. Season 6 Episode 1. Labeled authorship of Sarah Jessica Parker. 


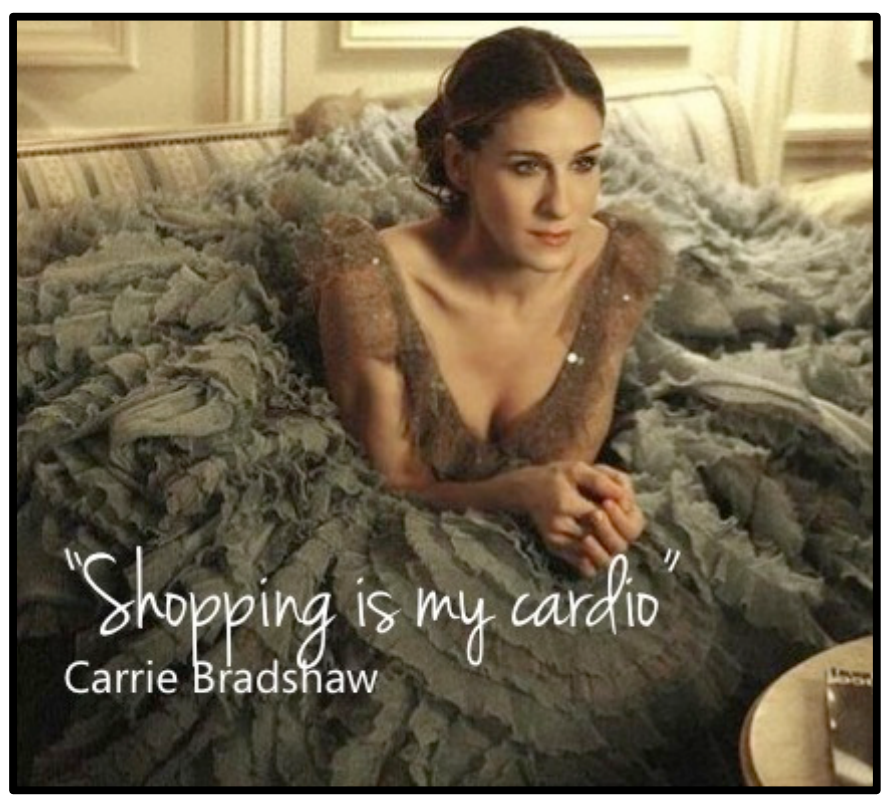

Figure 45. Quote by Carrie Bradshaw regarding shopping on TV-show Sex and the City (1998-2004).

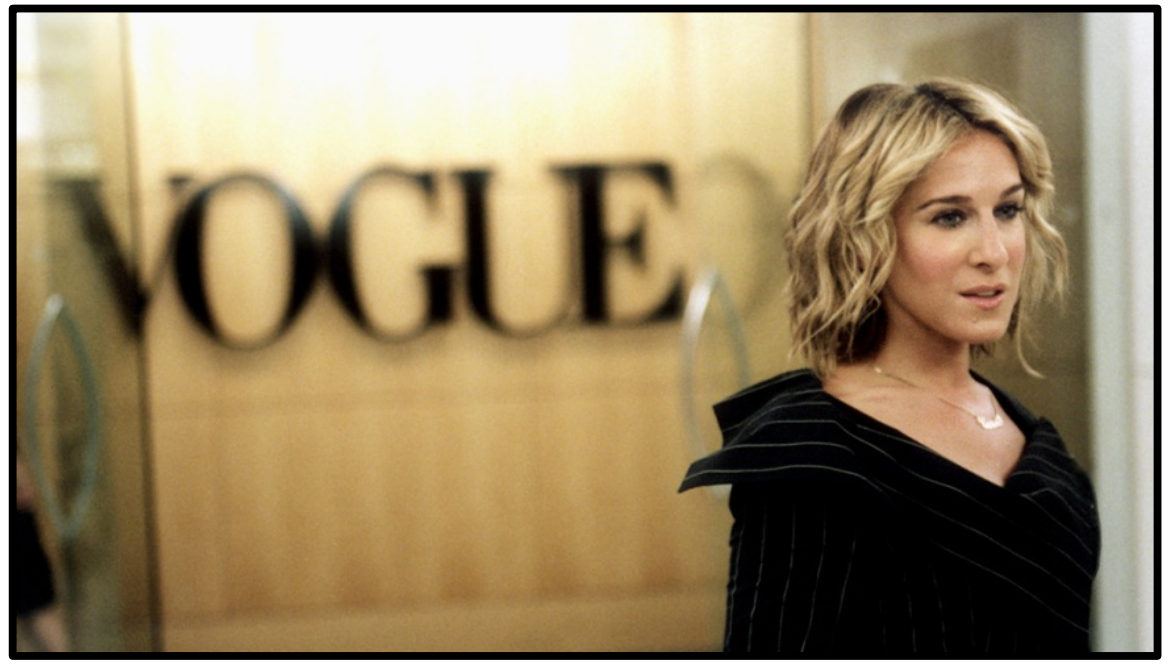

Figure 46. Sarah Jessica Parker as Carrie Bradshaw in Sex and the City (1998-2004). A Vogue Idea. 


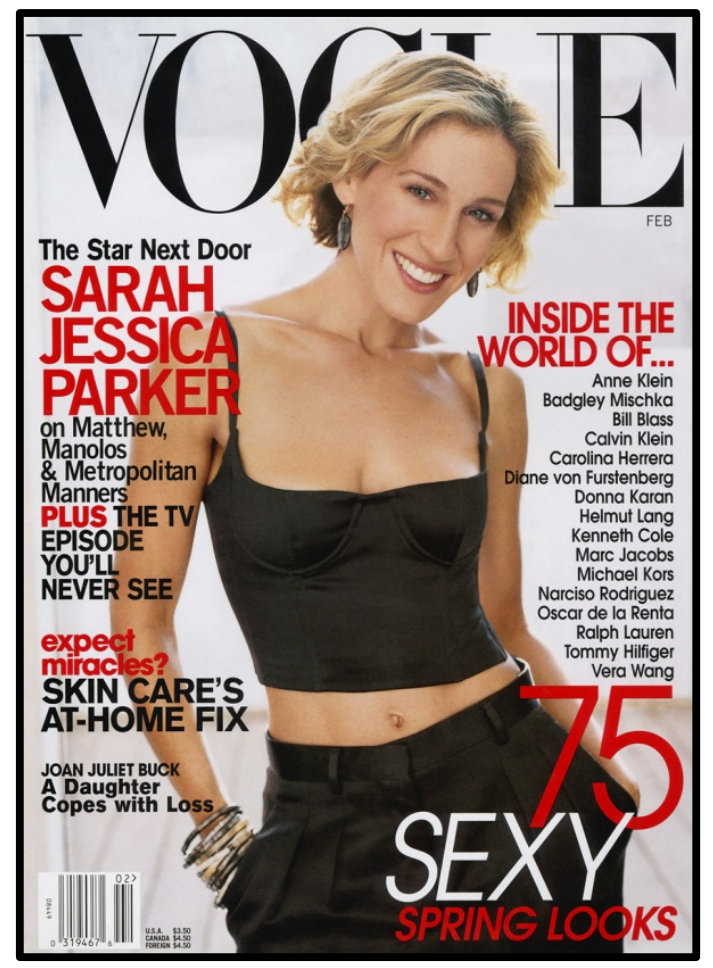

Figure 47. Sarah Jessica Parker on the cover of Vogue (US), February 2002.

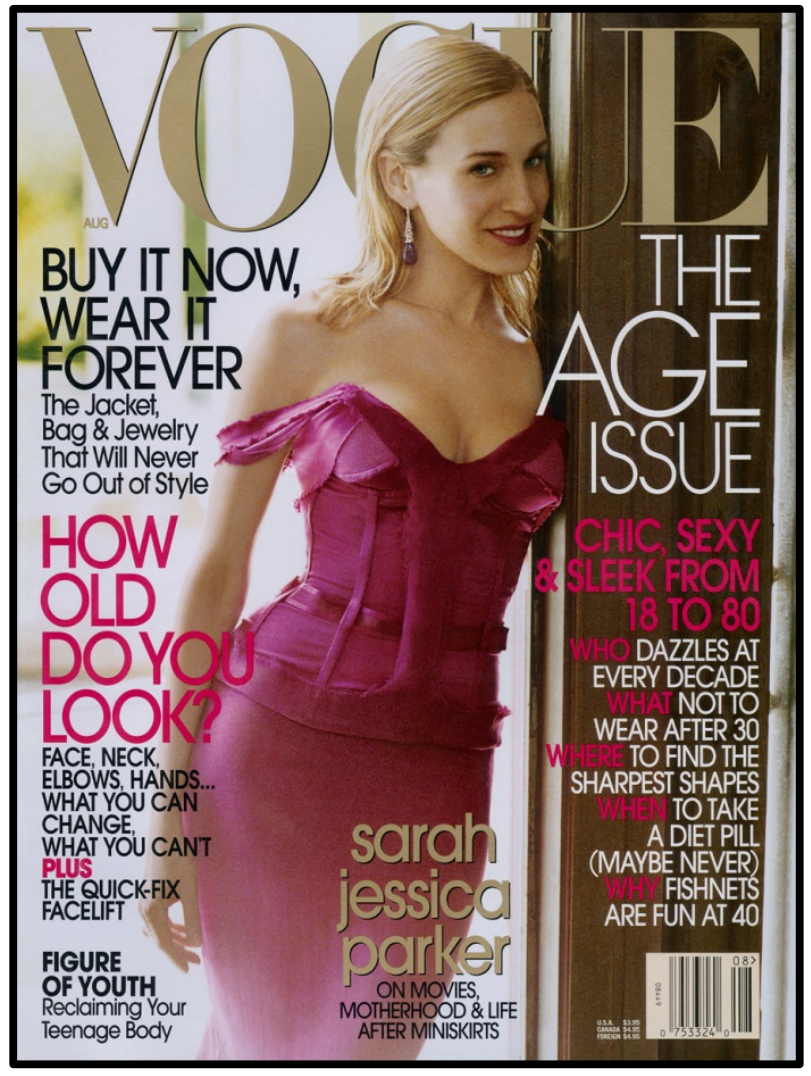

Figure 48. Sarah Jessica Parker on the cover of Vogue (US), August 2003. 


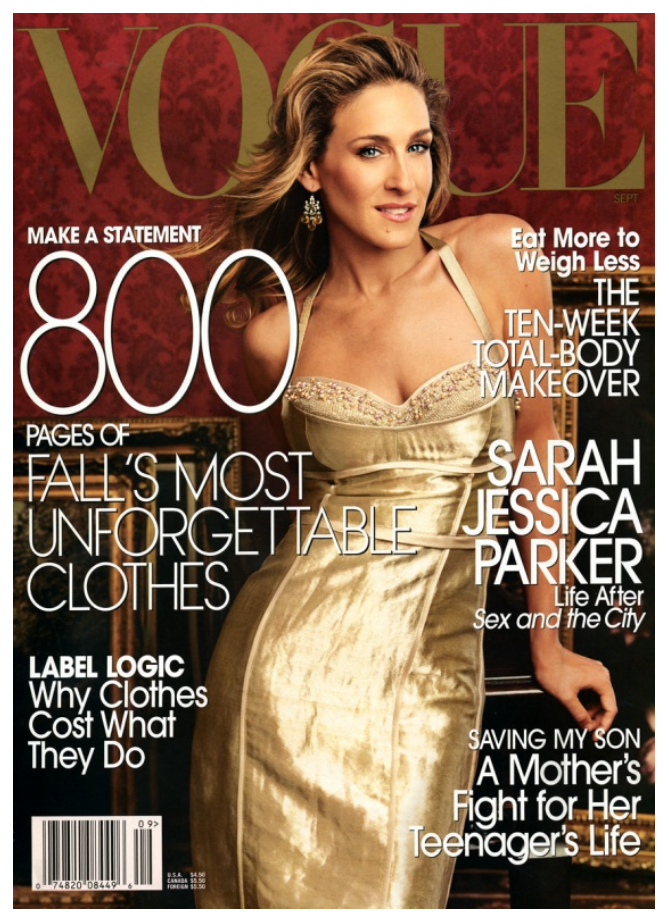

Figure 49. Sarah Jessica Parker on the cover of Vogue (US), September 2005.

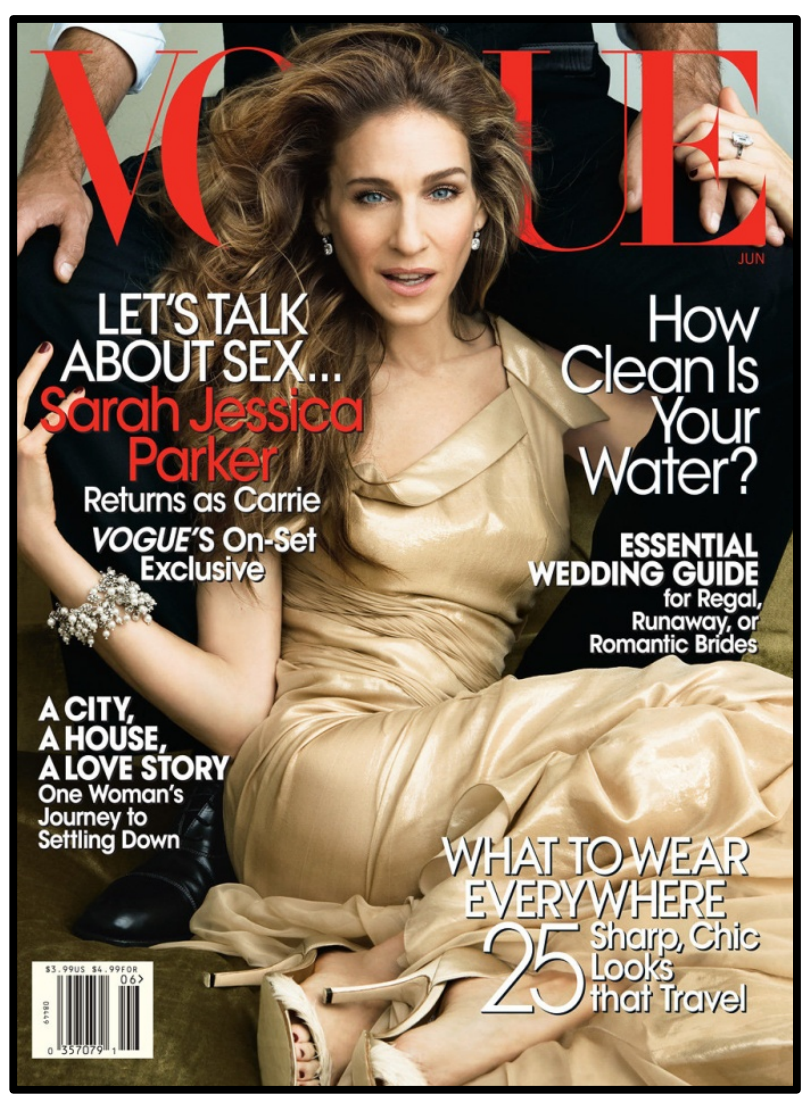

Figure 50. Sarah Jessica Parker on the cover of Vogue (US), June 2008. 


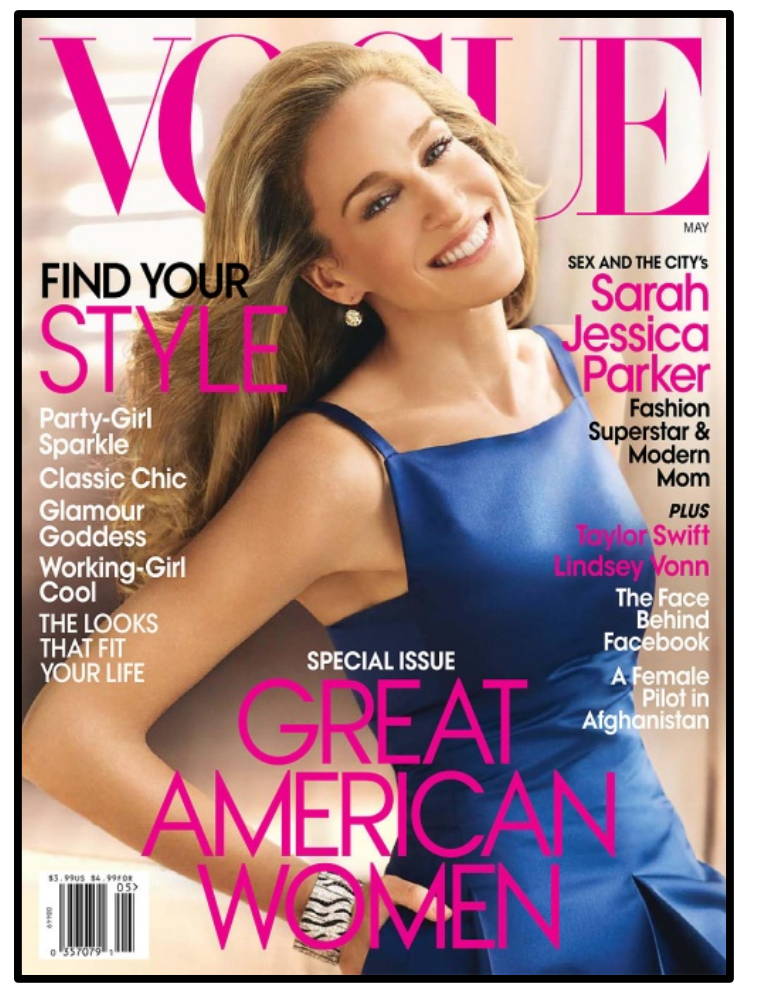

Figure 51. Sarah Jessica Parker on the cover of Vogue (US), May 2010.

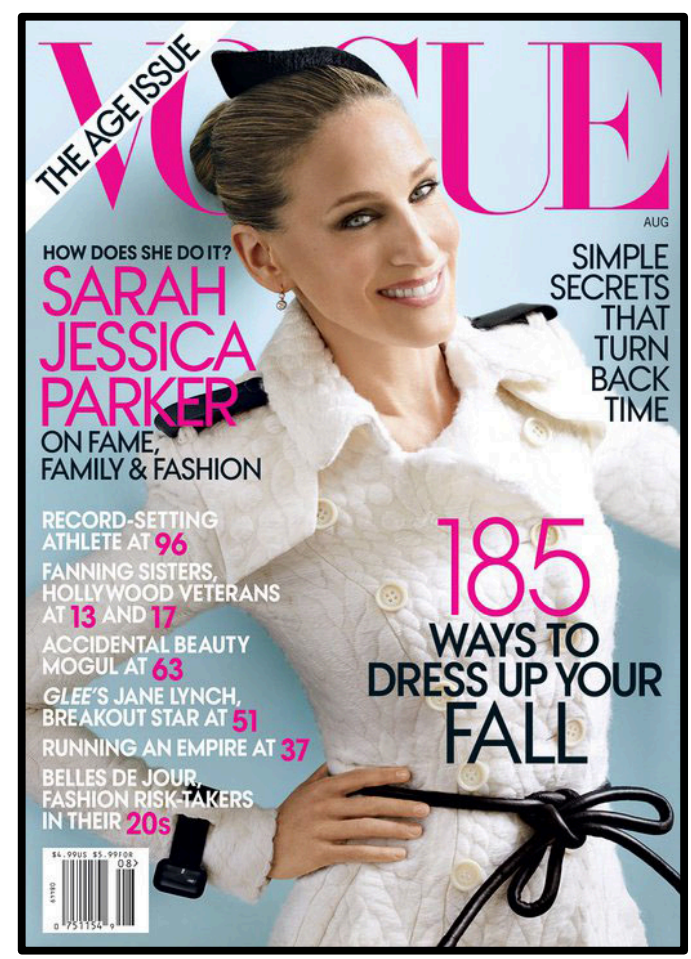

Figure 52. Sarah Jessica Parker on the cover of Vogue (US), August 2011. 


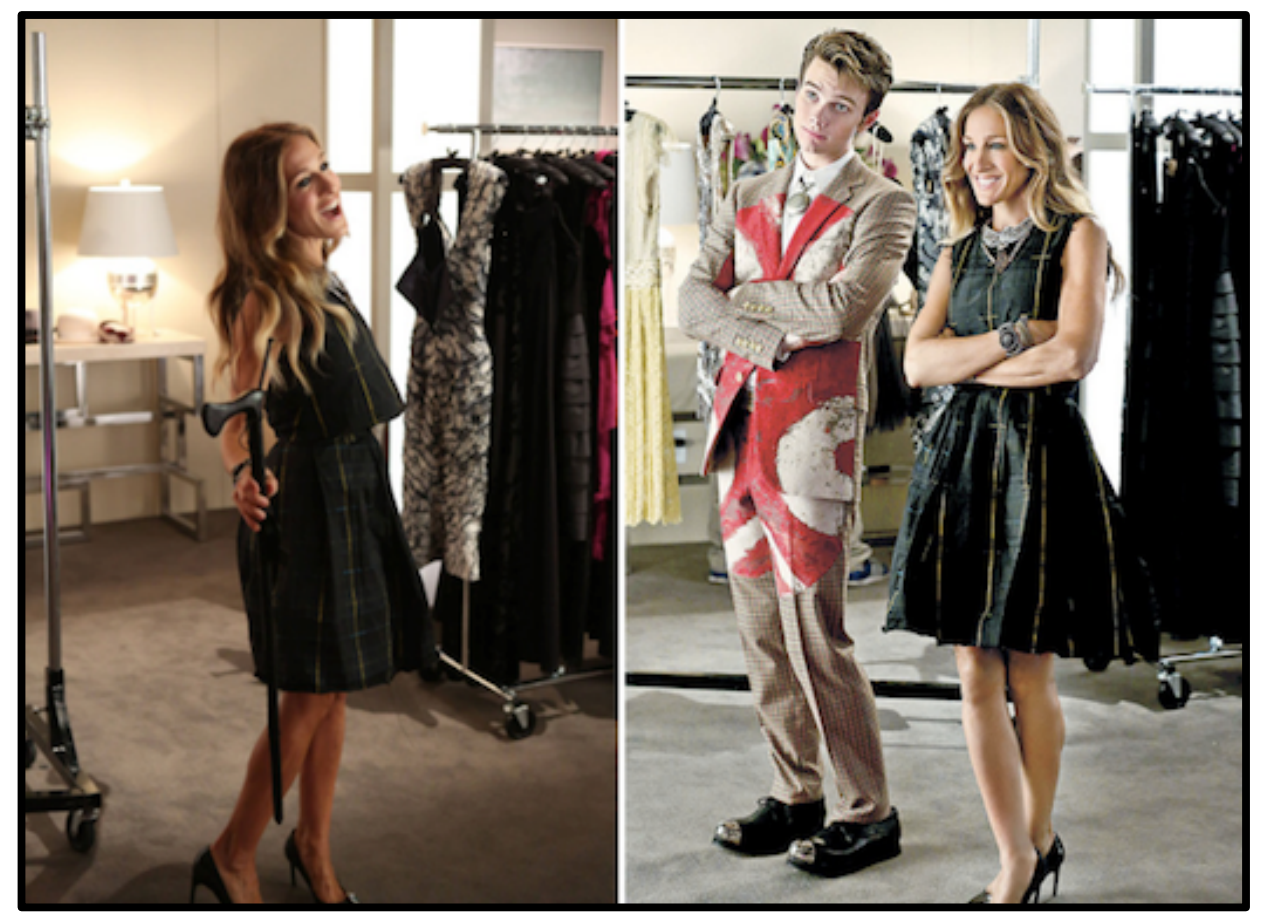

Figure 53. Sarah Jessica Parker stars in TV-show Glee (2012-2013) as an editor-in-chief of online Vogue.

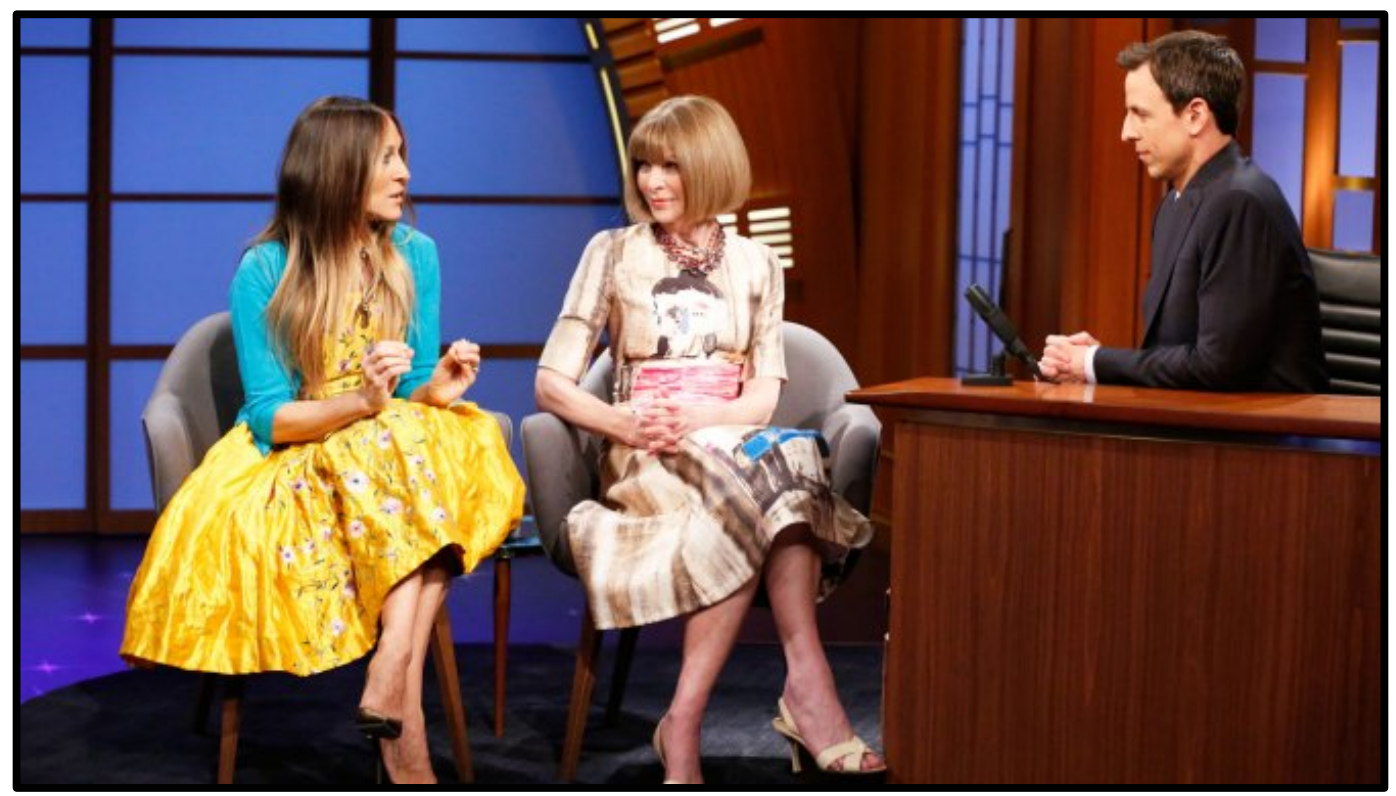

Figure 54. Sarah Jessica Parker with Anna Wintour on "Late Night With Seth Meyers" (2014). 


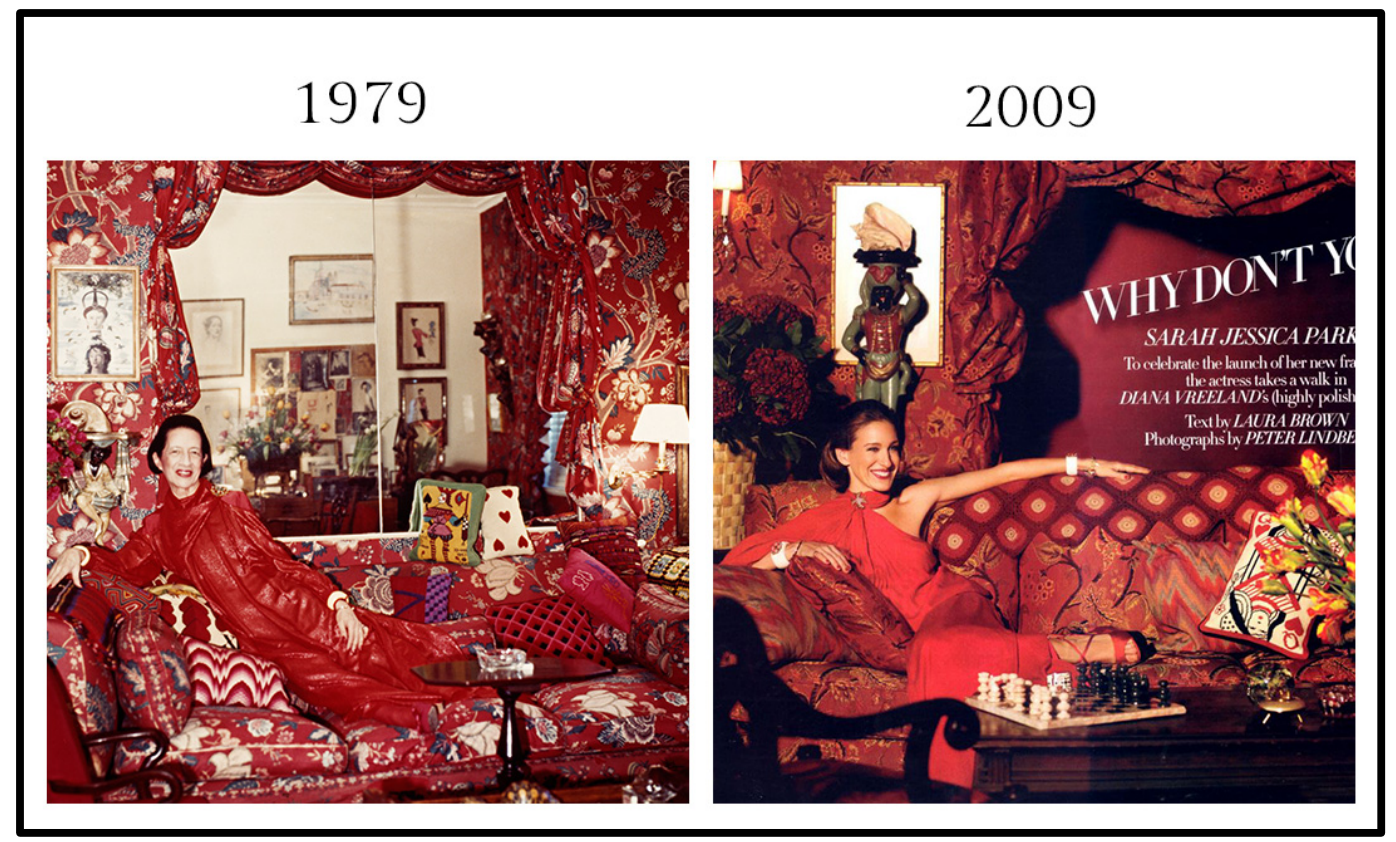

Figure 55. Sarah Jessica Parker pays homage to Diana Vreeland in Harper's Bazaar (March 2009).

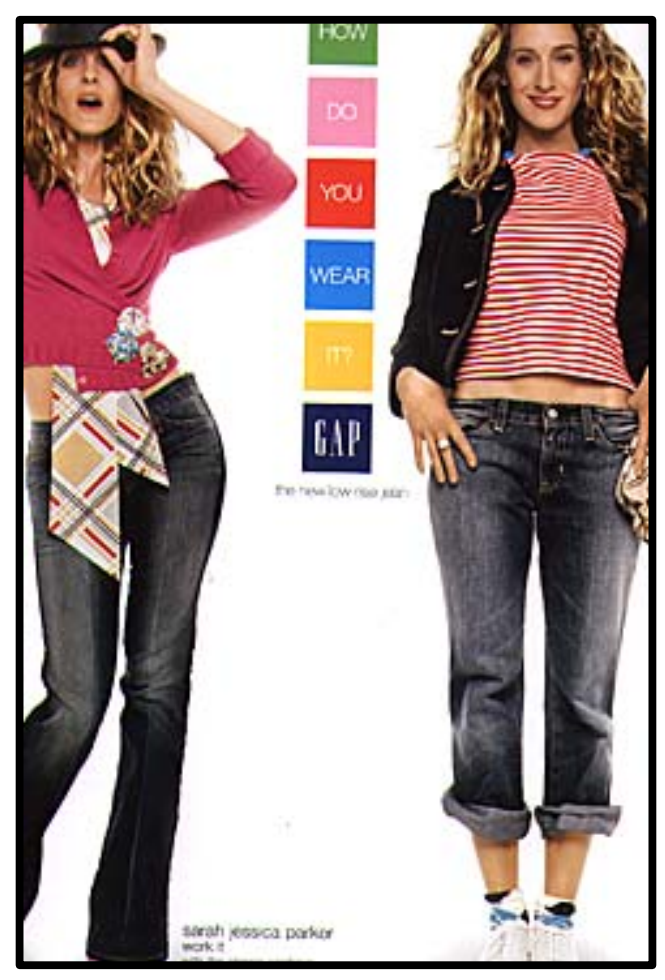

Figure 56. Sarah Jessica Parker in advertisement for Gap (2004). 


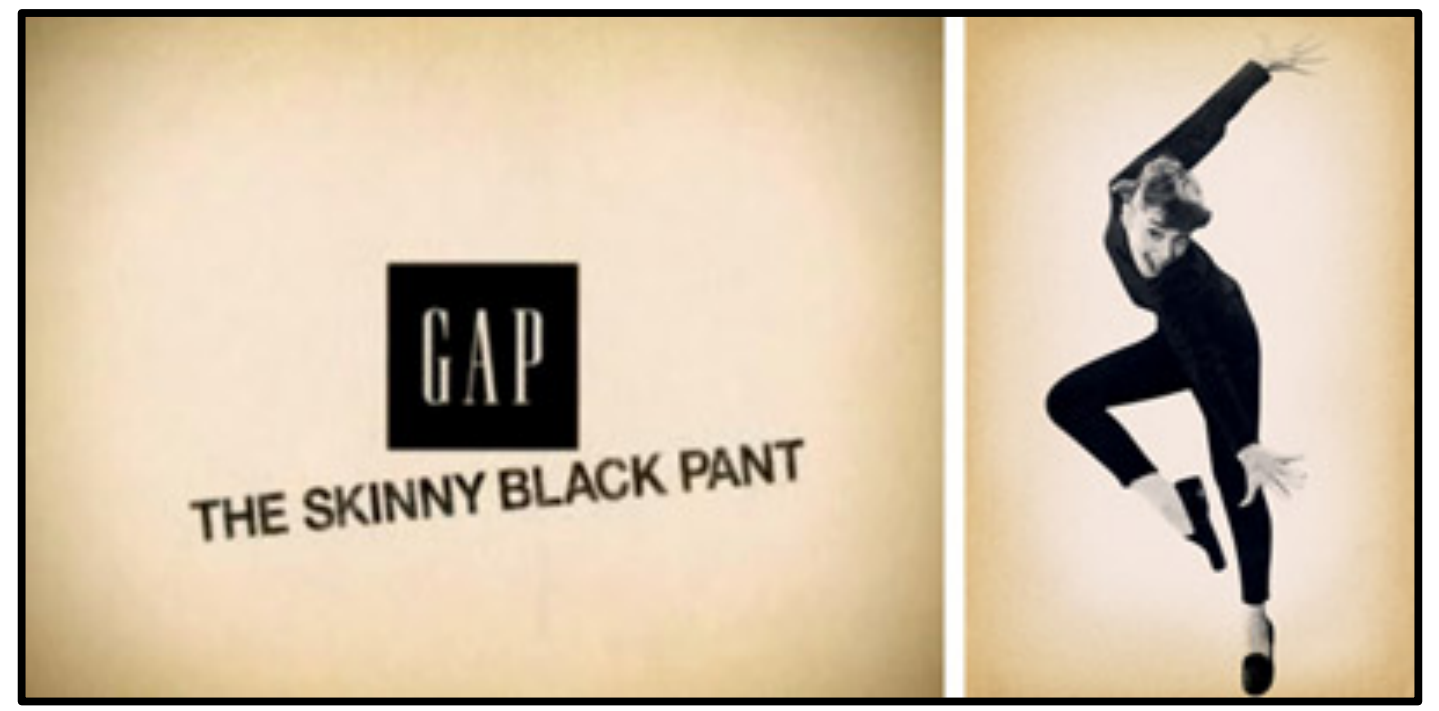

Figure 57. Image of Audrey Hepburn from Funny Face (1957) used in Gap ad campaign (2006).

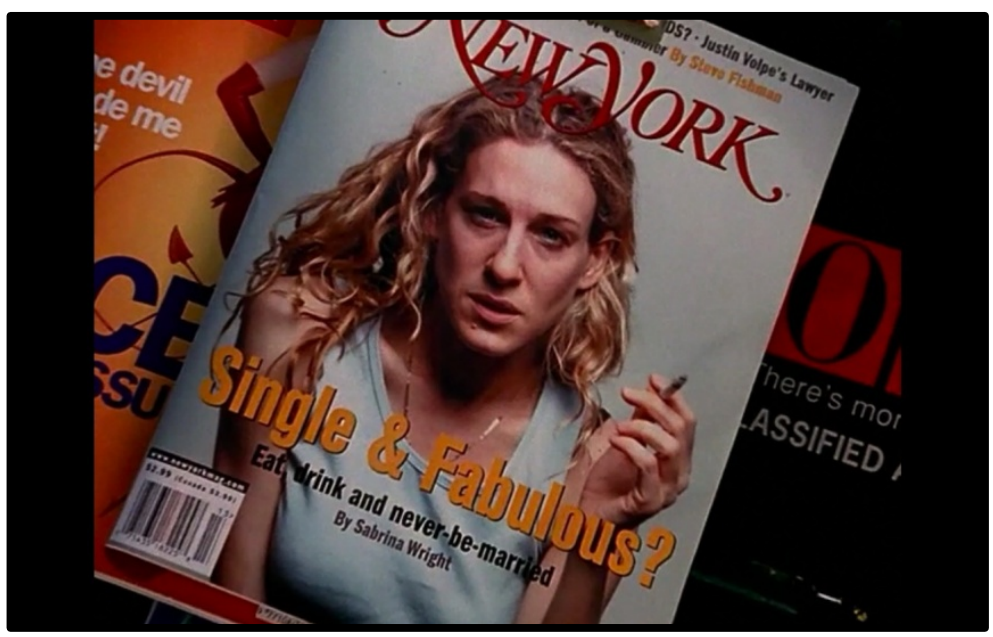

Figure 58. Unflattering photo of Sarah Jessica Parker as Carrie Bradshaw in Sex in the City (1998-2004), They Shoot Single People Don't They?

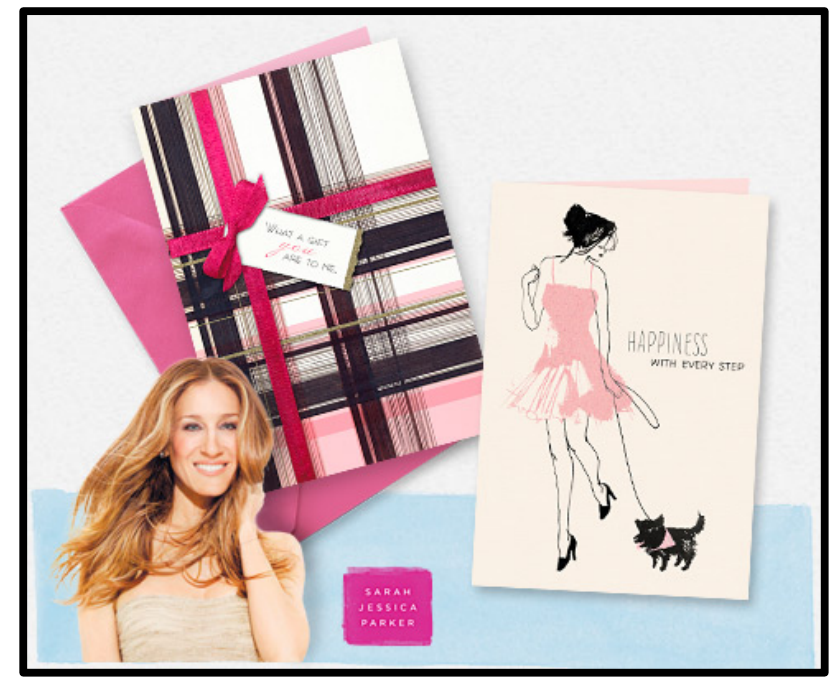

Figure 59. Sarah Jessica Parker's collaborated with Hallmark. 


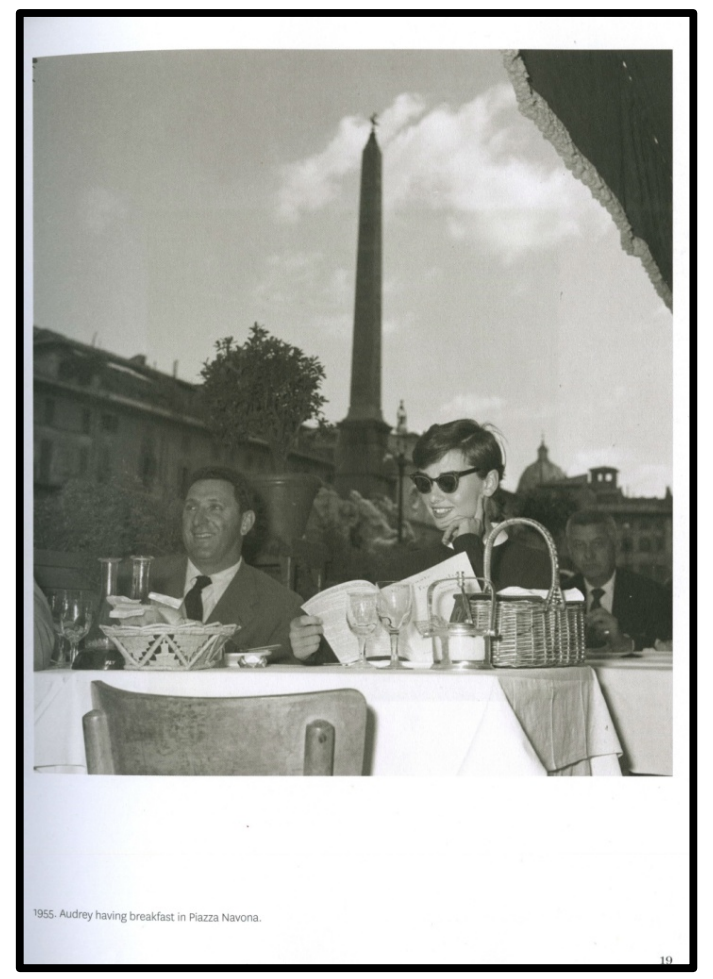

Figure 60. Audrey Hepburn in Rome. Image from “Audrey in Rome" (Luca Dotti).

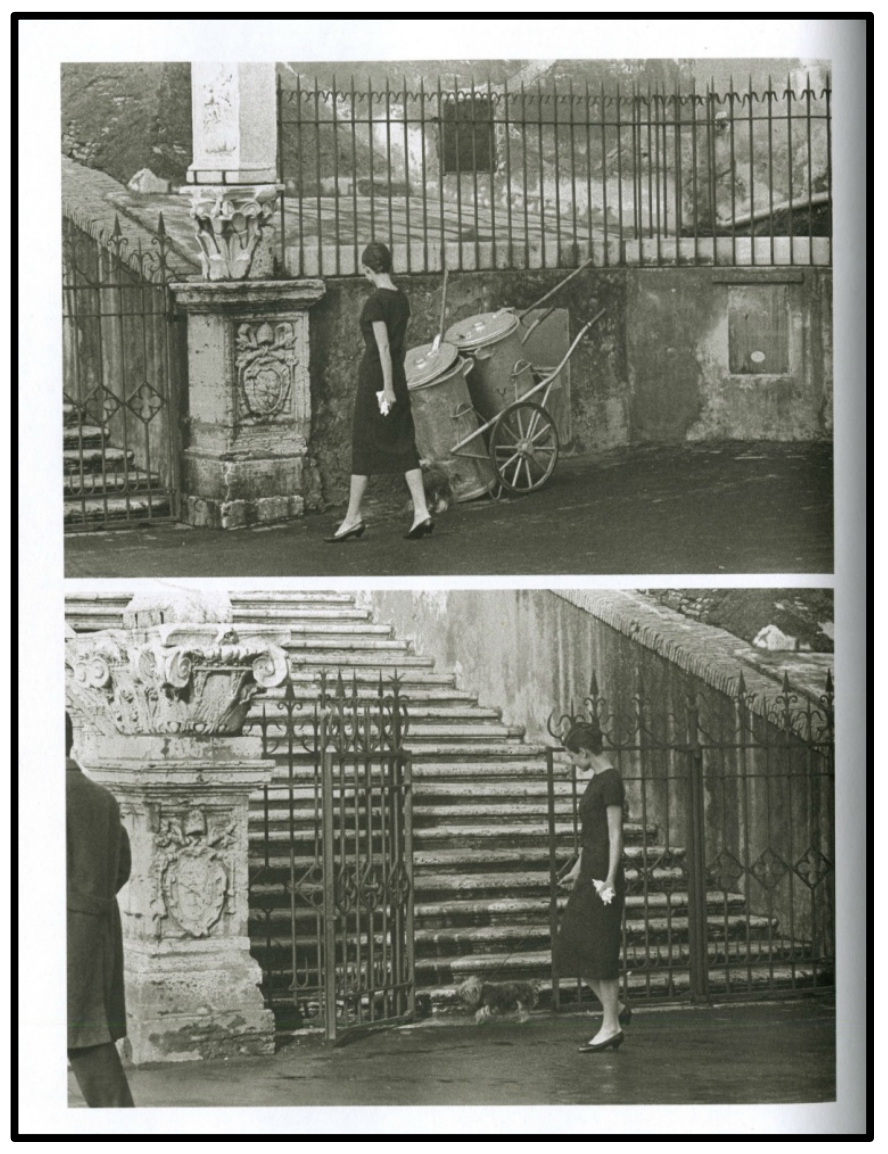

Figure 61. Audrey Hepburn in Rome. Image from "Audrey in Rome” (Luca Dotti). 


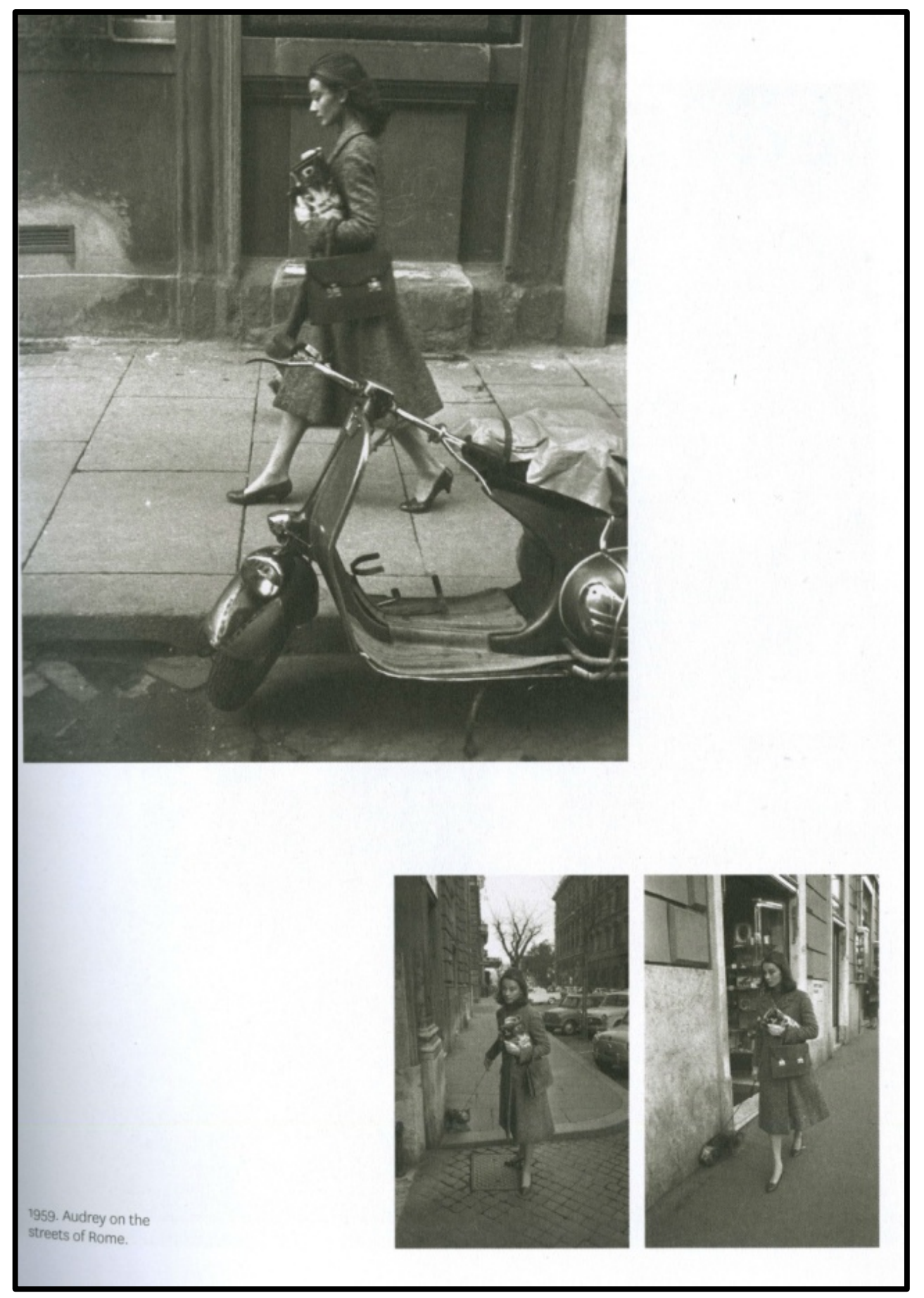

Figure 62. Audrey Hepburn in Rome. Image from "Audrey in Rome" (Luca Dotti). 


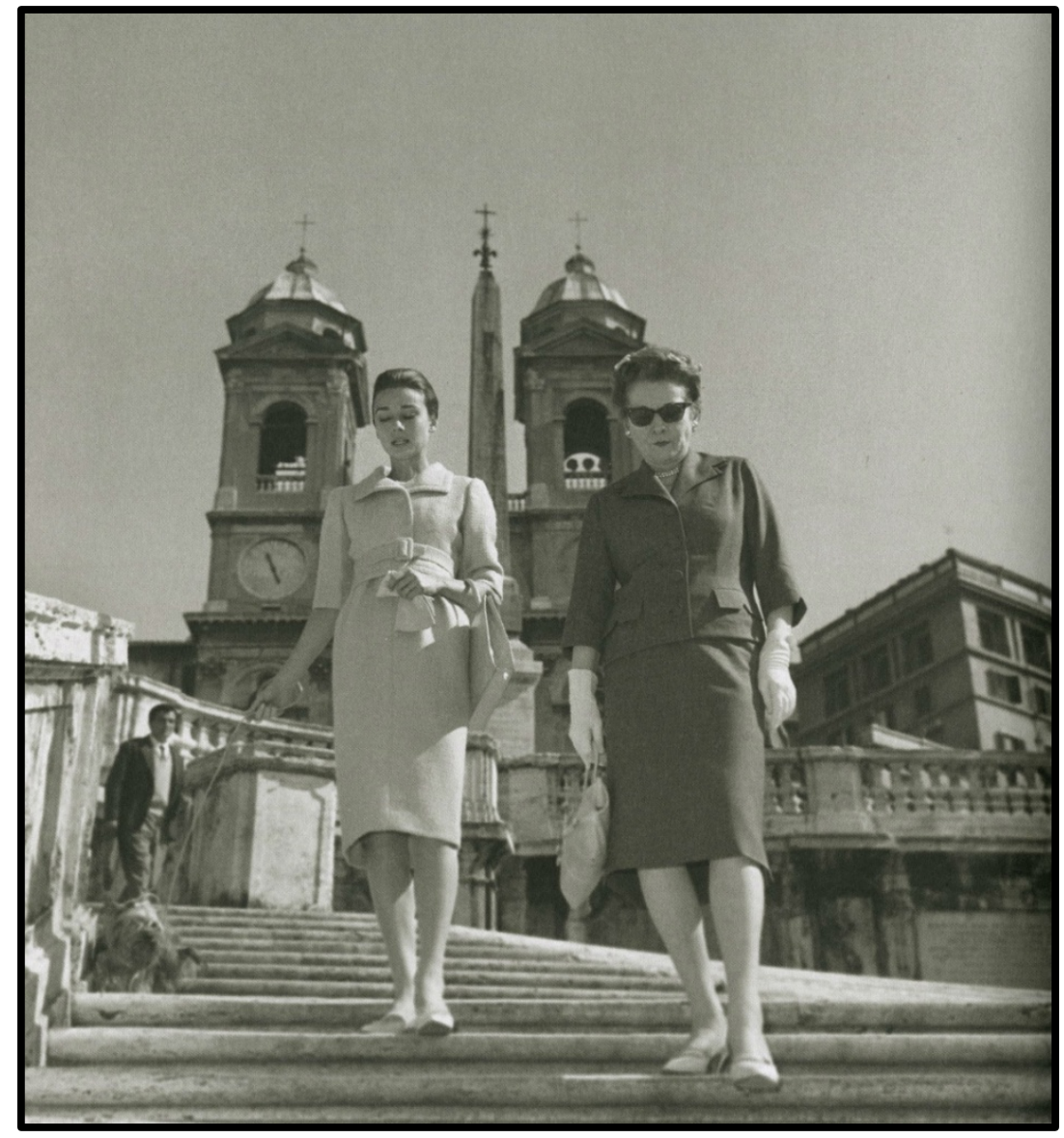

Figure 63. Audrey Hepburn and her mother in Rome. Image from "Audrey in Rome" (Luca Dotti).

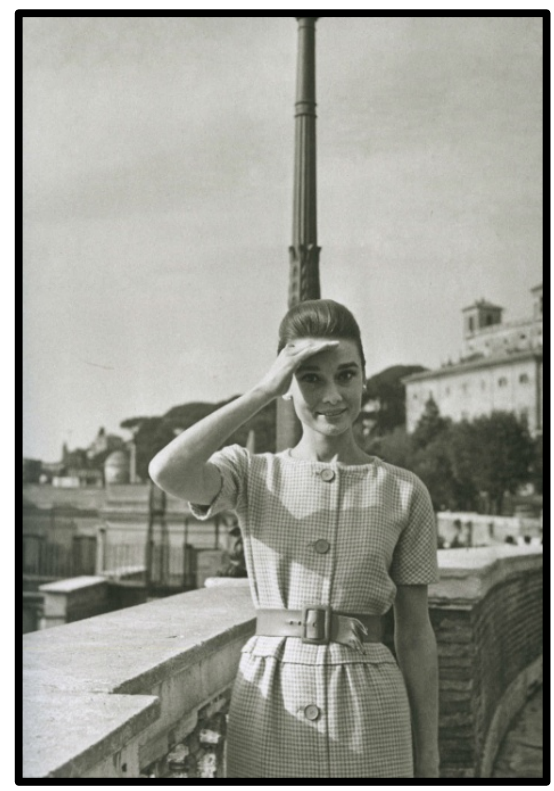

Figure 64. Audrey Hepburn in Rome. Image from "Audrey in Rome" (Luca Dotti). 


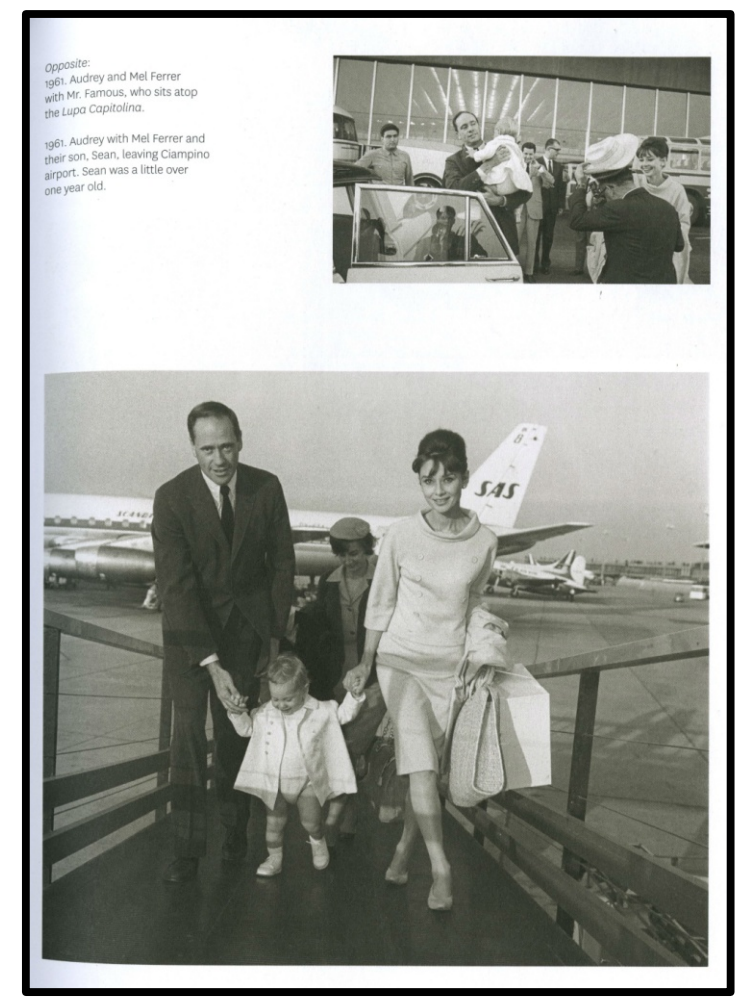

Figure 65. Audrey Hepburn and her husband, Mel Ferrer, in Rome. Image from “Audrey in Rome” (Luca Dotti).

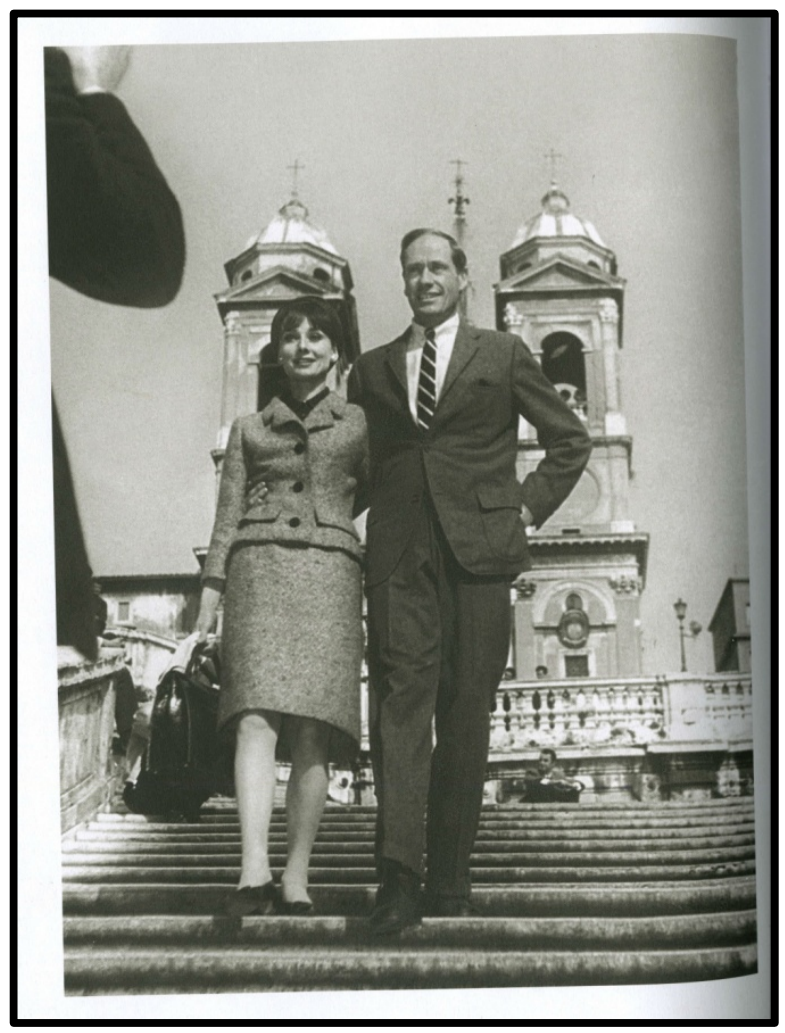

Figure 66. Audrey Hepburn and her husband, Mel Ferrer, in Rome on Spanish Steps, looking as a scene from a film Roman Holiday (1953). Image from "Audrey in Rome" (Luca Dotti). 


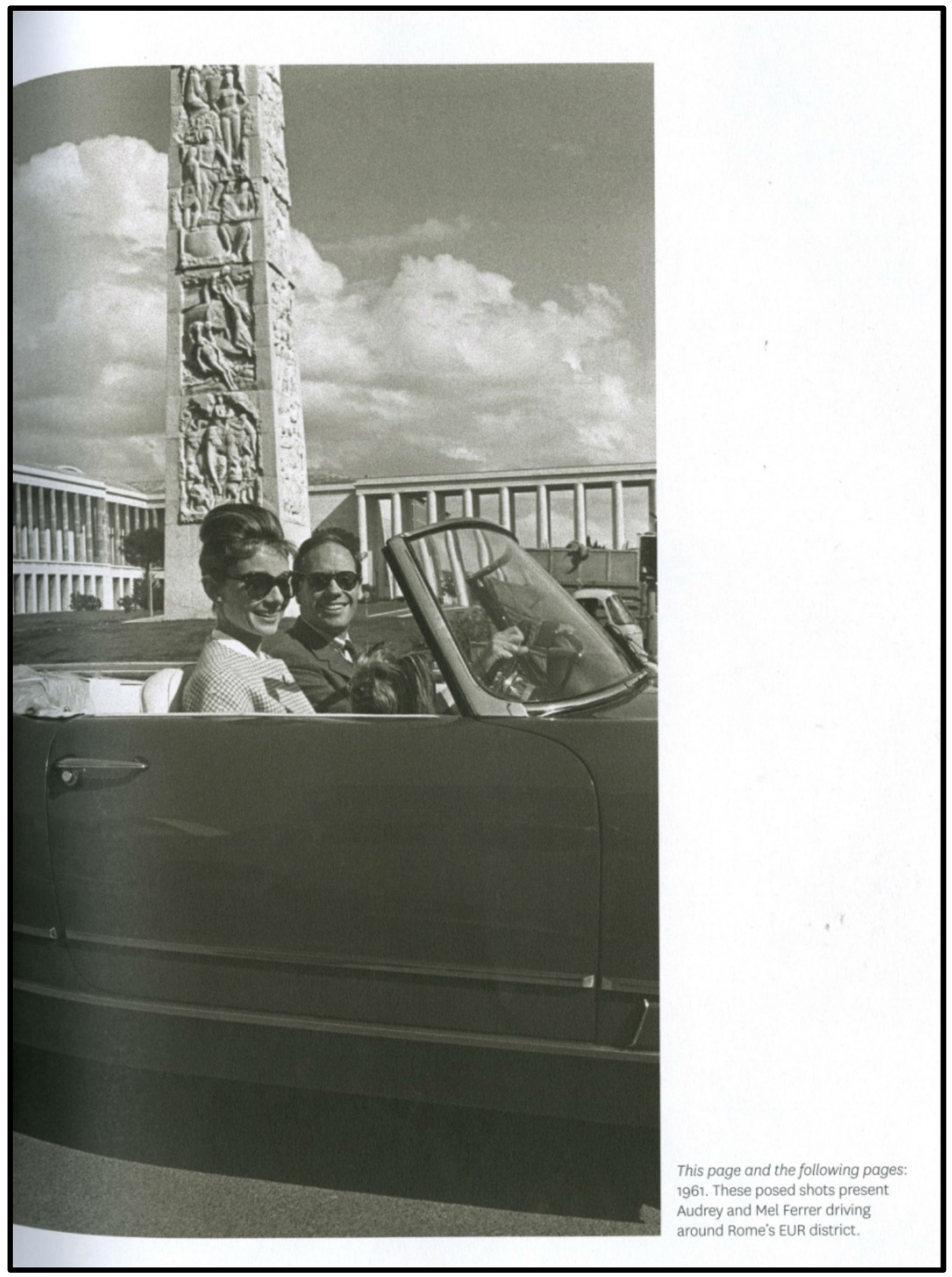

Figure 67. Audrey Hepburn and her husband, Mel Ferrer, in Rome. Image from "Audrey in Rome" (Luca Dotti). 


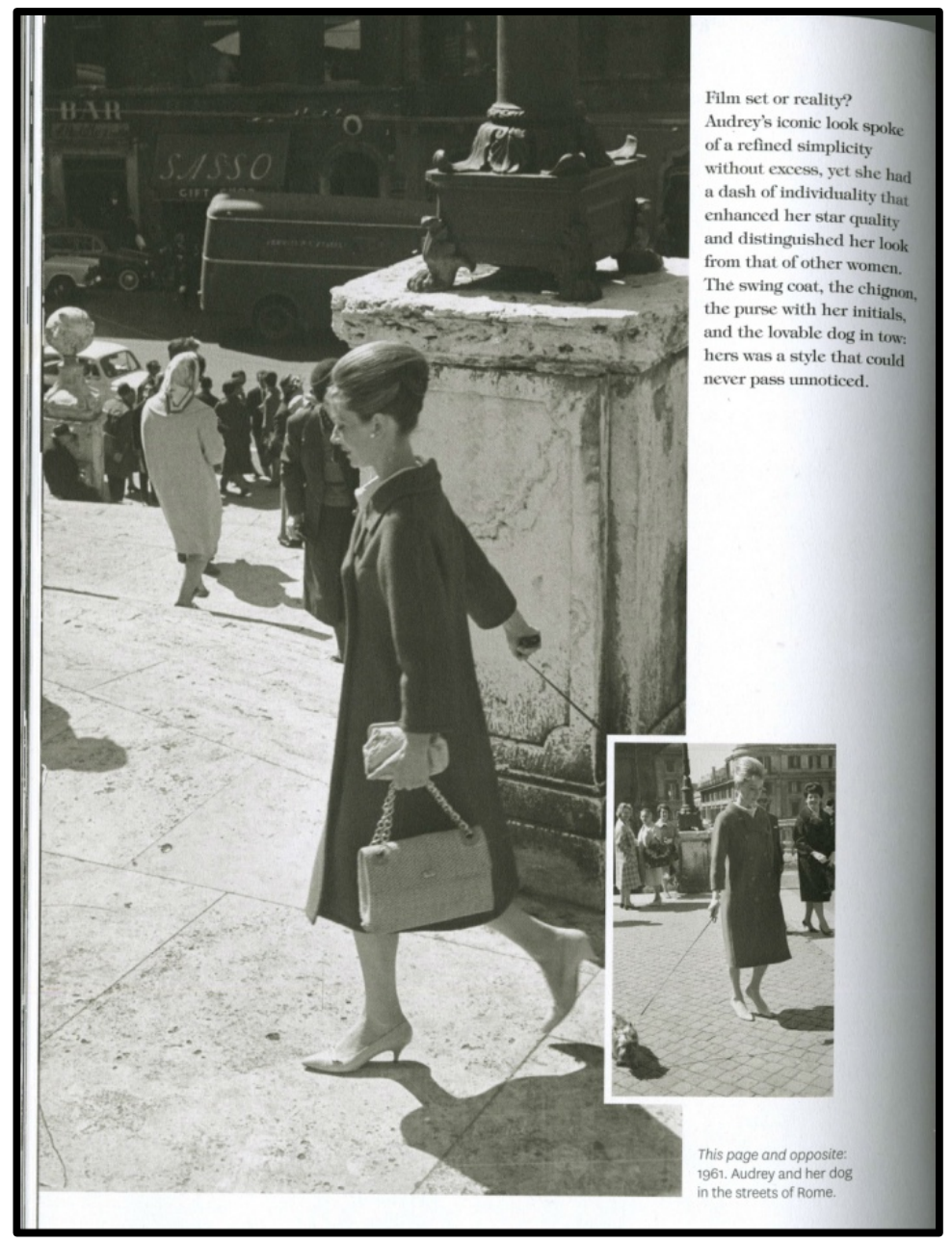

Figure 68. Audrey Hepburn in Rome. Image from "Audrey in Rome" (Luca Dotti).

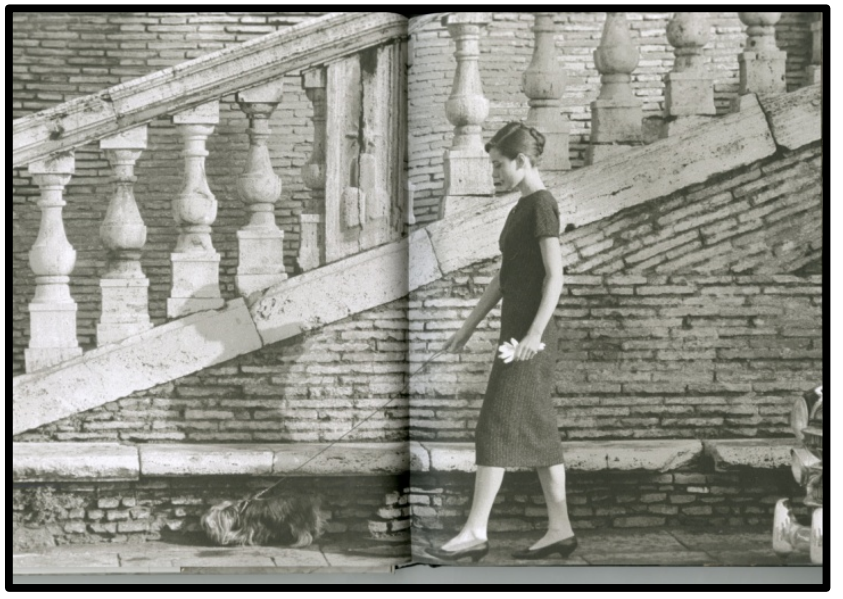

Figure 69. Audrey Hepburn in Rome. Image from "Audrey in Rome" (Luca Dotti). 


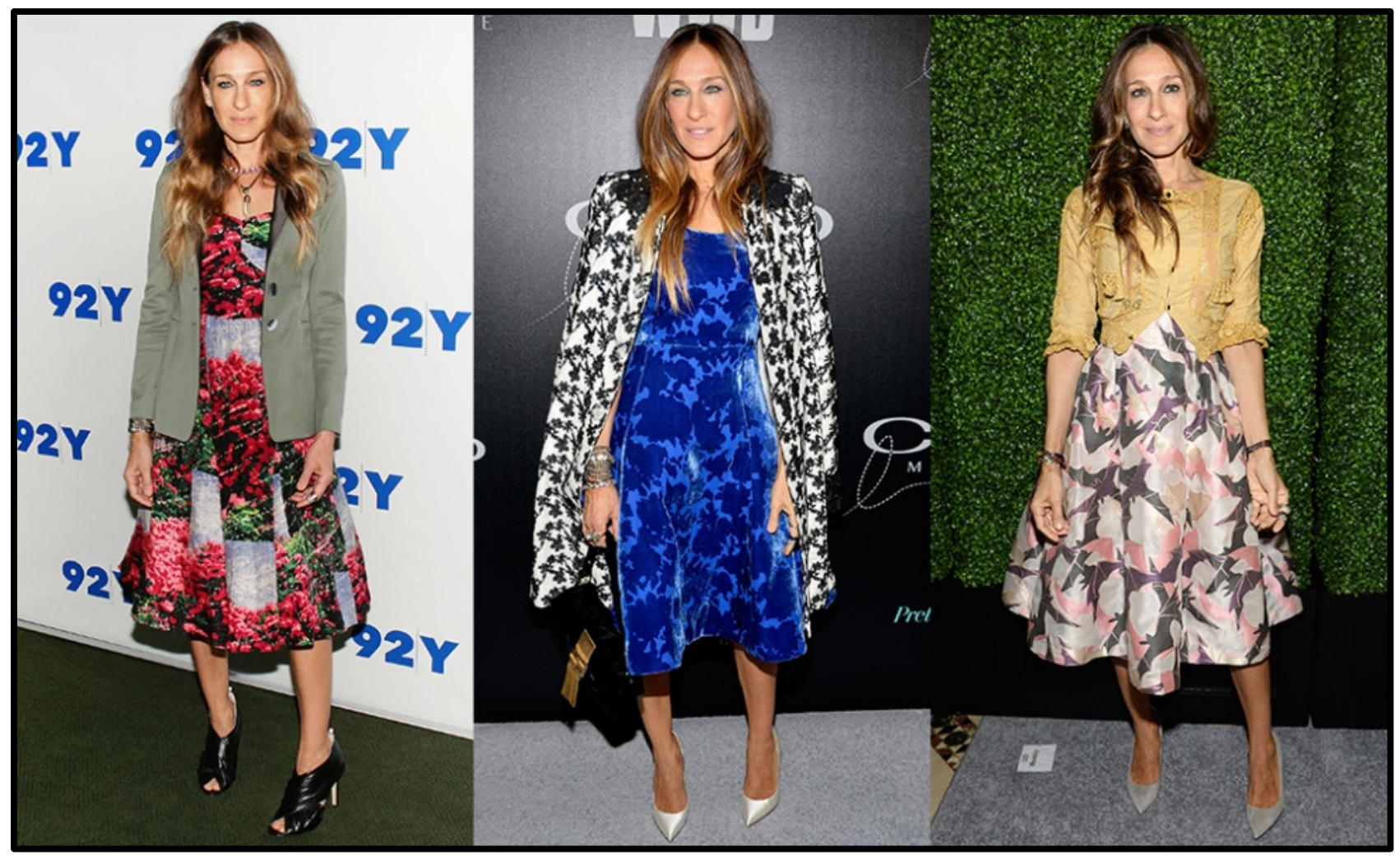

Figure 70. Sarah Jessica Parker at various event. Her style is very reminiscent of the style of her character Carrie Bradshaw 


\section{Works Cited}

100 Shoes. New York: The Metropolitan Museum of Art. New Haven; London: Yale University Press. 2011. Print.

Alexander J.C. “The Celebrity Icon”. Cultural Sociology 4.3 (2010) : 323-336. Print.

Ang, Ien. "Melodramatic Identifications: Television Fiction and Women's Fantasy."

Television and Women's Culture. Ed. Mary Ellen Brown. London: Sage Publications. 1990. 75-89. Print.

Arthurs, Jane. "Sex and the City and Consumer Culture: Remediating Postfeminist Drama." Feminist Media Studies 3.1 (2003) : 83-98. Print.

Barry, Elizabeth. "Celebrity, cultural production and public life." International Journal of Cultural Studies 1.3 (2008): 251-258. Print.

Barthes, Roland. Mythologies. Trans. Richard Howard and Annette Lavers. 1957. New York: Hill and Wang. 2013. Print.

Bazzi, Jonathan. "5 Italian Fashion Icons Before Fashion Icons Existed”. Swide. Swide S.r.l. 28 Nov. 2014. Web. 15 Apr. 2015.

Beltran, Mary C. “The Hollywood Latina Body as Site of Social Struggle: Media Constructions of Stardom and Jennifer Lopez's “Cross-over Butt”. Quarterly Review of Film \& Video 19.1 (2002) : 71-86. Print.

Breakfast at Tiffany’s. Dir. Blake Edwards. Perf. Audrey Hepburn, George Peppard.

Paramount Pictures, 1961. Film.

Brooks, Amanda. I Love Your Style: How To Define and Refine Your Style. New York: HarperCollins Publisher. 2009. Print.

Bruzzi, Stella and Pamela Church Gibson. "Visual Media and Dress.” Berg Encyclopedia of World Dress and Fashion. Ed. Joanne B. Eicher. 2010. Berg Fashion Library. Web. 15 Apr. 2015. 
Butler Breeze, Elizabeth. "Meaning, Celebrity, and the Underage Pregnancy of Jamie Lynn Spears." Cultural Sociology 4.3 (2010) : 337-355. Print.

Byers, Michele and Rosalin Krieger. "From Ugly Duckling to Cool Fashion Icon: Sarah Jessica Parker's Blonde Ambition.” Shofar. An Interdisciplinary Journal of Jewish Studies 24.4 (2007) : 43-63. Print.

Church Gibson, Pamela. Fashion and Celebrity Culture. New York: Berg Publishers. 2011. Berg Fashion Library. Web. 15 Apr. 2015.

David, Alison Matthews. "Vogue's New World: American Fashionability and the Politics of Style." Fashion Theory 10.1/2. (2006): 13-39. Print.

Dosamantes - Beaudry, Irma. "Frida Kahlo: The Creation of a Cultural Icon." The Arts in Psychotherapy 29.1 (2002) : 3-12. Print.

Dotti, Luca, Ludovica Damiani and Sciascia Gambaccini. Audrey in Rome. New York: Harper Design. 2013. Print.

Dyer, Richard. Stars. London: British Film Institute. 1979. Print Emisson, Michael and Philip.Smith. Researching the Visual: Images, Objects and Interactions in Social and Cultural Inquiries. London: Sage Publications. 2000. Print. Finnane, Garbielle. "Holly Golightly and the Fashioning of the Waif." Fashion in Fiction : Text and Clothing in Literature, Film, and Television. Eds. Peter McNeil, Vicki Karaminas and Catherine Cole. New York : Berg. 2009. Berg Fashion Library. Web. 15 Apr. 2015.

Funny Face. Dir. Stanley Donen. Perf. Audrey Hepburn, Fred Astaire. Paramount Pictures, 1957. Film.

Fydrych, Eve. “Fashion Icon- Frida Kahlo.” Fashion Studio Magazine. 8 Feb. 2011. Web. 23 Apr. 2015. 
Gullickson, Gay L. “Women, Power, and Myth.” Journal of Women's History 12.2 (2000) : 199-204. Print

"Grace Kelly: Style Icon- The Private View". V\&A Channel. Victoria \& Albert Museum. N.d. Web. 24 Apr. 2015.

Handyside, Fiona. “Paris Isn’t for Changin' Planes; It's for Changing Your Outlook”: Audrey Hepburn as European Star in 1950s France.” French Cultural Studies 14.3 (2003) : 288-298. Print.

Hariman, Robert and Lucaites, John Louis. No Caption Needed: Iconic Photographs, Public Culture, and Liberal Democracy. Chicago: The University of Chicago Press. 2007. Print.

Hepburn, Audrey. "The Costumes Make the Actor: A Personal View." Fashion in Film. Ed. Regine and Peter W. Engelmer. Munich: Prestel. 1997. 9-11. Print.

Holt, Douglas B. How Brands Become Icons: The Principles of Cultural Branding. Boston: Harvard Business School Press. 2004. Print.

“Icon.” Oxford English Dictionary. 2015. Web. 23 Apr. 2015.

“Introducing Holt Icon Privileges.” Holtrenfrew.com. Web. 15 Apr. 2015.

"Introducing the 2014 CFDA Fashion Icon of the Year." Cfda.com. Council of Fashion Designers of America. 24 Mar. 2014. Web. 23 Apr. 2015.

Koller, Veronika "Not Just a Colour: Pink as a Gender and Sexuality Marker in Visual Communication." Visual Communication 7.5 (2008 : 395-423. Print.

Konig, Anna. "Glossy Words: An Analysis of Fashion Writing in British Vogue.” Fashion Theory 10.1/2. (2006) : 205-225. Print.

---."Sex and the City in the British Fashion Press." Fashion Reader. Ed. Linda Welter and Abby Lillenthun. Second edition. Oxford: Berg. 2011. 420-422. Print. 
Luu, Phong. “Audrey Hepburn's Oscar Dress Up for Auction.” Telegraph.co.uk. 3 Nov. 2011. Web. 24 Apr. 2015.

Meades, Jonathan. “Iconic: Adjective of the Age.” Intelligent Life Magazine, Spring 2009. Web. 15 Apr. 2015.

Milligan, Lauren. "Greetings To You, From SJP”. Vogue.co.uk. Jan 20, 2014. Web. 22 Apr. 2015.

Mitchell, W. J.T. Iconology: Image, Text, Ideology. Chicago and London: The University of Chicago Press. 1987. Print.

Moseley, Rachel. "Dress, Class and Audrey Hepburn: The Significance of the Cinderella Story.” Fashioning Film Stars. Dress, Culture, Identity. Ed. Rachel Moseley. London: British Film Institute. 2005. 109-120. Print.

---. Growing Up with Audrey Hepburn: Text, Audience, Resonance. Manchester: Manchester University Press. 2002.

---. “Trousers and Tiaras: Audrey Hepburn, A Woman's Star.” Feminist review 71.1 (2002): 37-51. Print.

Nichols, Bill. Engaging Cinema: An Introduction to Film Studies. New York: W.W Norton \& Company Inc. 2010. Print.

Oberly, Nicholas. "Reality, Hyperreality.” Theories of Media. Keywords Glossary. University of Chicago. 2003. Web. 25 Apr. 2015. http://csmt.uchicago.edu/glossary2004/realityhyperreality.htm

Parker, Mike. Cultural Icons: A Case Study Analysis of their Formation and Reception. Doctoral thesis, University of Central Lancashire. 2012. Web. 15 Apr. 2015. "Pharrell, 2015 Fashion Icon.” Cfda.com. Council of Fashion Designers of America. 18 Mar. 2015. Web 25 Apr. 2015. 
Radner, Hilary. "Embodying the Single Girl in the 1960s." Body Dressing. Ed. Joanne Entwistle and Elizabeth Wilson. Berg. 2001. Berg Fashion Library. Web. 15 Apr. 2015.

Richards, Helen. "Sex and the City: A Visible Flaneuse for the Postmodern Era?" Continuum: Journal of Media \& Cultural Studies 17.2 (2003): 147-157. Print.

Rocamora, Agnès. Fashioning the City. Paris, Fashion and the Media. London; New York: I.B. Taurus. 2009. Print.

Rogers, Mary F. Barbie Culture. London: Sage Publications. 1999. Print.

Roman Holiday. Dir. William Wyler. Perf. Audrey Hepburn, Gregory Peck. Paramount Pictures, 1953. Film.

Rubenstein, Hal. 100 Unforgettable Dresses. New York: HarperCollins Publishers. 2011. Print.

Sex and the City. Creat. Darren Star. Perf. Sarah Jessica Parker, Kim Cattrall, Kirsten Davis, Cynthia Nixon. HBO Box Office, 1998-2004. Television.

Simmel, Georg. "Fashion.” The American Journal of Sociology 62.6. (1957) : 541-558. Print.

Stacey, Jackie. Star Gazing: Hollywood Cinema and Female Spectatorship. London; New York : Routledge. 1994. Print.

Staiger, Janet. Rev. of "Being Rita Hayworth: Labor, Identity, and Hollywood Stardom.” Film History: An International Journal 22. 3 (2010): 291-292. Print.

Storey, John. Cultural Theory and Popular Culture: An Introduction. 6th ed. Harlow England; New York: Pearson. 2012. Print.

Tortora, Phyllis G. "Iconic Figures in Western Culture." Berg Encyclopedia of World Dress and Fashion. Ed. Joanne B. Eicher. Berg Fashion Library. Web. April 15, 2015. Veblen, Thorstein. The Theory of the Leisure Class. 1899. New York; Toronto: Oxford University Press Inc. 2007. Print. 
Warner, Helen. "Fashion, Celebrity and Cultural Workers: SJP as Cultural Intermediary." Media, Culture and Society 35.3 (2013) : 382-391. Print

---. Fashion on Television: Identity and Celebrity Culture. London: Bloomsbury Academic. 2014. Print.

Wasson, Sam. Fifth Avenue, 5 A.M: Audrey Hepburn, Breakfast at Tiffany's, and the Dawn of the Modern Woman. New York: HarperCollins Publisher. 2010. Print.

Werle, Simone. Fashionista: A century of style icons. Munich; Berlin; London; New York: Prestel. 2009. Print.

White, Nicola. Reconstructing Italian Fashion: America and the Development of the Italian Fashion Industry. Oxford; New York: Berg. 2000. Print.

Wilson, Elizabeth. Adorned in Dreams: Fashion and Modernity. 1985. New York: I. B. Tauris \& Co Ltd. 2011. Print. 